\title{
Prognostic and predictive biomarkers in oesophagogastric cancer
}

Citation for published version (APA):

Hewitt, L. C. (2019). Prognostic and predictive biomarkers in oesophagogastric cancer. [Doctoral Thesis, Maastricht University]. Optima, Rotterdam. https://doi.org/10.26481/dis.20191128lh

Document status and date:

Published: 01/01/2019

DOI:

10.26481/dis.20191128Ih

Document Version:

Publisher's PDF, also known as Version of record

\section{Please check the document version of this publication:}

- A submitted manuscript is the version of the article upon submission and before peer-review. There can be important differences between the submitted version and the official published version of record.

People interested in the research are advised to contact the author for the final version of the publication, or visit the DOI to the publisher's website.

- The final author version and the galley proof are versions of the publication after peer review.

- The final published version features the final layout of the paper including the volume, issue and page numbers.

Link to publication

\footnotetext{
General rights rights.

- You may freely distribute the URL identifying the publication in the public portal. please follow below link for the End User Agreement:

www.umlib.nl/taverne-license

Take down policy

If you believe that this document breaches copyright please contact us at:

repository@maastrichtuniversity.nl

providing details and we will investigate your claim.
}

Copyright and moral rights for the publications made accessible in the public portal are retained by the authors and/or other copyright owners and it is a condition of accessing publications that users recognise and abide by the legal requirements associated with these

- Users may download and print one copy of any publication from the public portal for the purpose of private study or research.

- You may not further distribute the material or use it for any profit-making activity or commercial gain

If the publication is distributed under the terms of Article $25 \mathrm{fa}$ of the Dutch Copyright Act, indicated by the "Taverne" license above, 


\section{Prognostic and Predictive Biomarkers in Oesophagogastric Cancer}

Lindsay C. Hewitt 


\section{Prognostic and Predictive Biomarkers in Oesophagogastric Cancer}

Lindsay C. Hewitt

ISBN | 978-94-6361-341-5

Cover | painting by Michael Hewitt

Cover design 'artist's impression of tumour heterogeneity' | Gregorio Fazzi

Layout | Optima, Rotterdam

Printed by | Optima, Rotterdam

The research presented in this thesis was conducted at GROW, School for Oncology and Developmental Biology, Department of Pathology, Maastricht University.

CCopyright Lindsay Hewitt, 2019

All rights reserved. No part of this publication may be reproduced, stored in a retrieval system, or transmitted by another means, electronic, mechanical, photocopying, recording or otherwise, without prior permission from the author, or when applicable, from the copyrightowning journals for previously published chapters. The author requested permission for article reuse for previously published chapters in copyright-owning journals. 


\title{
Prognostic and Predictive Biomarkers in Oesophagogastric Cancer
}

\author{
Dissertation \\ to obtain the degree of Doctor at Maastricht University, \\ on the authority of the Rector Magnificus, \\ Prof.dr. Rianne M. Letschert \\ in accordance with the decision of the Board of Deans, \\ to be defended in public on \\ Thursday 28 November, 2019 at 12.00 hours \\ by \\ Lindsay Charlotte Hewitt
}

Born $10^{\text {th }}$ August 1983 
Supervisor |

Co-supervisor |

Assessment Committee |

Prof. dr. A.A.M. Masclee (chair)

Prof. dr. N.D. Bouvy

Prof. dr. T. Cramer

(RWTH Aachen University, Germany)

Prof. dr. M. van Engeland

Dr. J. Stoot

(Zuyderland Medisch Centrum, Sittard- Geleen)

Paranymphs

G.E. Fazzi

Dr. N. Vaes 


\section{CONTENTS}

$\begin{array}{lll}\text { Chapter 1| General introduction } & 7\end{array}$

Chapter 2 | KRAS, BRAF and Gastric Cancer 27

Translational Gastrointestinal Cancer 2015; 4: 6, 429-447.

Gastric Cancer Precision Medicine. Chen L, Kim SY and Sugimura H, eds. $1^{\text {st }}$ ed. AME publishing Company, 2017: 7-25.

Chapter 3 | KRAS status is related to histological phenotype in gastric cancer -

Results from a large multicentre study

Gastric Cancer. 2019 May 20.

doi: 10.1007/s10120-019-00972-6.

Chapter 4| Epstein-Barr Virus and Mismatch Repair Deficiency status differ between Oesophageal and Gastric Cancer: a large Multicentre Study Eur J Cancer. 2018 May; 94:104-114.

Chapter 5 | Intratumour heterogeneity of the tumour content in the diagnostic biopsy predicts survival benefit from neoadjuvant chemotherapy in patients with oesophageal cancer - results from the OE02 trial Submitted

Chapter 6 | Density of tumour infiltrating lymphocytes predicts survival benefit from adjuvant chemotherapy in patients with stage II/III gastric cancer - results from the CLASSIC trial In preparation

Chapter 7| General discussion

Partly adapted from: Hypothesis-free deep survival learning applied to the tumour microenvironment in gastric cancer submitted

Summary

Valorisation

Acknowledgements

About the author

Publications 





\section{GASTRIC CANCER}

Gastric cancer (GC) is the fifth most common cancer worldwide with more than 1 million new cases diagnosed annually and is accountable for more than 782,000 deaths each year (1). Globally, GC incidence rates are twofold higher in males than females (1). GC incidence is highest in Asia, whereas in Northern Europe, North America and Africa the rates are lower (1). The high GC incidence in Asian countries is the reason why a two-yearly population based GC screening programme has been implemented in countries such as Japan and South Korea with the aim of improving patient survival due to detection of GC at an early stage $(2,3)$. In other countries, screening programmes are not cost effective due to the lower incidence (4). In The Netherlands (NL), the estimated World Standardised Rate (WSR) [number of cancers per 100,000, adjusted for age distribution of the world population] for incidence and mortality in 2018 is 8.0 and 5.8, respectively (5). The estimated WSR for incidence and mortality in the UK for 2018 is 7.8 and 5.6, respectively (5).

On the basis of associated risk factors, GC can be classified as cardia and non-cardia GC (6). Cardia GC arises in the region directly distal from the gastro-oesophageal junction (6). Risk factors for cardia GC include alcohol consumption, tobacco smoking, increased body mass index and gastro-oesophageal reflux disease (7-10). The increasing incidence of cardia GC has been attributed to rising global obesity levels which itself is related to increased gastrooesophageal reflux disease (7). Non-cardia GC arises in the distal stomach (6) and has been associated with Helicobacter pylori (H. pylori) infection and chronic atrophic gastritis $(11,12)$. The declining incidence of non-cardia GC in recent years has been attributed to decreasing H.pylori infection rates $(13,14)$. Other risk factors for GC include diet (high consumption of salty food and low consumption of fruit and vegetables) (15) and genetic predisposition (16).

In Western countries, the Lauren classification remains the most widely used histological classification system, which classifies GC into diffuse, intestinal and mixed-type (17), see figure 1. Other schemes proposed over the years include Nakamura (18), Ming (19), Goseki (20), Carneiro (21), Solcia (22), Japanese Gastric Cancer Association (23) and World Health Organisation [WHO] (24), which for adenocarcinoma alone has over ten different subcategories (see table 1).

In addition to numerous histological classification schemes, several molecular GC classifications have been proposed in recent years, including from our own research group (25-27). In 2013, a classification system proposed by the Singapore-Duke group divided GC into proliferative, metabolic and mesenchymal subtypes, based on genetic and epigenetic expression of drug-responsive clusters (28). Subsequently, in 2014 The Cancer Genome Atlas described four distinct molecular GC subtypes: Epstein-Barr virus (EBV) positive, microsatellite instable (MSI), genomically stable (GS) and chromosomally instable (CIN) (29). The EBV subgroup is further characterised by PIK3CA mutations, programmed death ligand 1/2 (PD$\mathrm{L} 1 / 2$ ) overexpression, hypermethylation (CpG island methylator phenotype (CIMP)), CDKN2A 


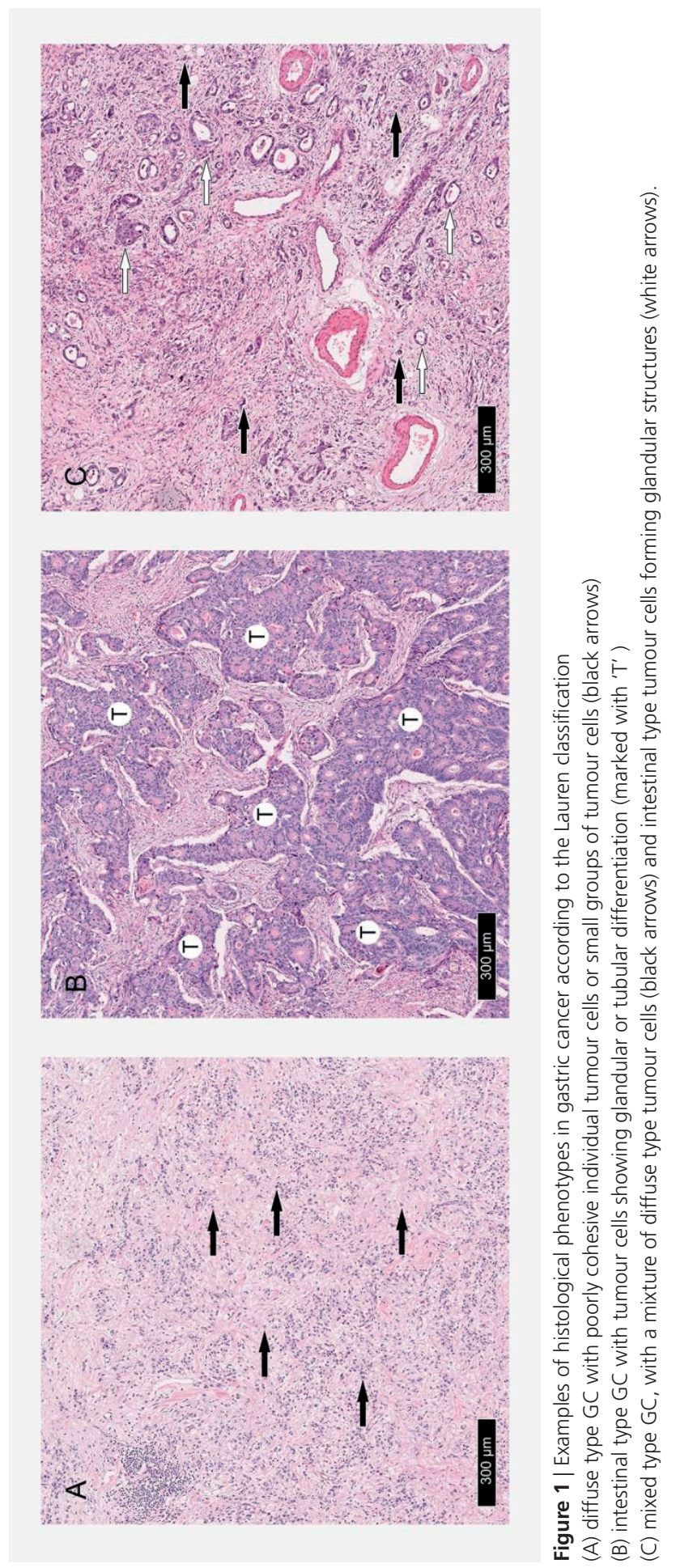


silencing and increased immune cell infiltration. The MSI phenotype is most frequently the result of a defective mismatch repair (MMR) mechanism due to somatic mutation of one of the MMR genes (such as MLH1, MLH2, MSH6 or PMS2) or hypermethylation of the

Table 1 | Histological classification of gastric cancer according to the World Health Organisation

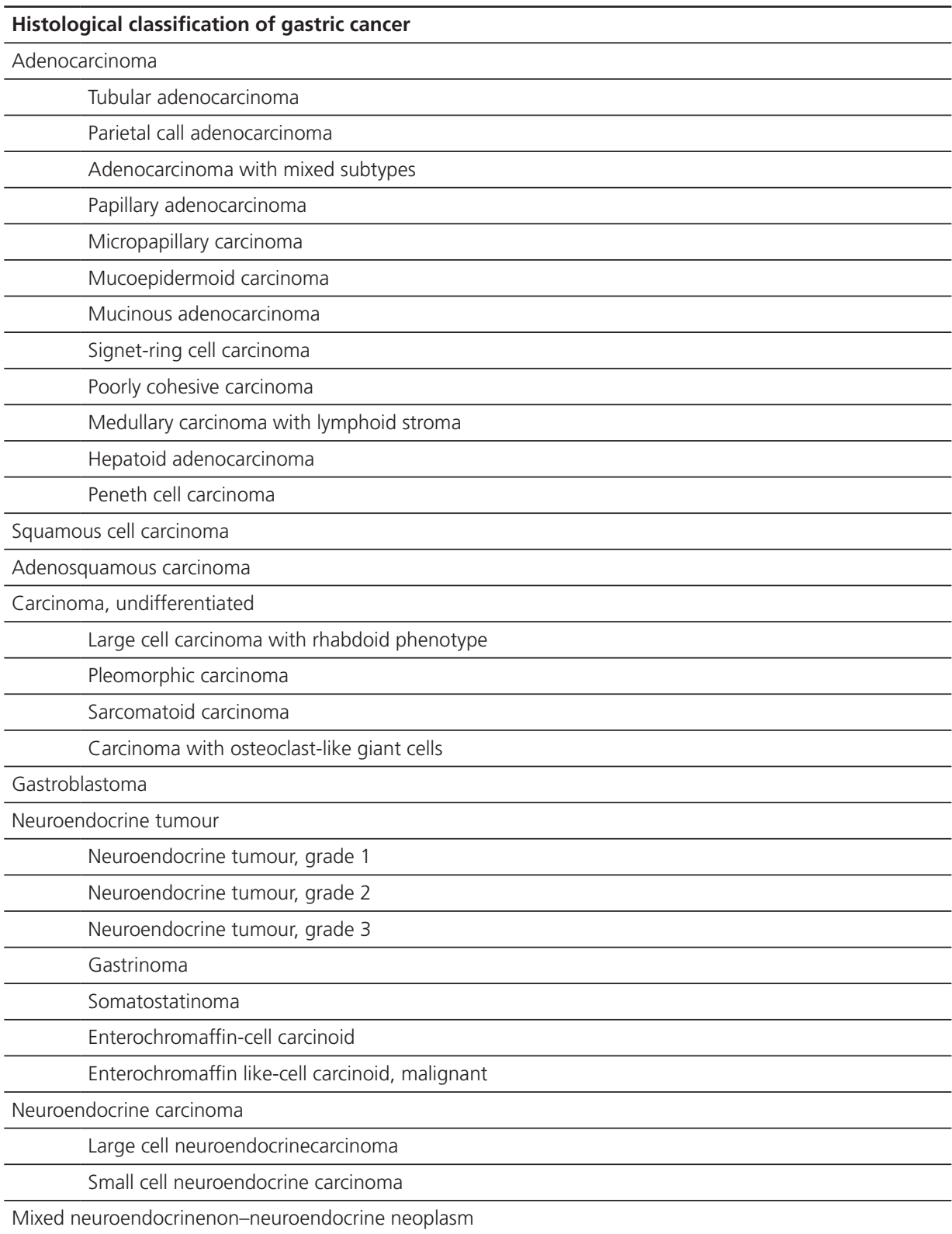

Adapted from (24) 
MLH1 promoter (30). The most common molecular alterations in GS GC are CDH1 or RHOA mutations, CLDN18-ARHGAP gene fusion and increased expression levels of genes/proteins involved in cell adhesion pathways. The CIN subtype is characterised by TP53 mutations and activation of genes in the receptor tyrosine kinase pathway, such as EGFR, HER2, FGFR2, MET and KRAS (29). Sohn et al. suggested a prognostic value of the TGCA GC classifier and predicted chemotherapy survival benefit using this classification system (31). In 2015, The Asian Cancer Research Group proposed a molecular GC classification system based on MSI, microsatellite stable (MSS)/epithelial to mesenchymal transition, MSS/TP53 active and MSS/ TP53 inactive GCs (32). This classification system was shown to have prognostic value and was validated in two additional Asian GC cohorts (32). Figure 2 shows a comparison of the main molecular classification systems proposed in GC. Subsequently, several research groups have proposed classification of GC using Epstein-Barr encoded RNA in situ hybridization and immunohistochemistry as a surrogate for molecular classification in GC (33-35). Despite all these classification efforts (molecular and histological), decisions regarding patient treatment are still currently based upon the clinical stage of the disease $(36,37)$ and patient's performance status and preferences.

\begin{tabular}{|c|c|c|c|c|c|}
\hline $\begin{array}{l}\text { Cancer Genome } \\
\text { Atlas }\end{array}$ & $\begin{array}{l}\text { EBV } \\
\text { - EBV-CIMP } \\
\text { - PIK3CA mutations } \\
\text { - PD-L1/2 expression }\end{array}$ & $\begin{array}{l}\text { MSI } \\
\text { - Gastric-CIMP } \\
\text {-MLH1 silencing }\end{array}$ & $\begin{array}{l}\text { GS } \\
\text {-Diffuse histology } \\
-C D H 1, R H O A \\
\text { mutations }\end{array}$ & $\begin{array}{l}\text { CIN } \\
\text { - Intestinal histology } \\
\text { - TP53 mutations }\end{array}$ & \\
\hline Singapore- Duke & & & $\begin{array}{l}\text { Mesenchymal } \\
\text { Diffuse } \\
\text { - Low TP53 } \\
\text { mutations } \\
\text { - Low level of } \\
\text { CDH1 (E- } \\
\text { cadherin) } \\
\text { - Lauren diffuse } \\
\text { type } \\
\text { - PIK3CA Mtor } \\
\text { inhibitors }\end{array}$ & $\begin{array}{l}\text { Proliferative } \\
\text { Diffuse } \\
\text { - High number of } \\
\text { TP53 mutations } \\
\text { - Lauren intestinal } \\
\text { type }\end{array}$ & $\begin{array}{l}\text { Metabolic } \\
\text { diffuse } \\
\text { - Low TP53 } \\
\text { mutations } \\
\text { - Expression of } \\
\text { genes } \\
\text { characteristic of } \\
\text { normal gastric } \\
\text { mucosa } \\
\text { - No histologic } \\
\text { correlate } \\
\text { - 5-FU+surgery }\end{array}$ \\
\hline $\begin{array}{l}\text { Asian Cancer } \\
\text { Research Group }\end{array}$ & & 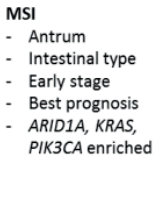 & $\begin{array}{l}\text { MSS/EMT } \\
\text { - Loss of CDH1 } \\
\text { - Young age } \\
\text { - Diffuse type } \\
\text { - Worst prognosis }\end{array}$ & 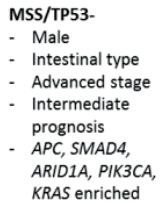 & $\begin{array}{l}\text { MSS/TP53+ } \\
\text { - Male } \\
\text { - Intestinal type } \\
\text { - Intermediate } \\
\text { prognosis } \\
\text { - ERBB2, EGFR, } \\
\text { CCND1 enriched }\end{array}$ \\
\hline
\end{tabular}

Figure 2 | Comparison of molecular classifications systems in gastric cancer Abbreviations: CIN, chromosomal instability; EBV, Epstein-Barr virus; EMT, epithelial-mesenchymal transition; FU, fluorouracil; GS, genomically stable; MSI, microsatellite instability; MSS, microsatellite stable. Adapted from (35). 


\section{OESOPHAGEAL CANCER}

Oesophageal cancer $(\mathrm{OeC})$ is the seventh most common cancer worldwide, with an estimated 572,000 new cases and 509,000 deaths in 2018 (1). Globally, the incidence of OeC is two to threefold higher in males compared to females (1). The incidence of $\mathrm{OeC}$ is highest in Eastern Asia, and Eastern and Southern Africa (1). In NL, the WSR for incidence and mortality in 2018 is 3.5 and 2.8, respectively (5). The estimated WSR for incidence and mortality in the UK for 2018 is 3.7 and 3.0, respectively (5). With the exception of high-risk areas of China (38), population screening is not proven to be cost effective for OeC (39).

The two main histological subtypes of $\mathrm{OeC}$ are squamous cell carcinoma $(\mathrm{SqC})$ and adenocarcinoma (AdC). More than $90 \%$ of $\mathrm{OeC}$ in the world are SqC with the highest incidence in Eastern countries, whereas UK and NL have the highest incidence of AdC in the World (1). Molecular characterisation of OeC by TCGA revealed that the molecular profile of oesophageal AdC more closely resembles GC than oesophageal SqC (40). Nevertheless, trials for patients with metastatic disease often include patients with GC, oesophageal adenocarcinoma and oesophageal squamous cell cancers in the same clinical trial. This is also true to a lesser extent for patients with resectable disease.

The risk factors for oesophageal SqC include tobacco smoking, alcohol consumption and diet, whereas obesity, gastro-oesophageal reflux disease and Barrett's oesophagus are associated with oesophageal adenocarcinoma (39). Population cancer screening for high-risk patients with Barrett's oesophagus is recommended (41).

\section{OESOPHAGEAL AND GASTRIC CANCER: DIAGNOSIS, PROGNOSIS AND TREATMENT}

GC and OeC are often grouped together under the term oesophagogastric cancer (OGCa) due to similarities in diagnosis and treatment strategies.

Patients with early stage OGCa are often asymptomatic. Due to the absence of an OGCa screening programme, patients in Western countries most commonly present with locally advanced disease at the time of diagnosis. Gold standard diagnosis of OGCa is by endoscopic biopsy and histopathological assessment. The Union for International Cancer Control (UICC) tumour-node-metastasis (TNM) staging system is used for clinical staging to decide patient treatment and pathological staging after resections in Europe (42). The TNM stage is a combination of depth of tumour invasion (T stage), number of tumour positive lymph nodes ( $\mathrm{N}$ stage) and the presence of distant metastases (M stage). Figure 3 shows a schematic representation of T stage in GC and OeC. The TNM stage groupings are established and regularly updated on the basis of their prognostic relevance, with high TNM stage being associated with a worse prognosis in OGCa $(43,44)$. The definition whether a tumour is a gastric or 
oesophageal cancer is dependent on the macroscopic location of the bulk/epicentre of the tumour with respect to the gastro-oesophageal junction. In accordance with TNM8, tumours are categorised as being either $\mathrm{OeC}$ (including the oesophagogastric junction) or GC (42).

A

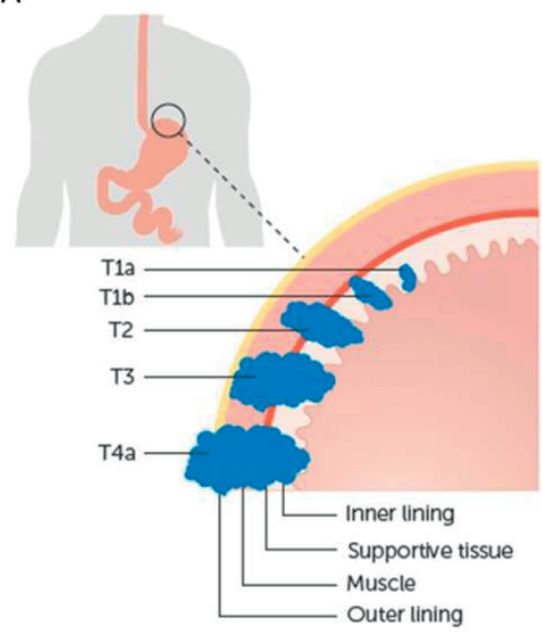

B
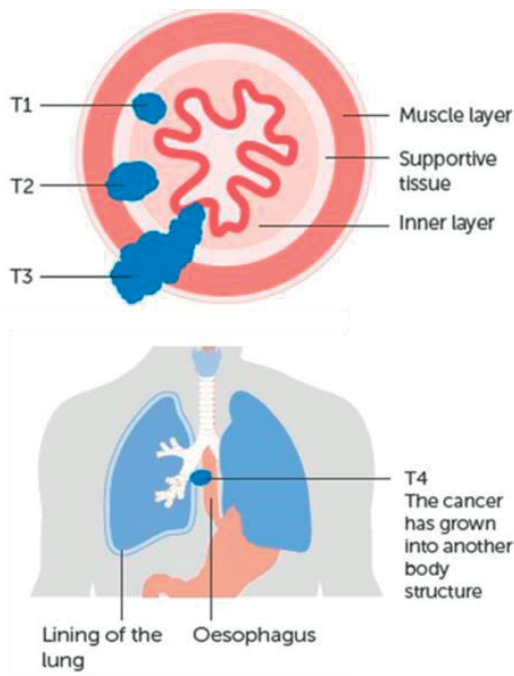

Figure 3 | Schematic representation of the depth of tumour invasion in gastric cancer (A) and oesophageal cancer (B). The T stage increases with increasing depth of the tumour.

Image reuse credit: Cancer research UK

\section{Treatment of oesophagogastric cancer patients}

Treatment decisions are currently based on TNM stage and patient related factors (36, 45-50). Thus, in early disease where the cancer is restricted to the mucosa and without clinical evidence of lymph node metastasis e.g. cT1aNOM0, endoscopic resection would be the preferred treatment option depending on size of the tumour, absence of ulceration and absence of poor differentiation (51). In locally advanced resectable OGCa ( $\geq$ CT2NO), which is the focus of this thesis, clinical trials have demonstrated the benefit of neoadjuvant/perioperative combination chemo(radio)therapy followed by surgical resection as the gold standard treatment in the West (52-55) and surgical resection followed by adjuvant chemotherapy in the East $(56,57)$. OGCa patients presenting with unresectable or metastatic disease are treated with combination chemotherapy and have a median life expectancy of less than 12 months if treated with cytotoxic chemotherapy (58). For a summary of treatment options for patients with OGCa, see figure 4 .

\section{Treatment of locally advanced gastric and gastro-oesophageal junction cancer}

In Europe, the results from the FLOT4 trial have been reported very recently (55) which resulted in a change of the standard perioperative chemotherapy backbone for the treatment 

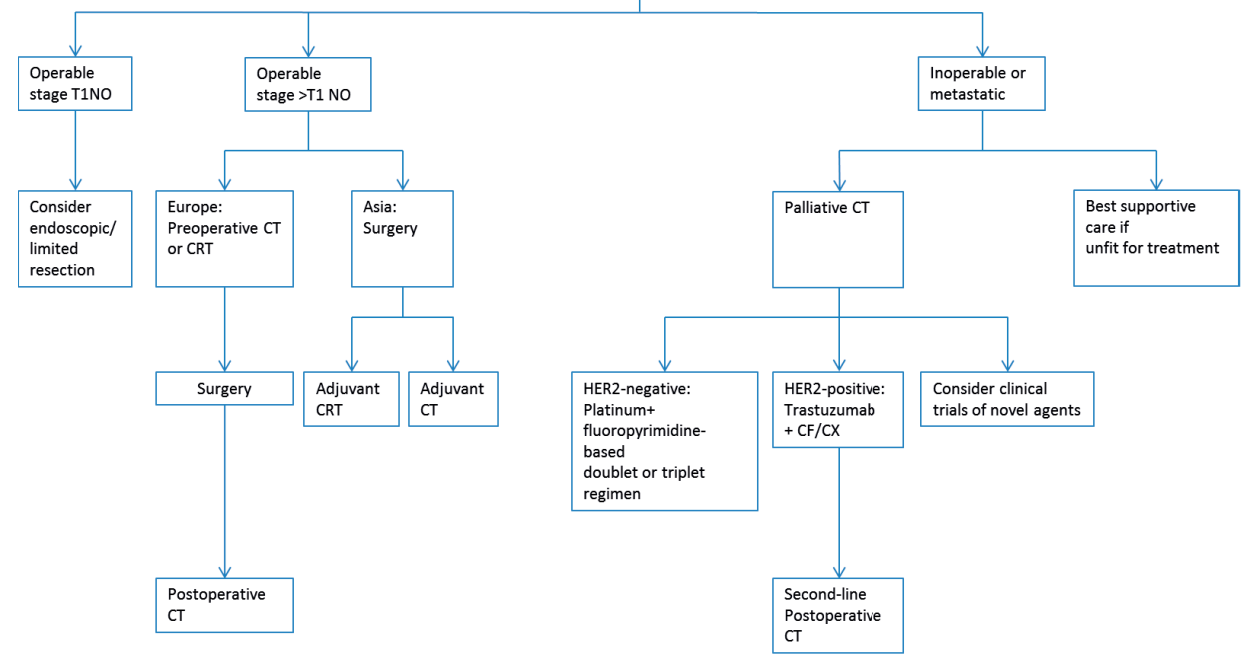

Figure 4 | Treatment algorithm for patients with oesophagogastric cancer in Europe and Asia

Abbreviations: CT, chemotherapy; CRT, chemoradiotherapy; HER2, human epidermal growth factor receptor 2; CF, cisplatin and 5-fluorouracil; CX, cisplatin and capecitabine

Adapted from (36).

of patients with locally advanced resectable gastric or gastro-oesophageal junction cancer from ECF/ECX (epirubicin, cisplatin, 5-fluorouracil/epirubicin, cisplatin, capecitabine (53)) to FLOT (fluorouracil plus leucovorin, oxaliplatin, and docetaxel). However, even with FLOT, 5 -year overall survival reaches only $45 \%$. Other attempts such as the use of preoperative chemotherapy combined with postoperative chemoradiotherapy in the CRITICS trial or the addition of targeted treatment such as bevacizumab in the ST03 trial did not improve overall survival compared to existing standard treatment regimens for patients with resectable GC $(59,60)$.

In Asia, the ACTS-GC and CLASSIC trials, randomising patients with pathological TNM stage II-III disease, established the benefit of adjuvant chemotherapy, with a 5-year survival of $72-78 \%(56,57)$. The addition of radiotherapy into the adjuvant treatment in the ARTIST trial did not improve patient survival (61).

For an overview of survival outcomes in studies evaluating different treatment regimens in patients with locally advanced resectable gastric cancer, see table 2 .

\section{Treatment of locally advanced oesophageal cancer}

OeC patients in the UK are usually treated with neoadjuvant chemotherapy (cisplatin/5-FU) followed by surgery based on the Oe02 trial (52). The Oe05 trial, which in comparison to Oe02 doubled the number of neoadjuvant chemotherapy cycles and increased the number of chemotherapy drugs to 3, was unable to demonstrate benefit from more intensified 
Table 2 | Overall survival reported in randomised phase III clinical trials, evaluating treatment regimens in patients with localised resectable gastric cancer

\begin{tabular}{|c|c|c|c|}
\hline $\begin{array}{l}\text { Trial/ } \\
\text { registry No./ } \\
\text { authors }\end{array}$ & Regimen & $\begin{array}{l}\text { No. of } \\
\text { patients }\end{array}$ & Outcome \\
\hline $\begin{array}{l}\text { SWOG 9008/ } \\
\text { INT-0116 (69) }\end{array}$ & $\begin{array}{l}\text { Surgery vs. surgery + } \\
\text { CRT }\end{array}$ & $\begin{array}{l}275 \text { vs. } \\
281\end{array}$ & $\begin{array}{l}\text { Median OS: } 27 \text { months vs. } 36 \text { months; } \\
\text { 3-year OS rate, } 41 \% \text { vs. } 50 \% \text {; } \\
\text { HR, } 1.35 ; 95 \% \text { Cl: } 1.09-1.66 ; P=0.005\end{array}$ \\
\hline ARTIST (61) & $\begin{array}{l}\text { Surgery }(D 2)+C T \text { vs. } \\
\text { surgery }(D 2)+C R T\end{array}$ & $\begin{array}{l}228 \text { vs. } \\
230\end{array}$ & $\begin{array}{l}\text { 5-year OS rate, } 73 \% \text { vs. } 75 \% \text {; } \\
\text { HR, } 1.130 ; 95 \% \text { Cl: } 0.775-1.647 ; P=0.5272\end{array}$ \\
\hline $\begin{array}{l}\text { ACTS GC } \\
(57,70)\end{array}$ & $\begin{array}{l}\text { Surgery (D2) vs. surgery } \\
(D 2)+S 1\end{array}$ & $\begin{array}{l}530 \text { vs. } \\
529\end{array}$ & $\begin{array}{l}\text { 3-year OS rate, } 70.1 \% \text { vs. } 80.1 \% \\
\text { HR, } 0.68 ; 95 \% \mathrm{Cl}: 0.52-0.87 ; \mathrm{P}=0.003\end{array}$ \\
\hline CLASSIC (56) & $\begin{array}{l}\text { Surgery (D2) vs. surgery } \\
(D 2)+\text { XELOX }\end{array}$ & $\begin{array}{l}520 \text { vs. } \\
515\end{array}$ & $\begin{array}{l}\text { 5-year OS rate, } 69 \% \text { vs. } 78 \% \\
\text { HR, } 0.66 ; 95 \% \mathrm{Cl}: 0.51-0.85 ; P=0.0015\end{array}$ \\
\hline MAGIC (53) & $\begin{array}{l}\text { Surgery vs. ECFx3 + } \\
\text { surgery + ECFx3 }\end{array}$ & $\begin{array}{l}253 \text { vs. } \\
250\end{array}$ & $\begin{array}{l}\text { 5-year OS rate, } 23.0 \% \text { vs. } 36.3 \% \\
\text { HR, } 0.75 ; 95 \% \mathrm{Cl}: 0.60-0.93 ; P=0.009\end{array}$ \\
\hline $\begin{array}{l}\text { FLOT4-AIO } \\
(55)\end{array}$ & $\begin{array}{l}\text { FLOTx4 + surgery + } \\
\text { FLOTx4 vs. ECFx3 + } \\
\text { surgery / ECFx3 }\end{array}$ & $\begin{array}{l}356 \text { vs. } \\
360\end{array}$ & $\begin{array}{l}\text { Median OS: } 50 \text { months vs. } 35 \text { months; } 5 \text {-year OS } \\
\text { rate, } 45 \% \text { vs. } 36 \% \text {; } \\
\text { HR, } 0.77 ; 95 \% \mathrm{Cl} \text { : } 0.63-0.94 ; \mathrm{P}=0.012\end{array}$ \\
\hline ST03 (60) & $\begin{array}{l}\text { (ECX + bevacizumab) } \\
\times 3+\text { surgery }+(E C X \\
+ \text { bevacizumab }) \times 3 \text { vs. } \\
\text { ECXx3 + surgery / ECXx3 }\end{array}$ & $\begin{array}{l}533 \text { vs. } \\
530\end{array}$ & $\begin{array}{l}\text { 3-year OS rate, } 48.1 \% \text { vs. } 50.3 \% \\
\text { HR, } 1.09 ; 95 \% \mathrm{Cl}: 0.91-1.29 ; P=0.36\end{array}$ \\
\hline
\end{tabular}

Abbreviations: SWOG 9008/INT-0116, Southwest Oncology Group 9008/Intergroup trial 0116; CRT, chemoradiation therapy; OS, overall survival; HR, hazard ratio; Cl, confidence interval; ARTIST, Adjuvant Chemoradiation Therapy in Stomach Cancer; CT, chemotherapy; ACTS GC, Adjuvant Chemotherapy Trial of S-1 for Gastric Cancer; CLASSIC, Capecitabine and Oxaliplatin Adjuvant Study in Stomach Cancer; XELOX, capecitabine/oxaliplatin; MAGIC, Medical Research Council Adjuvant Gastric Infusional Chemotherapy; ECF, epirubicin, cisplatin, and 5-fluorouracil; FLOT4-AIO, perioperative chemotherapy with docetaxel, oxaliplatin, and fluorouracil/leucovorin (FLOT) versus epirubicin, cisplatin, and fluorouracil or capecitabine (ECF/ECX) for resectable gastric or gastroesophageal junction (GEJ) adenocarcinoma; FLOT, 5-fluorouracil, leucovorin, oxaliplatin, and docetaxel; ECX, epirubicin, cisplatin, and capecitabine; ST03, Chemotherapy With or Without Bevacizumab or Lapatinib to Treat Operable Oesophagogastric Cancer.

Adapted from (71)

therapy and 3-year overall survival remained poor at 39\% with median overall survival at 26 months (62). Thus, although the Oe02 trial closed over 20 years ago, Oe02-style treatment remains one of the standard treatment options.

OeC patients in NL are treated with neoadjuvant chemoradiotherapy followed by surgery, based on the results from the CROSS trial, which reported a 5-year survival of $47 \%$, with median overall survival of 49 months (54).

Several meta-analyses have failed to show improved survival with the addition of radiotherapy to neoadjuvant chemotherapy $(63,64)$. For a conclusive answer to this question, we need to wait for the results from the ongoing Neo-AEGIS trial, which compares survival in patients treated with perioperative chemotherapy versus neoadjuvant chemoradiotherapy followed by resection (65). 
For an overview of survival outcomes in studies evaluating treatment regimens in localised resectable oesophageal cancer, see table 3.

Table $\mathbf{3}$ | Overall survival reported in randomised phase III clinical trials, evaluating treatment regimens in patients with localised resectable oesophageal cancer

\begin{tabular}{|c|c|c|c|}
\hline $\begin{array}{l}\text { Trial/ } \\
\text { registry No./ } \\
\text { authors }\end{array}$ & Regimen & $\begin{array}{l}\text { No. of } \\
\text { patients }\end{array}$ & Outcome \\
\hline RTOG 8911 (72) & Surgery vs. CFx3 + surgery & 227 vs. 213 & $\begin{array}{l}\text { Median OS, } 16.1 \text { vs. } 14.9 \text { months; } \\
\mathrm{HR}, 1.07 ; 95 \% \mathrm{Cl}: 0.87-1.32 ; \mathrm{P}=0.53\end{array}$ \\
\hline OEO2 $(52,73)$ & Surgery vs. CFx2 + surgery & 402 vs. 400 & $\begin{array}{l}\text { 5-year OS rate, } 17.1 \% \text { vs. } 23 \% \text {; } \\
\text { Median OS, } 13.3 \text { vs. } 16.8 \text { months; } \\
\text { HR, } 0.79 ; 95 \% \mathrm{Cl}: 0.67-0.93 ; \mathrm{P}=0.004\end{array}$ \\
\hline OE05 (62) & $\begin{array}{l}\text { CFX2 + surgery vs. ECX } \times 4 \\
+ \text { surgery }\end{array}$ & 451 vs. 446 & $\begin{array}{l}\text { Median OS, } 23.4 \text { vs. } 26.1 \text { months; } \\
\mathrm{HR}, 0.90 ; 95 \% \mathrm{Cl}: 0.77-1.05 ; \mathrm{P}=0.19\end{array}$ \\
\hline $\begin{array}{l}\text { FNCLCC/FFCD } \\
(74)\end{array}$ & $\begin{array}{l}\text { Surgery vs. } C \times 3+\text { surgery } \\
+ \text { CFx3 }\end{array}$ & 111 vs. 113 & $\begin{array}{l}\text { 5-year OS rate, } 24 \% \text { vs. 38\%; } \\
\text { HR, 0.69; } 95 \% \text { Cl: } 0.50-0.95 ; P=0.02\end{array}$ \\
\hline CROSS $(54,75)$ & $\begin{array}{l}\text { Surgery vs. CRT (with } \\
\text { carboplatin and paclitaxel) } \\
+ \text { surgery }\end{array}$ & 188 vs. 178 & $\begin{array}{l}\text { 5-year OS rate, } 33 \% \text { vs. } 47 \% \\
\text { Median OS, } 24 \text { vs. } 49.4 \text { months; } \\
\text { HR, } 0.657 ; 95 \% \mathrm{Cl}: 0.495-0.871 ; P=0.003\end{array}$ \\
\hline $\operatorname{POET}(76,77)$ & $\begin{array}{l}\text { Induction } C T+\text { surgery vs. } \\
\text { induction } C T+C R T+ \\
\text { surgery }\end{array}$ & 59 vs. 60 & $\begin{array}{l}\text { 3-year OS rate, } 27.7 \% \text { vs. } 47.7 \% ; P=0.07 \text {; } \\
\text { study closed early due to poor accrual }\end{array}$ \\
\hline $\begin{array}{l}\text { Burmeister et al } \\
\text { (78) }\end{array}$ & $\begin{array}{l}\mathrm{CT}+\text { surgery vs. CRT + } \\
\text { surgery }\end{array}$ & 36 vs. 39 & Median OS, 29 vs. 32 months; $P=0.83$ \\
\hline Ajani et al (79) & $\begin{array}{l}\text { CRT + surgery vs. } \\
\text { induction } \\
C T+C R T+\text { surgery }\end{array}$ & 63 vs. 63 & $\begin{array}{l}\text { Median OS, } 45.62 \text { vs. } 43.68 \text { months; } P= \\
0.69\end{array}$ \\
\hline NeoRes (80) & $\begin{array}{l}\mathrm{CT}+\text { surgery vs. } \mathrm{CRT}+ \\
\text { surgery }\end{array}$ & 91 vs. 90 & 3 -year OS rate, $49 \%$ vs. $47 \% ; P=0.77$ \\
\hline
\end{tabular}

Abbreviations: RTOG 8911, Radiation Therapy Oncology Group trial 8911; CF, cisplatin plus fluorouracil; OS, overall survival; $H R$, hazard ratio; $\mathrm{Cl}$, confidence interval; ECX, epirubicin, cisplatin, and capecitabine; FNCLCC, Federation Nationale des Centres de Lutte Contre le Cancer; FFCD, Federation Francophone de Cancerologie Digestive; CROSS, Chemoradiotherapy for Oesophageal Cancer Followed by Surgery Study; POET, PreOperative therapy in Esophagogastric adenocarcinoma Trial; CT, chemotherapy; CRT, chemoradiation therapy; NeoRes, Neoadjuvant Chemotherapy versus Chemoradiotherapy in Resectable Cancer of the Oesophagus and Gastric Cardia.

Adapted from (71)

\section{CHALLENGES IN OESOPHAGOGASTRIC CANCER PATIENT MANAGEMENT}

When a patient is confronted with a cancer diagnosis, the individual patient wants to know whether he/she will survive the cancer ('what is my prognosis?') and whether the proposed treatment will work ('will I benefit from the treatment and live longer, or will I only have side effects with a poor quality of life?'). As shown from the studies/summary above, there has been very little progress in improving the outcome of OGCa patients with locally advanced 
resectable disease in the last decade. The patient's treatment is still determined based on the clinical stage of the disease (see figure with the treatment algorithm). However, OGCa patients with the same clinical or pathological TNM stage receiving the same chemotherapy and surgical treatment can have very different outcomes $(66,67)$ suggesting that only a subset of OGCa patients truly benefit from chemotherapy, with the remaining patients suffering unnecessary toxicities. The clinical team currently has no patient specific biomarkers to support the discussion with the patient and provide satisfactory answers to individual patient's questions.

For OGCa patients with locally advanced resectable disease, the clinical team needs to be able to distinguish between patients with (1) 'indolent' disease most likely curable by surgery alone, (2) 'aggressive' disease which can be influenced by chemotherapy and (3) 'aggressive' disease, resistant to standard chemotherapy and for which other therapy options might need to be considered, for example via participation in ongoing trials. Despite the recently proposed histological and molecular classifications $(25-27,29,40,68)$ and the continued use of multimodal treatment, the challenge and the clinical need remains to identify clinically relevant biomarkers in order to improve and individualise the management of OGCa patients with locally advanced resectable disease.

Tumour heterogeneity and the tumour microenvironment have been suggested as potential factors influencing OGCa patient outcome, and are discussed below.

\section{Tumour heterogeneity}

OGCa is known to be a very heterogeneous disease at the molecular and histological level, both between tumours (inter-) and within the same tumour (intra-). Figure 5 provides an example of histological intertumour heterogeneity with respect to the relative tumour content per area in GC. Tumour heterogeneity has been proposed as one of the reasons for the disappointing results of recent clinical trials in OGCa patients (81). The numerous proposed molecular and morphological classification systems in GC have focussed on the heterogeneity of the epithelial component of a tumour (82). Heterogeneity of other components within OGCa and its relationship with patient prognosis and/or response to chemotherapy has not been investigated in detail.

\section{Tumour microenvironment}

Tumours including OGCa are highly complex tissues composed of neoplastic epithelial cells and 'stroma', the material in between the tumour cells, which includes fibroblasts, extracellular matrix, vessels and immune cells (see figure 5). In GC, our previous research has shown that the expression of stroma-related gene sets and the morphometric quantification of the tumour-stroma proportion is related to patient prognosis (83). In OeC, we demonstrated that the quantity of the intratumoural stroma in the pretreatment biopsies predicts benefit from neoadjuvant chemotherapy in patients recruited into the Oe02 trial (84). In addition, there 

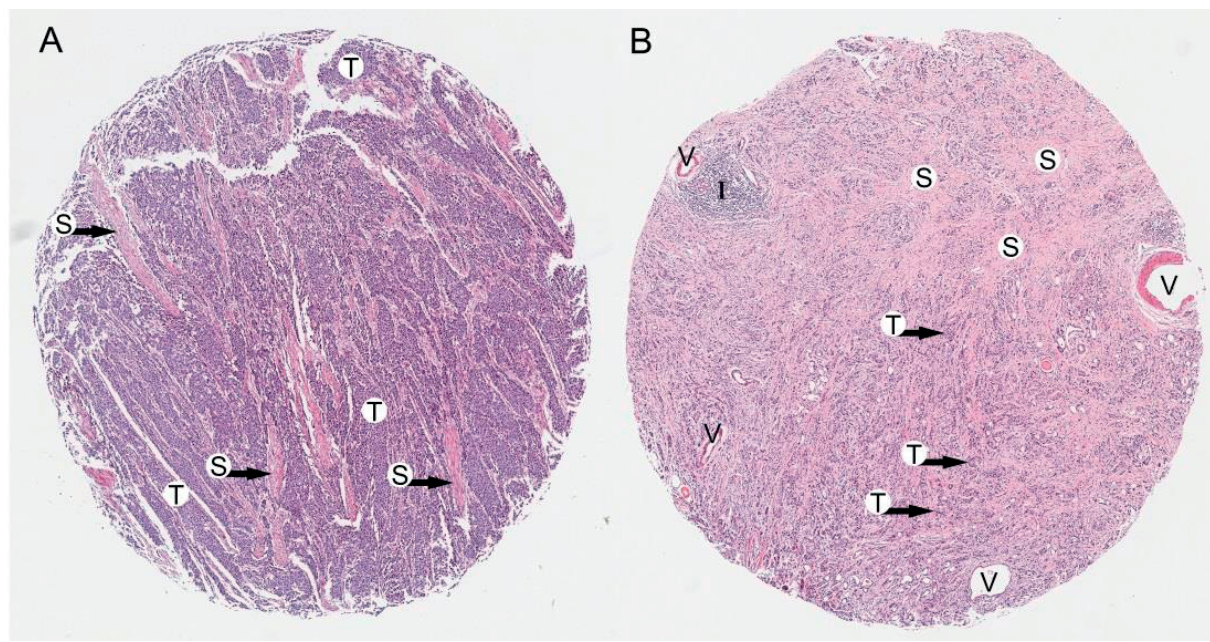

Figure $\mathbf{5}$ | Intertumour heterogeneity of the tumour microenvironment in gastric cancer. (A) High proportion of tumour epithelial cells [T] relative to the stroma [S]. No immune cell clusters in the stroma visible.

(B) Low proportion of tumour epithelial cells [T] relative to the stroma [S]. Within the stroma, there are vessels [V] and immune cell clusters [I] are visible.

Haematoxylin/Eosin stained tissue microarray cores from the CLASSIC trial. Cores taken from the area of highest tumour density in both cases. Core diameter $=3 \mathrm{~mm}$

is evidence to suggest that interactions between tumour cells and stroma resident immune cells may influence tumour progression. This could explain why patients with EBV-positive and MSI GCS, which are usually characterised by a relative high number of tumour-infiltrating lymphocytes, have a better prognosis compared to those with EBV-negative and MSS GCS $(85,86)$. As with proposed tumour-cell based biomarkers, clinical validation of stroma-based biomarkers is still lacking.

\section{AIM AND OUTLINE OF THE THESIS}

The aim of this thesis was to identify prognostic and predictive biomarkers in locally advanced resectable OGCa. We begin by focussing on the molecular characterisation of OGCa. We review the literature on KRAS and BRAF mutations in GC in chapter 2. In chapter $\mathbf{3}$, we follow on from this review and investigate the relationship between KRAS mutation and copy number status, histological phenotype, clinicopathological variables and survival in GC. In chapter 4, we determine the frequency of EBV and MMR in a large multicentre derived series of $\mathrm{OeC}$ and $\mathrm{GC}$ and relate the results to clinicopathological variables including patient survival. In chapter $\mathbf{5}$, the focus shifts to the tumour microenvironment where we investigate the intratumour heterogeneity of the relative tumour/stroma content in the diagnostic biopsy of OeC patients to predict survival benefit from neoadjuvant chemotherapy. In chapter $\mathbf{6}$, 
Chapter 1

we investigate the role of tumour infiltrating lymphocytes as a prognostic and predictive biomarker in GC. Chapter 7 discusses the implications of our research in the context of the current literature and the future perspectives of the clinical management of OGCa patients. 


\section{REFERENCES}

1. Bray F, et al. Global cancer statistics 2018: GLOBOCAN estimates of incidence and mortality worldwide for 36 cancers in 185 countries. CA Cancer J Clin. 2018;68(6):394-424.

2. Lee $\mathrm{KS}$, et al. Gastric cancer screening in Korea: report on the national cancer screening program in 2008. Cancer Res Treat. 2011;43(2):83-8.

3. Hamashima $C$, et al. Update version of the Japanese Guidelines for Gastric Cancer Screening. Jpn J Clin Oncol. 2018;48(7):673-83.

4. Areia M, et al. Endoscopic screening for gastric cancer: A cost-utility analysis for countries with an intermediate gastric cancer risk. United European Gastroenterol J. 2018;6(2):192-202.

5. International Agency for Research on Cancer. Global Cancer Observatory 2018 [Available from: http://gco.iarc.fr/].

6. Colquhoun A, et al. Global patterns of cardia and non-cardia gastric cancer incidence in 2012. Gut. 2015;64(12):1881-8.

7. Olefson $\mathrm{S}$, et al. Obesity and related risk factors in gastric cardia adenocarcinoma. Gastric Cancer. 2015;18(1):23-32.

8. Rota $\mathrm{M}$, et al. Alcohol consumption and gastric cancer risk-A pooled analysis within the StoP project consortium. Int J Cancer. 2017;141(10):1950-62.

9. Chow $\mathrm{WH}$, et al. The relation of gastroesophageal reflux disease and its treatment to adenocarcinomas of the esophagus and gastric cardia. JAMA. 1995;274(6):474-7.

10. Praud $D$, et al. Cigarette smoking and gastric cancer in the Stomach Cancer Pooling (StoP) Project. Eur J Cancer Prev. 2018;27(2):124-33.

11. Helicobacter, et al. Gastric cancer and Helicobacter pylori: a combined analysis of 12 case control studies nested within prospective cohorts. Gut. 2001;49(3):34753.
12. Ohata $\mathrm{H}$, et al. Progression of chronic atrophic gastritis associated with Helicobacter pylori infection increases risk of gastric cancer. Int J Cancer. 2004;109(1):138-43.

13. Wang $C$, et al. Changing trends in the prevalence of $\mathrm{H}$. pylori infection in Japan (1908-2003): a systematic review and meta-regression analysis of 170,752 individuals. Sci Rep. 2017;7(1):15491.

14. Jiang JX, et al. Downward trend in the prevalence of Helicobacter pylori infections and corresponding frequent upper gastrointestinal diseases profile changes. Springerplus. 2016;5(1):1601.

15. Fang $X$, et al. Landscape of dietary factors associated with risk of gastric cancer: A systematic review and dose-response meta-analysis of prospective cohort studies. Eur J Cancer. 2015;51(18):2820-32.

16. Lott PC, et al. Resolving gastric cancer aetiology: an update in genetic predisposition. Lancet Gastroenterol Hepatol. 2018;3(12):874-83.

17. Lauren P. The two histological main types of gastric carcinoma: diffuse and so called intestinal-type carcinoma. Acta Pathol Microbiol Scand. 1965;64:31-49.

18. Nakamura $K$, et al. Carcinoma of the stomach in incipient phase: its histogenesis and histological appearances. Gan. 1968;59(3):251-8.

19. Ming SC. Gastric carcinoma. A pathobiological classification. Cancer. 1977;39(6):2475-85.

20. Goseki N, et al. Differences in the mode of the extension of gastric cancer classified by histological type: new histological classification of gastric carcinoma. Gut. 1992;33(5):606-12.

21. Carneiro F, et al. New elements for an updated classification of the carcinomas of the stomach. Pathol Res Pract. 1995; 191:571-84. 
22. Solcia E, et al. A combined histologic and molecular approach identifies three groups of gastric cancer with different prognosis. Virchows Arch. 2009;455(3):197-211.

23. Japanese Gastric Cancer Association. Japanese classification of gastric carcinoma: 3rd English edition. Gastric Cancer. 2011;14(2):101-12.

24. WHO Classification of Tumours Editorial Board. World Health Organization Classification Tumours. Digestive System Tumours. Fifth Edition. WHO Classification of Tumours Editorial Board, editor. Lyon: IARC; 2019.

25. Deng N, et al. A comprehensive survey of genomic alterations in gastric cancer reveals systematic patterns of molecular exclusivity and co-occurrence among distinct therapeutic targets. Gut. 2012;61(5):67384.

26. Tan IB, et al. Intrinsic subtypes of gastric cancer, based on gene expression pattern, predict survival and respond differently to chemotherapy. Gastroenterol. 2011;141(2):476-85, 85 e1-11.

27. Ooi $\mathrm{CH}$, et al. Oncogenic pathway combinations predict clinical prognosis in gastric cancer. PLoS Genet. 2009;5(10):e1000676.

28. Lei $Z$, et al. Identification of molecular subtypes of gastric cancer with different responses to PI3-kinase inhibitors and 5-fluorouracil. Gastroenterol. 2013;145(3):554-65.

29. Cancer Genome Atlas Research Network. Comprehensive molecular characterization of gastric adenocarcinoma. Nature. 2014;513(7517):202-9.

30. Cortes-Ciriano I, et al. A molecular portrait of microsatellite instability across multiple cancers. Nat Commun. 2017;8:15180.

31. Sohn $B H$, et al. Clinical Significance of Four Molecular Subtypes of Gastric Cancer Identified by The Cancer Genome Atlas Project. Clin Cancer Res. 2017. doi: 10.1158/1078-0432.CCR-16-2211.
32. Cristescu R, et al. Molecular analysis of gastric cancer identifies subtypes associated with distinct clinical outcomes. Nat Med. 2015;21(5):449-56.

33. Kim HS, et al. Comprehensive expression profiles of gastric cancer molecular subtypes by immunohistochemistry: implications for individualized therapy. Oncotarget. 2016;7(28):44608-20.

34. Gonzalez RS, et al. Immunohistochemistry as a surrogate for molecular subtyping of gastric adenocarcinoma. Hum Pathol. 2016;56:16-21.

35. Setia $N$, et al. A protein and mRNA expression-based classification of gastric cancer. Mod Pathol. 2016;29(7):772-84.

36. Smyth EC, et al. Gastric cancer: ESMO Clinical Practice Guidelines for diagnosis, treatment and follow-up. Ann Oncol. 2016;27(suppl 5):v38-v49.

37. Japanese Gastric Cancer Association. Japanese gastric cancer treatment guidelines 2014 (ver. 4). Gastric Cancer. 2017;20(1):1-19.

38. National Health Commission of The People's Republic of China. Chinese guidelines for diagnosis and treatment of esophageal carcinoma 2018 (English version). Chin J Cancer Res. 2019;31(2):223-58.

39. Domper Arnal MJ, et al. Esophageal cancer: Risk factors, screening and endoscopic treatment in Western and Eastern countries. World J Gastroenterol. 2015;21(26):7933-43.

40. Cancer Genome Atlas Research Network. Integrated genomic characterization of oesophageal carcinoma. Nature. 2017:541(7636):169-75.

41. Shaheen NJ, et al. ACG Clinical Guideline: Diagnosis and Management of Barrett's Esophagus. Am J Gastroenterol. 2016;111(1):30-50; quiz 51.

42. Brierley JD, et al. Union for International Cancer Control. TNM Classification of Malignant Tumours. 8th ed: Wiley-Blackwell; 2016. $272 p$ 
43. Liu JY, et al. The prognosis role of AJCC/ UICC 8(th) edition staging system in gastric cancer, a retrospective analysis. Am J Transl Res. 2018;10(1):292-303.

44. Rice TW, et al. 8th edition AJCC/UICC staging of cancers of the esophagus and esophagogastric junction: application to clinical practice. Ann Cardiothorac Surg. 2017;6(2):119-30.

45. Lordick F, et al. Oesophageal cancer: ESMO Clinical Practice Guidelines for diagnosis, treatment and follow-up. Ann Oncol. 2016;27(suppl 5):v50-v7.

46. Ajani JA, et al. Esophageal and Esophagogastric Junction Cancers, Version 1.2015. J Natl Compr Canc Ne. 2015;13(2):194227.

47. Ajani JA, et al. Gastric Cancer, Version 3.2016, NCCN Clinical Practice Guidelines in Oncology. J Natl Compr Canc Netw. 2016;14(10):1286-312.

48. Integraal Kankercentrum Nederland. Oesofaguscarcinoom. Landelijke richtlijn, versie: 3.12015 [Available from: https:// www.mdl.nl/sites/www.mdl.nl/files/richlijnen/Richtlijn_Oesofaguscarcinoom.pdf].

49. Integraal Kankercentrum Nederland. Maagcarcinoom. Nation-wide guideline, version: 2.22017 [Available from: https:// www.oncoline.nl/richtlijn/doc/download. php?id=1014\&bijlage=1].

50. Nice Institute for Health and Care Excellence. Oesophago-gastric cancer. Assessment and mangement in adults 2018 [Available from: https://www.nice.org.uk/ guidance/ng83/resources/oesophagogastric-cancer-assessment-and-managementin-adults-pdf-1837693014469].

51. Bausys R, et al. Safety of expanded criteria for endoscopic resection of early gastric cancer in a Western cohort. BMC Surg. 2018;18(1):79.

52. Allum $\mathbf{W H}$, et al. Long-Term Results of a Randomized Trial of Surgery With or Without Preoperative Chemotherapy in Esophageal Cancer. J Clin Oncol. 2009;27(30):5062-7.

53. Cunningham $D$, et al. Perioperative chemotherapy versus surgery alone for resectable gastroesophageal cancer. N Engl J Med. 2006;355(1):11-20.

54. Shapiro J, et al. Neoadjuvant chemoradiotherapy plus surgery versus surgery alone for oesophageal or junctional cancer (CROSS): long-term results of a randomised controlled trial. Lancet Oncol. 2015;16(9):1090-8.

55. Al-Batran SE, et al. Perioperative chemotherapy with fluorouracil plus leucovorin, oxaliplatin, and docetaxel versus fluorouracil or capecitabine plus cisplatin and epirubicin for locally advanced, resectable gastric or gastro-oesophageal junction adenocarcinoma (FLOT4): a randomised, phase 2/3 trial. Lancet. 2019;393(10184):1948-57.

56. Noh SH, et al. Adjuvant capecitabine plus oxaliplatin for gastric cancer after D2 gastrectomy (CLASSIC): 5-year follow-up of an open-label, randomised phase 3 trial. Lancet Oncol. 2014;15(12):1389-96.

57. Sasako M, et al. Five-year outcomes of a randomized phase III trial comparing adjuvant chemotherapy with S-1 versus surgery alone in stage II or III gastric cancer. J Clin Oncol. 2011;29(33):4387-93.

58. Cunningham $D$, et al. Capecitabine and oxaliplatin for advanced esophagogastric cancer. N Engl J Med. 2008;358(1):36-46.

59. Cats $A$, et al. Chemotherapy versus chemoradiotherapy after surgery and preoperative chemotherapy for resectable gastric cancer (CRITICS): an international, open-label, randomised phase 3 trial. Lancet Oncol. 2018;19(5):616-28.

60. Cunningham D, et al. Peri-operative chemotherapy with or without bevacizumab in operable oesophagogastric adenocarcinoma (UK Medical Research Council ST03): primary analysis results of a multicentre, 
open-label, randomised phase 2-3 trial. Lancet Oncol. 2017;18(3):357-70.

61. Park $\mathrm{SH}$, et al. Phase III Trial to Compare Adjuvant Chemotherapy With Capecitabine and Cisplatin Versus Concurrent Chemoradiotherapy in Gastric Cancer: Final Report of the Adjuvant Chemoradiotherapy in Stomach Tumors Trial, Including Survival and Subset Analyses. I Clin Oncol. 2015;33(28):3130-6.

62. Alderson D, et al. Neoadjuvant cisplatin and fluorouracil versus epirubicin, cisplatin, and capecitabine followed by resection in patients with oesophageal adenocarcinoma (UK MRC OEO5): an open-label, randomised phase 3 trial. Lancet Oncol. 2017; 18(9):1249-60.

63. Sjoquist KM, et al. Survival after neoadjuvant chemotherapy or chemoradiotherapy for resectable oesophageal carcinoma: an updated meta-analysis. Lancet Oncol. 2011;12(7):681-92.

64. Jing SW, et al. Comparison of neoadjuvant chemoradiotherapy and neoadjuvant chemotherapy for esophageal cancer: a metaanalysis. Future Oncol. 2019;15(20):241322.

65. Reynolds JV, et al. ICORG 10-14: NEOadjuvant trial in Adenocarcinoma of the oEsophagus and oesophagoGastric junction International Study (Neo-AEGIS). BMC Cancer. 2017;17(1):401

66. Rocken $C$, et al. Validating the prognostic and discriminating value of the TNMclassification for gastric cancer - a critical appraisal. Eur J Cancer. 2015;51(5):57786.

67. Rice TW. Esophageal Cancer Staging. Korean J Thorac Cardiovasc Surg. 2015;48(3):157-63.

68. Zang ZJ, et al. Genetic and structural variation in the gastric cancer kinome revealed through targeted deep sequencing. Cancer Res. 2011;71(1):29-39.

69. Macdonald JS, et al. Chemoradiotherapy after surgery compared with surgery alone for adenocarcinoma of the stomach or gastroesophageal junction. N Engl J Med. 2001;345(10):725-30.

70. Sakuramoto $\mathrm{S}$, et al. Adjuvant chemotherapy for gastric cancer with S-1, an oral fluoropyrimidine. $N$ Engl J Med. 2007;357(18):1810-20.

71. Mizrak Kaya $D$, et al. Customization of therapy for gastroesophageal adenocarcinoma patients. Chronic Dis Transl Med. 2018;4(1):8-17.

72. Kelsen DP, et al. Chemotherapy followed by surgery compared with surgery alone for localized esophageal cancer. N Engl J Med. 1998;339(27):1979-84.

73. Bancewicz J, et al. Surgical resection with or without preoperative chemotherapy in oesophageal cancer: a randomised controlled trial. Lancet. 2002;359(9319):172733.

74. Ychou M, et al. Perioperative chemotherapy compared with surgery alone for resectable gastroesophageal adenocarcinoma: an FNCLCC and FFCD multicenter phase III trial. J Clin Oncol. 2011;29(13):1715-21.

75. van Hagen $\mathrm{P}$, et al. Preoperative chemoradiotherapy for esophageal or junctional cancer. N Engl J Med. 2012;366(22):207484.

76. Stahl $\mathrm{M}$, et al. Phase III comparison of preoperative chemotherapy compared with chemoradiotherapy in patients with locally advanced adenocarcinoma of the esophagogastric junction. J Clin Oncol. 2009;27(6):851-6.

77. Stahl M, et al. Preoperative chemotherapy versus chemoradiotherapy in locally advanced adenocarcinomas of the oesophagogastric junction (POET): Long-term results of a controlled randomised trial. Eur J Cancer. 2017;81:183-90.

78. Burmeister $\mathrm{BH}$, et al. Is concurrent radiation therapy required in patients receiving preoperative chemotherapy for adenocarcinoma of the oesophagus? A 
randomised phase II trial. Eur J Cancer. 2011;47(3):354-60.

79. Ajani JA, et al. A phase II randomized trial of induction chemotherapy versus no induction chemotherapy followed by preoperative chemoradiation in patients with esophageal cancer. Ann Oncol. 2013;24(11):2844-9.

80. Klevebro F, et al. A randomized clinical trial of neoadjuvant chemotherapy versus neoadjuvant chemoradiotherapy for cancer of the oesophagus or gastro-oesophageal junction. Ann Oncol. 2016;27(4):660-7.

81. Gullo I, et al. Heterogeneity in Gastric Cancer: From Pure Morphology to Molecular Classifications. Pathobiology. 2018;85(12):50-63.

82. Cislo M, et al. Distinct molecular subtypes of gastric cancer: from Lauren to molecular pathology. Oncotarget. 2018;9(27):1942742.
83. $\mathrm{Wu} Y$, et al. Comprehensive genomic meta-analysis identifies intra-tumoural stroma as a predictor of survival in patients with gastric cancer. Gut. 2013;62(8):110011.

84. Hale MD, et al. Biopsy proportion of tumour predicts pathological tumour response and benefit from chemotherapy in resectable oesophageal carcinoma: results from the UK MRC OE02 trial. Oncotarget. 2016;7(47):77565-75.

85. Cho J, et al. Epstein-Barr Virus-Associated Gastric Carcinoma and Specific Features of the Accompanying Immune Response. J Gastric Cancer. 2016;16(1):1-7.

86. Zhu L, et al. Microsatellite instability and survival in gastric cancer: A systematic review and meta-analysis. Mol Clin Oncol. 2015;3(3):699-705. 



\section{Chapter 2}

\section{KRAS, BRAF and Gastric Cancer}

Lindsay C. Hewitt | Gordon Hutchins | Veerle Melotte | Yuichi Saito | Heike I. Grabsch

Translational Gastrointestinal Cancer 2015; 4: 6, 429-447

Gastric Cancer Precision Medicine. Chen L, Kim SY and Sugimura H, eds. $1^{\text {st }}$ ed. AME publishing Company, 2017: 7-25 


\section{ABSTRACT}

Gastric cancer (GC) remains a major worldwide health problem and survival rates continue to be poor in patients with advanced stage disease despite multimodal treatment combining different chemo(radio)therapy regimens with surgery or best supportive care. Thus, there is an urgent clinical need to identify new potential drug targets in order to improve survival for GC patients.

KRAS encodes a small guanosine triphosphatase and point mutations in codons 12 and 13 of KRAS have been detected in many human cancers. BRAF is a member of the RAF family of protein kinases and has a hotspot for mutations in codon 600 (so called V600E mutation). KRAS and BRAF proteins are both components of the MAPK/ERK pathway. When mutated, KRAS becomes constitutively active resulting in enhanced BRAF activity. KRAS and BRAF mutations in colorectal cancers are known predictors of poor response to EGFR targeting agents. This PubMed and Web of Science based review aimed to analyze and summarize the current literature on mutations in KRAS and BRAF in GC and their relationship to clinicopathological and molecular variables including KRAS amplification. In total, 69 studies were included in this review. The median incidence of a KRAS mutation was $6.5 \%$ ranging from $0-29 \%$. The median incidence of KRAS mutations was similar in studies from the East and the West (East: $6 \%$, ranging from 0-20\%; West $7.5 \%$, ranging from 0-29\%). KRAS amplifications were reported at an incidence of $1-9 \%$. The median BRAF mutation incidence in GC was $0 \%$, ranging from $0 \%$ to $12 \%$. Due to the low incidence and often small study size, many of the published studies had insufficient statistical power to detect a potential relationship between KRAS mutation status and clinicopathological variables including patient survival.

In summary, the current literature on KRAS and BRAF in GC is still limited and very heterogeneous making any comparisons between different studies difficult. BRAF V600E mutations are very rare in $\mathrm{GC}$. Interestingly, the incidence of KRAS mutations in $\mathrm{GC}$ is much lower than that in colorectal cancer and there appears to be no difference by ethnicity of the patients. KRAS mutations and KRAS amplifications seem to be mutually exclusive suggesting the need to screen GC patients for both genetic aberrations. So far, all clinical studies in unselected patients with metastatic GC have failed to show a significant benefit for EGFR targeting therapy. However, there has been a recent report indicating that the subgroup of signet ring cell GC, which is known to be resistant to standard cytotoxic chemotherapy, has a higher incidence of KRAS mutations (15\%). Thus, EGFR targeted therapy in this particular histological subtype of GC could potentially be a promising treatment option in the future. 


\section{INTRODUCTION}

Gastric cancer (GC) is a common cancer with a worldwide incidence of nearly one million cases per year (1). In 2012, there were an estimated 723,100 GC deaths worldwide, making GC the third most frequent cause of cancer related death. There is large geographic variation in GC incidence, with the highest incidence rates in Eastern Asia (particularly in Korea, Mongolia, Japan, and China), Central and Eastern Europe, and South America and lowest rates in Northern America and most parts of Africa. The incidence of GC in men is about twice as high as in women (2) and approximately $10 \%$ of GCs have a familial component (3). Helicobacter pylori (H. pylori) infection is an established risk factor for developing GC. $89 \%$ of cases of non-cardia GC worldwide are attributed to this bacterium (4). Survival of GC patients remains poor. The overall 5-year survival of patients with locally advanced unresectable, recurrent or metastatic GC is $5-20 \%$ if treated with cytotoxic chemotherapy (5), increasing to $36 \%$ in patients with locally advanced resectable GC treated with perioperative chemotherapy followed by surgery (6). Thus, there is an urgent clinical need to identify new potential drug targets in order to and improve survival for GC patients.

Macroscopically, GCs are categorized according to the Borrmann classification into type I (polypoid), type II (fungating), type III (ulcerating), and type IV (diffusely infiltrating) (7). Histologically, GCs are most commonly categorized using the Lauren classification into intestinal, diffuse and mixed/indeterminate type (8). The intestinal-type occurs more commonly in elderly patients, whereas the diffuse-type is seen in particular in young female patients and has a poorer prognosis (9). In the West, the relative proportion of intestinal-type GC is up to $74 \%$ intestinal-type (10) compared to $44 \%$ in the East (11). Staging of GC is performed using the UICC (12), AJCC (13) or JGCA (14) Tumor Node Metastasis (TNM) staging system which follow same principles but have some minor variations.

Molecular aberrations are known to play an important role in the development of GC. In addition to mutations in oncogenes, such as TP53, APC, CDH1, p16 and PTEN, or tumor suppressor genes such as $\beta$-catenin, BRAF, KRAS, PIK3CA and ERBB2 (15), microsatellite instability (MSI) caused by deficient DNA mismatch repair (MMR) has been identified in 15\% to $30 \%$ GC (16). DNA aneuploidy, a surrogate marker for chromosomal instability, has been reported in 24-85\% GC (17) and Epstein-Barr Virus (EBV) infection has been identified in approximately $9 \%$ GCs (18). Several different molecular classifications of GCs have been proposed recently (19). For a recent review on this subject see Tan et al. (20).

The focus of this review is on the existing literature on genetic alterations in KRAS and $B R A F$ in GC. Reported incidence of mutations in KRAS and BRAF and their relation to clinicopathological and molecular variables including KRAS amplification are analyzed and summarized. Literature on KRAS/BRAF epigenetic changes has been excluded from this review. Results from GC are compared with studies investigating KRAS and BRAF mutations in colorectal cancer $(C R C)$ and cancer of the small bowel. Furthermore, the clinical relevance 
of determining the mutational status and DNA copy number of these genes in relation to patient treatment for $\mathrm{GC}$ will be discussed.

\section{METHODS}

The Web of Science (from 1988-14th May 2015) and PubMed (from 1946-14th May 2015) databases were searched for all known_gene aliases of KRAS and BRAF (gene aliases from www.genecards.org, accessed on $8^{\text {th }}$ May 2015). These aliases were used as search terms in combination with ("gastric cancer" or "stomach cancer" or "gastric carcinoma" or "stomach carcinoma", see table 1).

Table 1 | Search terms used in PubMed and Web of Science

\begin{tabular}{ll}
\hline Search Term \\
\hline KRAS & "KRAS" OR "Kirsten Rat Sarcoma Viral Oncogene Homolog" OR "KRAS2" OR "RASK2" OR \\
& "V-Ki-Ras2 Kirsten Rat Sarcoma 2 Viral Oncogene Homolog" OR "V-Ki-Ras2 Kirsten Rat Sarcoma \\
& Viral Oncogene Homolog" OR "C-Ki-ras" OR "K-Ras 2" OR "CFC2" OR "NS" OR "C-K-RAS" OR \\
& "K-RAS2A" OR "K-RAS2B" OR "K-RAS4A" OR "K-RAS4B" OR "KI-RAS" OR "KRAS1" OR "NS3" \\
& OR "C-Kirsten-Ras Protein" OR "Cellular C-Ki-Ras2 Proto-Oncogene" OR "GTPase KRas" OR \\
& "K-Ras P21 Protein" OR "Oncogene KRAS2" OR "PR310 C-K-Ras Oncogene" OR "Transforming \\
& Protein P21" OR "Ki-Ras" OR "c-K-ras") AND ("gastric cancer" or "gastric carcinoma" or \\
& "stomach cancer" or "stomach carcinoma") \\
\hline BRAF "BRAF" OR "V-Raf Murine Sarcoma Viral Oncogene Homolog B" OR "V-Raf Murine Sarcoma Viral \\
Oncogene Homolog B1" OR "Proto-Oncogene B-Raf" OR "BRAF1" OR "RAFB1" OR "NS7" OR \\
"94 KDa B-Raf Protein" OR "B-RAF1" OR "B-Raf Proto-Oncogene Serine/Threonine-Protein Kinase \\
(P94)" OR "Murine Sarcoma Viral (V-Raf) Oncogene Homolog B1" OR "Serine/Threonine-Protein \\
Kinase B-Raf" OR "EC 2.7.11.1" OR "p94") AND ("gastric cancer" OR "gastric carcinoma" OR \\
"stomach cancer" OR "stomach carcinoma")
\end{tabular}

Eligibility to be included in the current review was restricted to original articles reporting gastric cancer (GC) studies using human tissue, blood or plasma samples irrespective of sample size and stage of disease. Other tumors of the stomach such as lymphomas or gastrointestinal stromal tumors, and cell line studies were excluded. The reference lists of publications eligible to be included in this review were searched for further relevant articles. Each article was analyzed for information on study size, geographical origin of patient cohort (East versus West), age, gender, survival, and whether any chemo(radio)therapy was given. With regard to DNA isolation from tumor tissue, the reported tumor cell density, number of blocks used, and tissue processing (frozen versus formalin-fixed paraffin embedded (FFPE)) were analyzed. Furthermore, information on the mutation incidence, the mutation detection method and investigated codons was collected from each study. The relationship of mutation status with clinicopathological variables, DNA mismatch repair status and microsatellite instability, and DNA ploidy was noted. 


\section{RESULTS}

The initial database searches found 1369 articles in total. After screening, applying exclusion criteria and including additional articles from references, the final number of articles used for this review was 69. For a Preferred Reporting Items for Systematic Reviews and MetaAnalyses (PRISMA) flow diagram illustrating the manuscript selection process, see Figure 1.

\section{Identification}

-Articles identified through searching Web of Science and Pubmed databases: $n=1369$

\section{Screening}

-Articles not in English: $\mathrm{n}=100$

-Articles remaining after limitations applied: $n=1269$

-Number of duplicate articles: $\mathrm{n}=237$

-Articles remaining after removal of duplicates: $n=1032$

-Title or abstract did not meet eligibility criteria: $n=948$

-Articles remaining after screening: $\mathrm{n}=84$

\section{Eligibility}

-Unable to access full text: $n=21$

-Article full text obtained: $n=63$

-Articles excluded as eligibility criteria not met after reading full paper: $n=10$

\section{Included}

-Full text articles included in current study describing KRAS and/or BRAF in gastric cancer $\mathrm{n}=53$

-Additional articles found from reference lists: $n=16$

-Total number of articles included in review: $n=69$

Figure 1 | PRISMA flow diagram showing the number of studies included at each stage of the review process

\section{KRAS}

Mammalian cells encode three functional RAS genes: HRAS, KRAS and NRAS (21, 22). Although these different isoforms share a similar structure, their expression and/or activation 
differs by tissue and cancer types (23-25). This review will focus on KRAS as it is the most frequently mutated RAS gene in GC (26).

Kirsten Rat Sarcoma Viral Oncogene Homolog (KRAS) was discovered in 1982 by Chang $\mathrm{EH}$ et al (21). KRAS is a tumor suppressor gene which is located on chromosome 12p12 (www.genecards.org, accessed $\underline{8}^{\text {th }}$ May 2015 ). It has six exons and alternative splicing of exon 4 produces KRAS4A and KRAS4B which contains 188 and 189 amino acids, respectively (27). KRAS encodes a small guanosine triphosphatase (GTPase) protein with a molecular mass of $21.6 \mathrm{kD}(28)$.

The KRAS protein contains four domains which determine the interaction with GTP (Gdomain, amino acids 1-165), the anchoring of the protein in the plasma membrane (hypervariable region at the C-terminus, amino acids 165-188) as well as the binding of other regulators and effectors such as RAF and PI3K (28).

KRAS cycles between an inactive GDP-bound state and an active GTP-bound state (29). Activation of KRAS is triggered through a number of different types of receptors including tyrosine kinase receptors such as epidermal growth factor receptor (EGFR), as well as cytokine receptors, T cell receptors, and subunits of heterotrimeric $G$ proteins (30). Active RAS-GTP undergoes a conformational change affecting its interaction with various downstream effector molecules such as RAF and Mitogen-Activated protein kinase kinase (MAPK) (31) or PI3K/ AKT (32). This in turn activates nuclear transcription factors inducing a cascade of cellular processes such as proliferation, angiogenesis, apoptosis, or cell survival (26). Mutant KRAS functions as an oncogene inducing malignant transformation of cells due to permanent activation of downstream effectors (33).

KRAS mutations have been found in many human cancers. The most common mutations are located in codon 12 or 13 in exon 1, and less frequently in codon 61, 63, 117, 119 and 146 (28). Mutations in codons 12 and 13 are known to result in conformational changes and permanent expression ('activation') of the KRAS protein (34). Overexpression of KRAS as a result of loss of p16INK4 or loss of p53 has also been reported (35). For a more general review on KRAS mutations in human cancer, see Jancik et al (28).

\section{KRAS in Gastric Cancer}

\section{KRAS mutations}

The first report of a KRAS mutation in a single gastric cancer (GC) was published in 1986. Investigators described the presence of a single mutated KRAS allele (gly-12 to ser), together with a 30-50 fold amplification of the other KRAS allele (36). Since this first publication, 64 studies have reported on the incidence of KRAS mutations in GC, with the majority of studies $(61 \%)$ originating from Asia (see table $2 \mathrm{a}$ and $2 \mathrm{~b}$ ). Two studies compared KRAS mutations between GC patients from the East and the West $(37,38)$. Forty-five $(70 \%)$ studies investigated the KRAS mutation status in patient cohorts comprising less than 100 patients. 
Table 2a | Published literature on KRAS mutation status in gastric cancer excluding studies testing chemotherapeutic agents

\begin{tabular}{|c|c|c|c|c|c|}
\hline Reference & Year & Origin & $\begin{array}{l}\text { Total } \\
\mathbf{n}\end{array}$ & $\begin{array}{l}\text { mut KRAS } \\
\mathrm{n}(\%)\end{array}$ & Comment \\
\hline Nagata et al & 1990 & Japan & 25 & $2(8)$ & \\
\hline Victor et al & 1990 & South Africa & 11 & 0 & \\
\hline Kihana et al & 1991 & Japan & 35 & $3(9)$ & $\begin{array}{l}3 \text { of } 7 \text { adenoma had mut } K R A S \text {; mut } \\
\text { KRAS in well diff GC only }\end{array}$ \\
\hline Miki et al & 1991 & Japan & 31 & $4(13)$ & mut $K R A S$ only found in intestinal-type \\
\hline Capella et al & 1991 & Europe & 14 & $1(7)$ & \\
\hline Ranzani et al & 1993 & Europe & 32 & $3(9)$ & 1 mut KRAS also had allelic losses \\
\hline Koshiba et al & 1993 & Japan & 37 & $1(3)$ & no mut KRAS in 13 adenoma \\
\hline Craanen et al & 1995 & Europe & 45 & 0 & only early GC tested \\
\hline Sakurai et al & 1995 & Japan & 19 & 0 & only early GC tested \\
\hline Hongyo et al & 1995 & Europe & 34 & $7(21)$ & $\begin{array}{l}\text { only intestinal-type GC tested; no mut } \\
\text { KRAS in stage III }\end{array}$ \\
\hline Lee et al & 1995 & South Korea & 140 & $11(8)$ & $\begin{array}{l}\text { mut KRAS more common in DNA } \\
\text { aneuploid and in upper third GC }\end{array}$ \\
\hline Hosoi et al & 1995 & Japan & 31 & 0 & biopsy samples tested \\
\hline Hao et al & 1998 & China & 206 & 0 & \\
\hline Iwaya et al & 1998 & Japan & 5 & $1(20)$ & $\begin{array}{l}\text { synchronous primary cancers of the } \\
\text { esophagus and other organs }\end{array}$ \\
\hline Arber et al & 2000 & USA & 32 & $1(3)$ & \\
\hline Russo et al & 2001 & Europe & 63 & $5(8)$ & mut KRAS not related to DNA ploidy \\
\hline Lee et al & 2002 & South Korea & 71 & $1(1)$ & \\
\hline Yoo et al & 2002 & South Korea /US & 104 & $10(10)$ & $\begin{array}{l}\text { mut } K R A S \text { related to intestinal-type GC } \\
\text { and higher pT }\end{array}$ \\
\hline Hiyama et al & 2002 & Japan & 48 & $4(8)$ & $\begin{array}{l}\text { mut } K R A S \text { related to well diff histology } \\
\text { type, younger age and } \mathrm{H} \text {. pylori infection }\end{array}$ \\
\hline Lee et al & 2003 & South Korea & 319 & $9(3)$ & mut $K R A S$ related to advanced $\mathrm{GC}$ \\
\hline Brennetot et al & 2003 & Europe & 82 & $10(12)$ & $\begin{array}{l}\text { mut KRAS only seen in MSI not in MSS } \\
\text { GC }\end{array}$ \\
\hline Kim et al & 2003 & South Korea & 66 & $4(6)$ & \\
\hline Wu et al & 2004 & Japan & 62 & $1(2)$ & $\begin{array}{l}\text { mut } K R A S \mathrm{GC} \text { related to } \mathrm{MSI} ; K R A S \text { and } \\
B R A F \text { mutations were exclusive }\end{array}$ \\
\hline Zhao et al & 2004 & China & 94 & $8(9)$ & $\begin{array}{l}7 \text { of } 8 \mathrm{GC} \text { with mut } K R A S \text { were } \mathrm{MSI} \text {. All } \\
\text { mut } K R A S \text { in } \mathrm{GC} \text { from antrum }\end{array}$ \\
\hline Yashiro et al & 2005 & Japan & 180 & $20(11)$ & $\begin{array}{l}\text { only advanced GC tested. mut KRAS more } \\
\text { common in well diff GC and Bormann } \\
\text { type I. No relationship with H-pylori } \\
\text { infection }\end{array}$ \\
\hline Oliveira et al & 2005 & Europe & 25 & $6(24)$ & only MSI GC tested \\
\hline Tajima et al & 2006 & Japan & 133 & $7(5)$ & $\begin{array}{l}\text { only early GC tested; no KRAS mutation } \\
\text { in } 63 \text { gastric adenoma }\end{array}$ \\
\hline
\end{tabular}


Table 2a | (continued)

\begin{tabular}{|c|c|c|c|c|c|}
\hline Reference & Year & Origin & $\begin{array}{l}\text { Total } \\
\mathrm{n}\end{array}$ & $\begin{array}{l}\text { mut KRAS } \\
\mathrm{n}(\%)\end{array}$ & Comment \\
\hline Sasao et al & 2006 & Japan & 55 & $1(2)$ & \\
\hline Kusano et al & 2006 & Japan & 78 & $4(5)$ & \\
\hline Gylling et al & 2007 & Europe & 59 & $4(7)$ & $\begin{array}{l}\text { mut KRAS only seen in MSI not in MSS } \\
\text { GC }\end{array}$ \\
\hline Tajima et al & 2007 & Japan & 134 & $8(6)$ & only differentiated GC tested \\
\hline Kimura et al & 2007 & Japan & 66 & $3(5)$ & \\
\hline Liu et al & 2009 & China & 52 & $5(10)$ & mut $K R A S$ only seen in males \\
\hline Mita et al & 2009 & Japan & 86 & 0 & $5 \%$ KRAS amp \\
\hline Betge et al & 2011 & Austria & 12 & $1(8)$ & GC with concomitant renal cancer \\
\hline Liu et al & 2011 & China & 58 & $6(10)$ & mut $K R A S$ only seen in males \\
\hline Corso et al & 2011 & Europe & 63 & $11(18)$ & $\begin{array}{l}\text { only MSI GC tested; mut KRAS more } \\
\text { common in elderly patients }\end{array}$ \\
\hline Chen et al & 2011 & China & 123 & $12(10)$ & KRAS tested in blood \\
\hline Saxena et al & 2012 & India & 62 & 0 & \\
\hline Matsubara et al & 2013 & Japan & 71 & $1(1)$ & \\
\hline Van Grieken et al & 2013 & $\begin{array}{l}\text { Europe/Japan/ } \\
\text { Singapore }\end{array}$ & 712 & $29(4)$ & $\begin{array}{l}\text { mut KRAS associated with MMR- } \\
\text { deficient GC. In Europe cohort mut KRAS } \\
\text { associated with pN, in Japan cohort mut } \\
\text { KRAS associated with elderly patients }\end{array}$ \\
\hline Kim et al & 2013 & South Korea/Japan & 30 & $2(7)$ & mut KRAS associated with CIMP \\
\hline Warneke et al & 2013 & Europe & 475 & $17(4)$ & $\begin{array}{l}\text { mut KRAS associated with worse survival } \\
\text { in proximal GC. Mut KRAS intestinal-type } \\
\text { GC with worse prognosis than KRAS wild- } \\
\text { type intestinal-type. } 9 \% \text { KRAS amp. }\end{array}$ \\
\hline Kim et al & 2014 & South Korea & 17 & $1(6)$ & $\begin{array}{l}\text { early and advanced GC tested. Missense } \\
\text { mutation detected }\end{array}$ \\
\hline Kim et al & 2014 & South Korea & 89 & $3(3)$ & $\begin{array}{l}\text { only metastatic GC tested. KRAS amp in } 2 \\
\text { cases; } 1 \text { case had increased copy number }\end{array}$ \\
\hline Peng and Zhao & 2014 & China & 126 & $9(7)$ & tissue and plasma tested \\
\hline Palacio-Rua et al & 2014 & Colombia & 29 & $2(7)$ & \\
\hline Qian et al & 2014 & China & 131 & $8(6)$ & $\begin{array}{l}\text { mut KRAS and KRAS amp (5\%) mutually } \\
\text { exclusive; associated with different } \\
\text { outcomes }\end{array}$ \\
\hline TGCA & 2014 & Multicenter & 215 & $36(17)$ & \\
\hline Ali et al & 2015 & USA & 116 & $12(10)$ & $\begin{array}{l}6 \% \text { KRAS amp. Includes } 36 \text { samples from } \\
\text { metastatic sites }\end{array}$ \\
\hline Lu et al & 2015 & China & 156 & $7(4)$ & mut $K R A S$ associated with $\mathrm{pNO} \mathrm{GC}$ \\
\hline Deng et al & 2015 & Singapore & 139 & $1(1)$ & $9 \%$ KRAS amp \\
\hline Cristescu et al & 2015 & South Korea & 223 & $18(8)$ & $8 \%$ KRAS amp \\
\hline Yoda et al & 2015 & Japan & 50 & $4(8)$ & $8 \%$ KRAS amp \\
\hline
\end{tabular}

Abbreviations: mut KRAS, mutant KRAS; MSI, microsatellite instability; well diff, well differentiated; PFS, progression free survival; OS, overall survival; CIMP, CpG island methylator phenotype; KRAS amp, KRAS amplification. 
Table 2b | Published literature on KRAS mutation status in gastric cancer studies investigating chemotherapeutic agents

\begin{tabular}{|c|c|c|c|c|c|c|c|}
\hline Reference & Year Origin & $\begin{array}{l}\text { Total } \\
\mathbf{n}\end{array}$ & $\begin{array}{l}\text { mut } \\
K R A S \\
\mathrm{n}(\%)\end{array}$ & $\begin{array}{l}\text { Stage of } \\
\text { disease }\end{array}$ & Treatment & $\begin{array}{l}\text { Sample } \\
\text { type used } \\
\text { for KRAS } \\
\text { testing }\end{array}$ & $\begin{array}{l}\text { Mutant KRAS } \\
\text { relationship } \\
\text { to survival }\end{array}$ \\
\hline Pinto et al & 2009 Europe & 32 & $3(9)$ & $\begin{array}{l}\text { advanced } \\
\text { unresectable. } \\
\text { Includes some } \\
\text { junctional } \\
\text { cancer }\end{array}$ & $\begin{array}{l}\text { Cetuximab + cisplatin } \\
\text { and docetaxel }\end{array}$ & $\begin{array}{l}\text { not } \\
\text { specified }\end{array}$ & $\begin{array}{l}\text { not reported } \\
\text { (no association } \\
\text { with ORR) }\end{array}$ \\
\hline Han et al & $2009 \begin{array}{l}\text { South } \\
\text { Korea }\end{array}$ & 38 & & $\begin{array}{l}\text { recurrent } \\
\text { metastatic }\end{array}$ & $\begin{array}{l}\text { Cetuximab + } \\
\text { oxaliplatin/ } \\
\text { leucovorin/5- } \\
\text { fluorouracil }\end{array}$ & $\begin{array}{l}\text { not } \\
\text { specified }\end{array}$ & no mut KRAS \\
\hline Park et al & $2010 \begin{array}{l}\text { South } \\
\text { Korea }\end{array}$ & 30 & $4(13)$ & metastatic & $\begin{array}{l}\text { cetuximab + } \\
\text { chemotherapy }\end{array}$ & $\begin{array}{l}\text { primary } \\
\text { tumor }\end{array}$ & $\begin{array}{l}\text { no association } \\
\text { with PFS and } \\
\text { OS }\end{array}$ \\
\hline $\begin{array}{l}\text { Lordick } \\
\text { et al }\end{array}$ & 2010 Europe & 52 & 1 (3) & $\begin{array}{l}\text { metastatic } \\
\text { or locally } \\
\text { advanced } \\
\text { unresectable }\end{array}$ & $\begin{array}{l}\text { Cetuximab + } \\
\text { oxaliplatin/ } \\
\text { leucovorin/5- } \\
\text { fluorouracil }\end{array}$ & $\begin{array}{l}\text { not } \\
\text { specified }\end{array}$ & not reported \\
\hline $\begin{array}{l}\text { Moehler } \\
\text { et al }\end{array}$ & 2011 Europe & 29 & & advanced & Sunitinib monotherapy & $\begin{array}{l}\text { not } \\
\text { specified }\end{array}$ & no mut KRAS \\
\hline $\begin{array}{l}\text { Rohrberg } \\
\text { et al }\end{array}$ & 2011 Europe & 7 & $2(29)$ & advanced & $\begin{array}{l}\text { Erlotinib + } \\
\text { bevacizumab }\end{array}$ & $\begin{array}{l}\text { not } \\
\text { specified }\end{array}$ & $\begin{array}{l}\text { no association } \\
\text { with PFS, OS } \\
\text { and DC }\end{array}$ \\
\hline Woll et al & 2011 Europe & 13 & & $\begin{array}{l}\text { metastatic } \\
\text { or locally } \\
\text { advanced } \\
\text { unresectable }\end{array}$ & $\begin{array}{l}\text { Oxaliplatin, irinotecan } \\
\text { + cetuximab }\end{array}$ & $\begin{array}{l}\text { biopsies/ } \\
\text { resected } \\
\text { primary } \\
\text { tumor }\end{array}$ & no mut KRAS \\
\hline Okines et al & 2013 Europe & 494 & $30(6)$ & $\begin{array}{l}\text { unresectable } \\
\text { and/or } \\
\text { metastatic GC. } \\
\text { Includes some } \\
\text { esophageal and } \\
\text { junctional ca }\end{array}$ & $\begin{array}{l}\text { REAL 3: Epirubicin, } \\
\text { oxaliplatin and } \\
\text { capecitabine } \pm \\
\text { panitumumab } \\
\text { MAGIC: Epirubicin, } \\
\text { cisplatin, 5-fluorouracil }\end{array}$ & $\begin{array}{l}\text { REAL 3: } \\
\text { pre- } \\
\text { treatment } \\
\text { biopsies } \\
\text { MAGIC: } \\
\text { resections }\end{array}$ & $\begin{array}{l}\text { REAL 3: no } \\
\text { association } \\
\text { with RR } \\
\text { MAGIC: no } \\
\text { association } \\
\text { with OS }\end{array}$ \\
\hline $\begin{array}{l}\text { Richards } \\
\text { et al }\end{array}$ & 2013 USA & 40 & $5(13)$ & metastatic & $\begin{array}{l}\text { docetaxel plus } \\
\text { oxaliplatin } \pm \\
\text { cetuximab }\end{array}$ & $\begin{array}{l}\text { not } \\
\text { specified }\end{array}$ & $\begin{array}{l}\text { not reported } \\
\text { (no association } \\
\text { with response) }\end{array}$ \\
\hline $\begin{array}{l}\text { Takahashi } \\
\text { et al }\end{array}$ & 2014 Japan & 164 & $8(5)$ & Advanced & $\begin{array}{l}\text { Cisplatin/S-1/5- } \\
\text { fluorouracil/5- } \\
\text { fluorouracil + } \\
\text { methotrexate/ } \\
\text { paclitaxel + } \\
\text { capecitabine } \\
+ \text { cisplatin } \pm \\
\text { bevacizumab in } \\
\text { metastatic disease }\end{array}$ & resection & $\begin{array}{l}\text { No association } \\
\text { with OS }\end{array}$ \\
\hline
\end{tabular}

Abbreviations: mut KRAS, mutant KRAS; PFS, progression free survival; OS, overall survival; DC, disease control; ORR, objective response rate; ca, cancer; RR; response rate. 


\section{Gastric cancer cohorts}

The median number of patients per study was 61, ranging from 5 to 712 patients. Excluding three international multicenter studies and two studies that did not mention the geographical origin of their patients, there were 39 (66\%) studies from the East and 22 (37\%) studies from the West. Studies from the East had a higher median study size of 66 patients, ranging from 5 to 319 patients compared to studies from the West with a median study size of 33 patients, ranging from 7 to 494 patients. The largest GC study was an international multicenter study including 712 GCs: 278 GC from the United Kingdom, 230 GC from Japan and 204 CG from Singapore (38).

Twenty-five (39\%) studies performed KRAS testing on samples from multiple centers (19, 37-60), 20 (31\%) studies used samples from a single center (61-80), and the remaining did not report this information. Twenty-seven (42\%) studies were performed using DNA extracted from formalin-fixed paraffin embedded tissue samples (37-39, 41, 42, 44, 45, 47, 48, 50-52, $56,61,63-66,68,69,72-74,81-84)$. With the exception of 11 studies which did not report at all which tissue was used $(40,54,77,80,85-91)$, all other studies used DNA from 'paraffin embedded tissue' (fixation method not reported) (43, 92-94), frozen tissue (19, 46, 53, 59, $60,67,70,71,75,76,78,79,95-98)$, blood or plasma samples (99), or a combination of the above $(49,55,57,58,62)$. Of the studies using tissue samples, 37 (59\%) used DNA extracted from resection specimens $(38,39,44,46,47,50,52-54,60-64,67,68,70,71,73-76,78-82$, $84,88-91,93,95-98), 10$ (16\%) used a combination of biopsy and resection specimens (37, $40,45,51,65,69,72,87,92,94)$ and two (3\%) used biopsy specimens $(77,86)$. The remaining $14(22 \%)$ did not report on the type of specimen used $(19,41-43,48,49,55-59,66$, $83,85)$. No study reported extracting DNA from multiple blocks, thus we have assumed that all studies used a single block for DNA extraction. Thirty-seven (59\%) studies considered the tumor cell density of the tissue prior to DNA extraction by either performing microdissection or preselecting areas of tumor with tumor cell density ranging from $>20 \%$ to $>80 \%$ (19, 37-40, 44, 46-54, 61, 62, 64-71, 73-76, 81, 82, 84, 89, 93, 94, 98). Twenty-two (34\%) studies investigated only subgroups of GC patients, thus 8 (36\%) studies investigated advanced disease $(40-44,61,62,82), 4$ (18\%) studies metastatic and advanced GC $(48,49,81,94), 3$ (14\%) studies early GC $(45,65,84), 2$ (9\%) studies metastatic disease $(66,90), 2$ (9\%) studies compared early with advanced disease $(46,93)$, one (5\%) study intestinal GC (47), one (5\%) study MSI GC (85) and one study (5\%) investigated GC with concomitant renal cancer (63).

\section{KRAS mutation detection methods}

A wide variety of methods was used to detect KRAS mutations. Twenty-six (41\%) studies used polymerase chain reaction (PCR) $(37,43,44,49,60,61,66,70,74,75,80,88,98)$ or single-strand conformation polymorphism (SSCP) $(39,45,47,52,64,65,71,72,85,93,95$, $97,99)$ for mutation screening, followed by confirmatory direct Sanger sequencing. Other methods used to detect KRAS mutations included restriction fragment length polymorphism 
(RFLP) $(51,76-78,83,86)$, next-generation sequencing (NGS) $(19,46,48,59,67,81,87$, 96), pyrosequencing $(63,68)$, Q-PCR $(41,94)$, nested and COLD-PCR $(55)$, denaturing gradient gel electrophoresis (DGGE) (89, 91), dot blot hybridization assay $(56-58,69,73,82)$, high-resolution melting analysis (HRMA) $(42,50,53,54)$ and direct Sanger sequencing (62, 79). The largest international multicenter study used a combination of HRMA followed by Sanger sequencing, pyrosequencing, and MassARRAY (38). One study used RFLP and SSCP followed by direct sequencing (92), while other studies used a combination of RFLP and dot blot hybridization (84) or a combination of Q-PCR and Sanger sequencing (40). One study did not report which KRAS mutation detection method was used (90).

\section{Investigated KRAS codons}

Excluding eight studies that performed whole genome sequencing, 49 (88\%) studies published information on investigated codons for mutation testing. The remaining seven (13\%) studies did not provide any information which codons they investigated, however, they later report only mutations in specific codons. All studies investigated multiple codons, with 49 (100\%) investigating codon 12, 45 (92\%) codon 13, 18 (37\%) codon 61, and 1 codon 146. Only a single study investigated all four codons (codons 12, 13, 61 and 146) (62) and one study investigated codon 59, in addition to codons 12, 13 and 61 (93).

\section{Incidence of KRAS mutations}

The overall median incidence of a KRAS mutation in GC was $6.5 \%$ ranging from $0-29 \%$. The median KRAS incidence was similar in studies from the East and the West (East: $6 \%$, ranging from $0-20 \%$; West $7.5 \%$, ranging from $0-29 \%$ ). Likewise, the largest international multicenter study reported an overall incidence of KRAS mutations of $4.2 \%$ which did not differ between Eastern and Western countries (UK: 6\%, Japan 4\%, Singapore 2\%) (38).

Of the 36 studies that reported the location of the mutations in KRAS, 154 mutations were found in codon 12, 66 mutations in codon 13, 6 mutations in codon 61. No mutation has been found so far in codon 146 . The only study to report KRAS mutations in codon 11 , was the result of SSCP and direct sequencing of exon 1. This revealed that 2 of the 7 mutations found in 34 GCS were located in codon 11, all other mutations were in codons 12 and 13 (47). Another study, in addition to identifying one KRAS mutation in codon 12 and two KRAS mutations in codon 13, also found one K5N mutation in exon 2 and five A59T mutations in exon 4 (93). There was only a single report of a single GC having multiple mutations in codon 12 and codon 13 (78).

\section{KRAS mutation status and clinicopathological variables}

Twenty-nine (45\%) studies have investigated the relationship between KRAS mutation status and one or more clinicopathological variables $(19,37,38,40,46,47,50-54,56,60,62-64$, $68,69,71-73,75,76,82,88,91,93,96,98)$. These included grade of tumor differentiation, Lauren classification, tumor location, tumor invasion depth (pT), lymph node status (pN), 
Borrmann classification, age, gender, and infection with H.Pylori or EBV. The most frequent investigated association was between KRAS mutation status and $\mathrm{pT}$, followed by gender and age reported in $33 \%, 30 \%$ and $30 \%$ of studies, respectively.

\section{KRAS mutation and age}

Nineteen (30\%) studies investigated the relationship between patient age and KRAS mutation status mostly suggesting that KRAS mutations are more frequent in elderly GC patients. Seven (37\%) studies reported individual ages or the median age of patients with a KRAS mutation $(19,46,60,62,63,69,96)$, whereas the remaining studies stratified patient age into a range of subcategories $(38,50,52-55,68,72,76)$. Only Hiyama et al reported a significantly higher incidence of KRAS mutations in patients younger than 60 years (72). One study reported an equal number of KRAS mutations in patients $\leq 65$ years old and $>65$ years old (54). All other studies found KRAS mutations more frequently in elderly patients although this association often did not reach statistical significance $(38,50,52,53,55,68,76,98)$.

\section{KRAS mutation and gender}

Nineteen (30\%) studies investigated the relationship between gender and KRAS mutation status in GC. Although no statistically significant relationship between KRAS mutation status and gender was found, most studies seem to suggest that KRAS mutations are more frequent in males. Nine (47\%) studies found a higher incidence in males $(38,46,50,55,62,68,69$, $72,76), 3(16 \%)$ studies reported that KRAS mutations were exclusively found in males (53, $54,63)$ whereas $4(21 \%)$ studies found an equal incidence of KRAS mutations in males and females $(60,75,91,96)$.

\section{KRAS mutation and tumor location}

Twelve (19\%) studies investigated the relationship between KRAS mutation status and GC location within the stomach. Tumors in the upper third of the stomach had a significantly higher incidence of KRAS codon 12 mutations compared to GCs in the middle or lower (3\%) third of the stomach (76). Summarizing and interpreting the results from the other studies is difficult as stomach area categorization varied substantially between studies. We therefore defined that GCs located in the cardia or upper third are 'proximal' and GCs located in all other regions are 'distal'. These studies found a higher incidence of KRAS mutations in distal GC $(19,37,38,60,63,64,68,72,75,91)$.

\section{KRAS mutation and Borrmann classification}

A single study investigated the relationship between KRAS mutation status and macroscopic classification according to Borrmann. This study investigated KRAS codons 12 and 13 in 108 GC patients with advanced disease and found a significant relationship between KRAS mutation status and Borrmann Type 1 (polypoid) GC (82). The incidence of KRAS mutation 
was 6/14 (43\%), 8/29 (28\%), 2/11 (18\%), and 4/54 (7\%) in Borrmann type 1 to 4 GCs, respectively. Interestingly all KRAS mutations in polypoid GCs were located in codon 12 . This is in contrast to a study investigating 48 GC which did not find any relationship between macroscopic appearance (classified according to the Japanese Research Society for Gastric Cancer) and KRAS mutation status (72).

\section{KRAS mutation and primary tumor invasion depth ( $p T$ category)}

Twenty-one (33\%) studies investigated the relationship between KRAS mutation status and $\mathrm{pT}$ in GC. Unfortunately, different staging systems were used in different publications and some studies compared groups of pT categories against each other making the results interpretation difficult. None of the studies reported a significant association between $\mathrm{PT}$ category/stage and KRAS mutation status. Overall, there was a higher incidence of KRAS mutations in higher pT (pT 2-4) GC compared to lower pT (pT1) GC (19, 37, 38, 47, 50, 53, $54,60,63,68,75,76,82,88,91,93,96)$.

\section{KRAS mutation and lymph node status ( $p N$ category)}

Eleven (17\%) studies investigated the relationship between KRAS mutation status and presence of lymph node metastases with conflicting results. Five (45\%) studies found that KRAS mutant GCs tended to have either no lymph node metastases $(46,50,53,54)$ or significantly fewer lymph node metastases (38). Whereas other studies report that KRAS mutations are more frequent in GCs with lymph node metastases $(19,63,68,91,96)$.

\section{KRAS mutation and histological subtype according to Lauren classification}

Seventeen (27\%) studies including a total of 2583 patients investigated the association between KRAS mutation status and histological subtype according to the Lauren classification $(19,37,38,40,46,47,56,60,62,63,68,72,75,76,88,91,93)$. Although 11 (65\%) of studies reported a higher incidence of KRAS mutations in intestinal-type GC (see figure 2), this association did not reach statistical significance in any of the studies $(19,37,38,40,56$, $60,62,68,72,75,91)$.

\section{KRAS mutation and grade of tumor differentiation}

Fifteen (23\%) studies investigated the relationship between KRAS mutation and grade of tumor differentiation reporting discordant results. One (7\%) study investigating advanced disease found that KRAS mutations were significantly more frequent in histologically differentiated GC (82), three (20\%) studies found a higher incidence of KRAS mutations in well-differentiated GCs $(47,69,72)$ whereas nine (60\%) studies reported a higher incidence of KRAS mutations in poorly-differentiated GCs $(38,46,50,53,54,63,73,75,76)$. Two studies (13\%) found the same incidence of KRAS mutations in well- and poorly- differentiated GC $(40,96)$. 


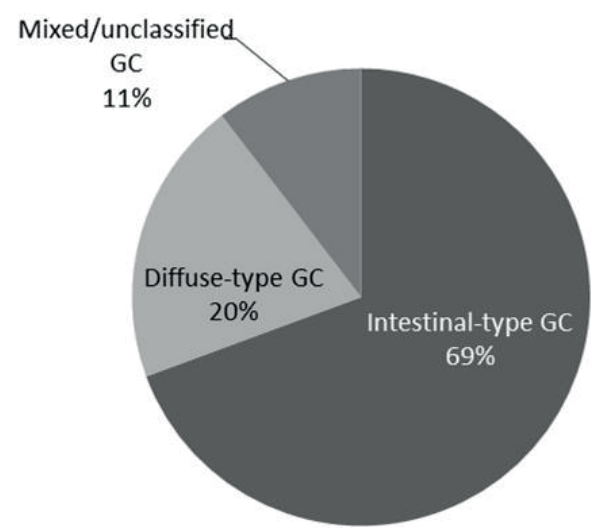

Figure 2 | Distribution of KRAS mutation incidence in gastric cancer (GC) by Lauren classification.

\section{KRAS mutation and survival}

Seven $(11 \%)$ studies investigated the relationship between KRAS mutation status and survival $(38,41,62,66,68,76,79)$, The largest international multicenter study reported a trend towards better survival in patients with a KRAS mutant GC (38) . In contrast, subgroup analysis in a different study showed that the median survival of patients with KRAS mutant proximal GCs was significantly shorter (3.5 \pm 3.1 months) compared with KRAS wild-type GCs (12.7 \pm 0.7 months, $p=0.021$ (68). The same study found that KRAS mutant intestinaltype GCs had a worse prognosis compared to KRAS wild-type intestinal-type GC, however this difference was not significant on univariate analysis $(p=0.098)$. Similarly, patients with a KRAS mutant GC in the upper third of the stomach may have improved survival over patients with KRAS mutant GC in the middle or distal stomach (76).

\section{KRAS mutation and chemotherapeutic agents}

Ten $(16 \%)$ studies investigated the relationship between KRAS mutations and the use of chemotherapeutic agents (see table $2 \mathrm{~b}$ ). Four studies (40\%) did not find any association between KRAS mutation status and progression free survival or overall survival $(40,41,62$, $66)$, three $(30 \%)$ studies did not detect any KRAS mutations $(42,44,94)$ and two $(20 \%)$ studies did not find an association between KRAS mutations and response to chemotherapy $(43,90)$.

\section{KRAS mutation and H.pylori infection}

Six (9\%) studies have investigated the relationship between $H$. pylori infection and KRAS mutation status. Three studies reported a higher incidence of KRAS mutations in H.py/ori infected GCs, but the difference was not significant or statistical analysis was not performed $(47,82,97)$. In contrast, thirteen (87\%) KRAS mutant GCs were found to be H.pylori negative, compared to two H.pylori KRAS mutant GCS (68). One study reported an equal 
incidence of KRAS mutations in H.pylori positive and negative GCs (75). The study by Hiyama et al found that KRAS mutations in $\mathrm{H}$. pylori-chronic gastritis were significantly more frequent in patients with $\mathrm{GC}$ than those without and in patients with KRAS mutated GC than in KRAS wild-type GC (72).

\section{KRAS mutation and EBV infection}

Four (6\%) studies investigating a total of 848 GC for KRAS mutation status and EBV infection found no relationship between EBV and KRAS mutation (19, 63, 68, 97).

\section{KRAS mutation status and molecular variables}

\section{KRAS mutation and DNA mismatch repair deficiency/microsatellite instability (MMR/MSI)}

Thirteen (20\%) studies investigated the relationship between KRAS mutation status and MMR/MSI with controversial results. One study which included only MSI GC reported that $18 \%$ harbored a KRAS mutation (98). Eight (62\%) studies reported a higher incidence of MSI in KRAS mutant GCs $(39,63,67,70,74)$, which was significant in three studies $(19,75$, 91). This finding was supported by one study which found that KRAS mutations were more frequent in MMR-deficient GC (38). In contrast, two studies reported that KRAS mutant GC were more frequently microsatellite stable $(\mathrm{MSS})(46,68)$.

\section{KRAS mutation and DNA ploidy}

Three (5\%) studies investigated the relationship between DNA ploidy and KRAS mutation status. Two investigated DNA ploidy by DNA flow cytometry. One study investigated KRAS mutations in codons 12 and 13 (71), whereas the other study focused on codon 12 (76). Another study investigated DNA ploidy by NGS (19). No associations were reported in any study.

\section{KRAS amplification}

Eight (13\%) studies investigated KRAS amplification in addition to KRAS mutations with contradictory results. Three studies found that the incidence of KRAS amplification varied between $5 \%$ and $9 \%$ but was higher than that of KRAS mutation in GC (between $0 \%$ and $4 \%)(59,68,80)$. In contrast, four studies found that KRAS mutations are more frequent than KRAS amplifications in GC $(48,67,87)$. One study, reported similar frequencies of KRAS amplification (6\%) and KRAS mutation (6\%) (79). Interestingly, the 5-year survival of patients with a KRAS amplification was worse than that of the patients KRAS mutant GC (HR 3.0, 95\% Cl: 1.3-7.0). Furthermore, KRAS amplification and KRAS mutation were exclusive. Deng et al reported that patients with GC with a KRAS amplification had a significantly poorer prognosis, however, as only one KRAS mutation was detected, the relationship between KRAS mutation and prognosis could not be analyzed (59). 


\section{BRAF}

$B R A F$ is a member of the RAF family of protein kinases which has three members: ARAF, $B R A F$ and CRAF (100). All RAF proteins share a common structure (101), but BRAF is the only one known to be activated by mutation in human cancer, and therefore the focus of this review (102).

BRAF is also known as v-raf murine sarcoma viral homolog B1 (100) and was discovered in 1988 by lkawa et al (103). BRAF is a proto-oncogene and is located on chromosome 7 (7q34) (www.genecards.org, accessed $\underline{8}^{\text {th }}$ May 2015). BRAF exists in multiple spliced forms, which seem to exhibit tissue specific expression patterns (104).

The BRAF protein is 75 to $100 \mathrm{kDa}$ and has three conserved regions (CR): CR1, CR2 and CR3 (100). CR1 and CR2 are located at the N-terminus and are both regulatory domains, whereas CR3 is a kinase domain and is located at the C-terminus. CR1 is composed of the RAS-binding domain and a cysteine-rich domain binding RAS and membrane phospholipids. CR2 is a serine/threonine rich domain which when phosphorylated can bind regulatory proteins. CR3 is the protein kinase domain which is regulated through phosphorylation (101).

After RAS is activated via extracellular stimuli, it activates BRAF by phosphorylation of two residues in the kinase domain. Activated BRAF phosphorylates and activates MEK1 and MEK2 which then activate MAP kinases ERK1 and ERK2. ERK1/2 activates numerous cytoplasmic and nuclear targets including transcription factors (100).

More than 65 different mutations have been identified in BRAF in human cancer. Most of these mutations are in exon 11 or exon 15 in the catalytic kinase domain (100). The most frequently detected BRAF mutation is a single amino acid substitution (V600E) in exon 15 (105). BRAF is most commonly mutated in melanomas $(67 \%)$ and CRC $(10 \%)(105,106)$. Mutant BRAF displays an elevated kinase activity (105) and becomes insensitive to negative feedback mechanisms (107). For a review on BRAF mutations in benign and malignant human tumors, see Michaloglou et al (108).

\section{BRAF in gastric cancer}

In total, 22 studies have investigated the incidence of BRAF mutations in GC. Seven (32\%) studies screened for BRAF mutations by PCR, followed by direct sequencing $(43,61,62,68$, $70,75,98,109)$. Other detection methods included denaturing high pressure liquid chromatography, $\operatorname{SSCP}(39,40,52,93,110), \operatorname{HRMA}(42), \operatorname{NGS}(46,48,81)$, amplification-refractory mutation system-PCR, PCR-high resolution melting (50), real-time PCR, immunohistochemistry using a mutation-specific probe (111) or a combination of the above $(38,88,112)$.

Fourteen (64\%) studies used FFPE samples (38, 39, 42, 43, 48, 50, 52, 61, 68, 81, 88, 93, $109,111)$, five $(23 \%)$ used frozen tissue samples $(46,70,75,98,110)$ and one study used a combination of FFPE and frozen samples (62). Two studies did not report this information $(40,112)$. Excluding the study that performed IHC, ten studies selected areas of tumor with a median tumor cell density of $>55 \%$, ranging from $>20 \%$ to $>80 \%(38,46,48,50,68,70$, 
$81,98,109,110)$. Six studies performed microdissection of the selected area $(39,40,52,62$, $75,93)$. The remaining five studies did not provide this information $(42,43,61,88,112)$.

All studies investigated the BRAF exon 15 'mutation hotspot' (V600E mutation). Some studies extended their mutation search to exon 11 and other regions of exon 15, or whole genome sequencing. The median BRAF mutation incidence in $\mathrm{GC}$ is $0 \%$, ranging from $0 \%$ to $12 \%(38,39,42,43,46,48,50,52,61,62,68,70,75,81,88,93,98,109-112)$. Only six of the BRAF mutations identified were in V600E of exon $15(38,40,70,110,112)$. Six mutations were found in codon 396 and four mutations in codon 608 of exon 15 identified by Sasao et al (52). Lee et al found two mutations in codon 593 and the remaining five mutations were in codon 599 (V599 M) (93) and Okines et al identified a mutation in V600M and G596D of exon 15 (40).

The highest BRAF mutation incidence (12\%) was reported in a Korean study of 17 early and advanced GC using whole-genome sequencing by NGS. The two mutations identified were missense mutations; one was detected in a mixed-type early cancer, the other one in an intestinal-type advanced cancer (46). There has been a single publication that used immunohistochemistry and a mutation specific antibody to detect the mutated BRAF protein as a surrogate for a $B R A F$ mutation. All cases were negative (no evidence suggesting a BRAF mutation) (111).

Due to the low incidence of $B R A F$ mutations no studies have reported a relationship between $B R A F$ mutation status and DNA ploidy or clinicopathological variables. There are three studies that have investigated the relationship between microsatellite instability and BRAF mutation. BRAF mutations were not found in any of $37 \mathrm{MSI}$ GC (110) which was confirmed in a study by Wu et al where the BRAF mutant GC was MSS (70). However, in another study the two BRAF mutant GC were found to be MSI (46).

\section{EGFR pathway in gastric cancer}

The EGFR pathway is known to be activated in GC (113). When EGFR is bound to its ligand, it triggers homodimerisation and heterodimerisation of the EGFR receptor. This activates a signaling cascade, including MAPK, through effector molecules RAS and RAF (113). AntiEGFR monoclonal antibodies block ligand-induced binding EGFR tyrosine kinase activation by binding to the extracellular domain of EGFR (114).

\section{DISCUSSION}

\section{KRAS and BRAF mutations in GC}

Current literature investigating KRAS and BRAF mutations in $\mathrm{GC}$ is very heterogeneous in terms of sample size, patient ethnicity, patient treatment, mutation detection methods, tumor stage and grade of differentiation, as well as other clinicopathological variables. 
The majority of studies (70\%) investigated the KRAS mutation status in less than 100 patients. Such small studies may not be representative of the GC patient population and thus the patient selection bias may significantly influence any results. Thus, two of the smallest studies with five and seven patients reported some of the highest incidence of KRAS mutations, of $20 \%$ and $29 \%$, respectively $(41,95)$. Similarly, for $B R A F$, the smallest study of 17 patients reported the highest BRAF mutation incidence of $12 \%$ (46). Furthermore, twenty-two (34\%) studies investigating KRAS mutations deliberately selected subgroups of GC patients to study the KRAS/BRAF mutation status, such as advanced and/or metastatic disease and early disease.

Despite the much higher incidence in the East, the number of studies investigating the relationship between KRAS and BRAF in GC from the East and the West is almost equal. Nevertheless, potential bias due to differences in the histological subtypes (diffuse-type GC is more prevalent in the East), disease stage (GC is diagnosed at an earlier stage in the East) and patient survival (better overall survival in the East) (115) needs to be considered when comparing study results, particularly in the twenty studies that performed KRAS mutation testing on series from a single center. However, the incidence of KRAS mutations between East and West were comparable and do not seem to be related to the differences in GC incidence between the East and the West (38). Thus, bias due to the patient's country of origin appears to have no or minimal influence on the incidence of KRAS/BRAF mutations in GC.

An issue that was not addressed in any of the studies included in this review was the potential influence of tumor heterogeneity on the results. Tumor heterogeneity of KRAS and $B R A F$ mutations has been described in CRC suggesting that more than one tumor block should be investigated if possible (116). None of the studies investigating KRAS and/or BRAF mutations in GC seem to have investigated multiple blocks. Studies either did not provide any information or investigated single blocks. Thus, it is impossible to assess whether the incidence of KRAS and/or BRAF mutations in GC is underestimated based on the current literature.

Over 10 different methods were used to detect KRAS and/or BRAF mutations in GC. It is known that the sensitivity (ratio of mutant to wild-type) of different methodologies varies between techniques (117), with COLD-PCR having the highest sensitivity (1\%) and direct Sanger sequencing having the lowest (10-30\%). Despite this low sensitivity, Sanger sequencing is considered the 'gold standard' technique due to its ability to detect substitutions, insertion and deletions. The median KRAS mutation incidence in GC appears to be similar irrespective of the detection method and thus, the detection methodology does not appear to effect the incidence of mutations detected in GC.

Several of the studies investigating the use of chemotherapeutic agents in the treatment of GC that also performed KRAS mutation testing, did not provide sufficient information on the type of tissue used for KRAS testing (biopsy/primary resection/recurrent resection/pre- or post-treatment), detection methods used, or codons investigated. Thus it is not possible to 
accurately interpret the results and make comparisons between such studies. Future studies need to report detailed methodologies in order for conclusions to be drawn from the results.

A recent study suggested that KRAS amplifications contribute to the activation of KRAS in GC (80) and that activation by KRAS amplification may account for the low incidence of KRAS mutations in GC compared to other types of cancer (59). However, the results from studies comparing the incidence and relationship of KRAS mutations (0-10\%) and KRAS amplifications (1-9\%) in GC remain contradictory (48, 59, 67, 68, 79, 80, 87). However, three studies seem to indicate that KRAS amplifications and mutations are mutually exclusive $(48,79,80)$ suggesting a need to screen GC patients for both KRAS mutations and amplifications.

\section{Incidence of KRAS and BRAF mutations - comparison between gastric cancer, small bowel and colorectal cancer}

According to the RASCAL collaborative, the incidence of KRAS mutation in CRC is $38 \%$ (118), and a similar incidence has been reported in other studies. Thus, the incidence of KRAS mutations in GC is much lower than in CRC. The incidence of KRAS mutations in small bowel adenocarcinomas seems to vary dramatically from $9-43 \%(51,119-121)$. Based on data from four studies investigating each less than 100 patients and therefore partly comparable to that of GCs and partly similar to CRCs.

In contrast to GC, in CRC many studies have reported a significant association between $B R A F$ mutation and either deficient mismatch repair status or microsatellite instability (106, $110,122-126)$. This could be related to the fact that $B R A F$ mutations are much more frequent in CRC (5-22\% (127)) than in GC (0-12\%). In adenocarcinomas of the small bowel, the incidence of BRAF mutations is comparable to those reported in GC (119-121). Whereas in CRC KRAS and BRAF mutations appear to be mutually exclusive (128), there are two reports indicating that GC can harbor a KRAS and BRAF mutations simultaneously $(48,93)$. In summary, KRAS mutations in GC are a rare event compared to other cancers of the gastrointestinal (GI) tract. Such differences in the incidence of these mutations between cancers of the Gl tract may reflect differences in carcinogenesis.

Although no significant relationship between gender and incidence of KRAS mutations has been reported in GC, KRAS mutations are more frequently reported in males. In addition, the incidence of KRAS mutations is higher in intestinal-type than diffuse-type GC. Both observations may be explained by the fact that the incidence of GC in men is twice as high as in women (2) and that intestinal-type GC is found more frequently in males (129). In CRC, the worldwide incidence is also higher in males but the relative difference is not as prominent as in GC (746,000 new CRC cases per year in males versus 614,000 in females (2)). The relationship between KRAS mutations in CRC and gender is not consistent. One study found a higher incidence of KRAS mutations in females(130), whereas the QUASAR study did not find a difference (122) . 
Twelve studies investigated the relationship between KRAS mutations and MMR/MSI in GC mostly suggesting a higher incidence of MSI in KRAS mutant GC compared to KRAS wild-type GC. This is in contrast to CRC, where KRAS mutant tumors are found to be less frequent MMR-deficient (118).

In CRC, patients with KRAS wild-type cancer seem to have a better survival (131). Few studies (9\%) investigating the relationship between KRAS mutation status and survival in GC and the results do not concur with those from CRC.

\section{$K R A S$ and $B R A F$ mutations and response to anti-EGFR therapy}

In CRC, KRAS mutation and BRAF mutation are known predictors of poor response to EGFR targeted agents, such as cetuximab and panitumumab (132) and RAS/BRAF mutation screening is now part of routine clinical diagnosis. In contrast, the predictive value of KRAS and $B R A F$ mutations in GC is far less clear. In vitro, several studies in KRAS wild-type GC cell lines reported sensitivity to EGFR targeting drugs (133-135). Other investigators report that, both KRAS mutant and wild-type GC cell lines were resistant to cetuximab (136). In GC xenografts, apoptosis was only induced in KRAS wild-type tumor cells treated with Cetuximab (136). Cetuximab was shown to reduce tumor volume, dissemination and vascularisation in EGFR-expressing, KRAS wild-type xenografts (133).

To date, the use of anti-EGFR agents (Cetuximab and Panitumumab) in phase III metastatic GC trials in patients has either showed no difference (137) or poorer survival than the control group (138). In the REAL3 trial, KRAS mutation status did not predict resistance to Panitumumab in GC (40).

Due to the low incidence of BRAF mutations in GC, a clinical trial which stratifies GC patients according to their BRAF status is probably not feasible due to the high number of patients that would need to be screened. Although all studies investigated the V600E mutation, three of the studies that also investigated exon 11 and 15 found BRAF mutations other than the hotspot V600E mutation $(40,52,93)$. Thus, there could be an argument for investigating the whole length of the BRAF gene for mutations in GC.

\section{CONCLUSIONS}

In conclusion, despite the decrease in the incidence, GC remains a major worldwide health problem. KRAS was one of the first oncogenes discovered in GC in 1986. Nevertheless, the current literature on KRAS and BRAF in GC is still limited and very heterogeneous making any comparisons between different studies difficult. However, it appears that the incidence of KRAS mutations in GC is much lower than in CRC, does not differ significantly by ethnicity and that BRAF V600E mutations are very rare in GC. Due to the low incidence and often small studies, many of the published studies did not have enough power to detect a poten- 
tial relationship between KRAS mutation status and clinicopathological variables including patient survival. Even fewer studies have assessed KRAS amplifications as a mechanism for KRAS activation. So far all clinical studies in unselected metastatic GC have failed to show a significant benefit for EGFR inhibitors. A recent meeting abstract reported the incidence of KRAS mutations in signet ring cell GC is higher (15\%) than in other types of GC (139). As the incidence of this histological subtype of GC is increasing, particularly in the West (10) and as this subgroup of GC appears to be highly resistant to standard chemotherapy (140). EGFR targeted therapy in signet ring gastric cancer could potentially be a promising treatment option in the future. 


\section{REFERENCES}

1. Kamangar $F$, et al. Patterns of cancer incidence, mortality, and prevalence across five continents: defining priorities to reduce cancer disparities in different geographic regions of the world. J Clin Oncol. 2006;24(14):2137-50.

2. Torre LA, et al. Global cancer statistics, 2012. CA Cancer J Clin. 2015;65(2):87108.

3. Chun N, et al. Genetic testing by cancer site: stomach. Cancer J. 2012;18(4):35563.

4. Plummer M, et al. Global burden of gastric cancer attributable to Helicobacter pylori. Int J Cancer. 2015;136(2):487-90.

5. Bang YJ, et al. Trastuzumab in combination with chemotherapy versus chemotherapy alone for treatment of HER2-positive advanced gastric or gastro-oesophageal junction cancer (ToGA): a phase 3, openlabel, randomised controlled trial. Lancet. 2010;376(9742):687-97.

6. Cunningham D, et al. Perioperative chemotherapy versus surgery alone for resectable gastroesophageal cancer. N Engl J Med. 2006;355(1):11-20.

7. $\mathrm{Hu}$ B, et al. Gastric cancer: Classification, histology and application of molecular pathology. J Gastrointest Oncol.. 2012;3(3):251-61.

8. Lauren P. The two histological main types of gastric carcinoma: diffuse and so called intestinal-type carcinoma. Acta Pathol Microbiol Scand. 1965;64:31-49.

9. Kong $X_{\text {, }}$ et al. Comparison of the clinicopathological characteristics of young and elderly patients with gastric carcinoma: a meta analysis. J Surg Oncol. 2012;106(3):346-52.

10. $\mathrm{Wu} \mathrm{H}$, et al. Stomach carcinoma incidence patterns in the United States by histologic type and anatomic site. Cancer Epidemiol Biomarkers Prev. 2009;18(7):1945-52.
11. Qiu MZ, et al. Clinicopathological characteristics and prognostic analysis of Lauren classification in gastric adenocarcinoma in China. J Transl Med. 2013;11:58.

12. Kwon SJ. Evaluation of the 7th UICC TNM Staging System of Gastric Cancer. J Gastric Cancer. 2011;11(2):78-85.

13. Washington $K$. 7th edition of the AJCC cancer staging manual: stomach. Ann Surg Oncol. 2010;17(12):3077-9.

14. Japanese Gastric Cancer Association. Japanese classification of gastric carcinoma: 3rd English edition. Gastric Cancer. 2011;14(2):101-12

15. Shi J, et al. Pathogenetic mechanisms in gastric cancer. World J Gastroenterol. 2014;20(38):13804-19.

16. Velho $\mathrm{S}$, et al. Causes and consequences of microsatellite instability in gastric carcinogenesis. World J Gastroenterol. 2014;20(44):16433-42.

17. Oki $\mathrm{E}$, et al. Clinical aspect and molecular mechanism of DNA aneuploidy in gastric cancers. J Gastroenterol. 2012;47(4):3518.

18. Gulley ML. Genomic assays for EpsteinBarr virus-positive gastric adenocarcinoma. Exp Mol Med. 2015;47:e134.

19. Cancer Genome Atlas Research Network. Comprehensive molecular characterization of gastric adenocarcinoma. Nature. 2014;513(7517):202-9.

20. Tan P, et al. Genetics and Molecular Pathogenesis of Gastric Adenocarcinoma. Gastroenterol. 2015149(5):1153-1162.e3.

21. Chang $\mathrm{EH}$, et al. Human genome contains four genes homologous to transforming genes of Harvey and Kirsten murine sarcoma viruses. P Natl Acad Sci USA. 1982;79(16):4848-52.

22. Shimizu K, et al. Isolation and preliminary characterization of the transforming gene of a human neuroblastoma cell line. P Natl Acad Sci USA. 1983;80(2):383-7. 
23. Lowy $D R$, et al. Function and regulation of ras. Annu Rev Biochem. 1993;62:851-91.

24. Pylayeva-Gupta $Y$, et al. RAS oncogenes: weaving a tumorigenic web. Nat Rev Cancer. 2011;11(11):761-74.

25. Bos JL. ras oncogenes in human cancer: A review. Cancer Res. 1989;49(17):4682-9.

26. Charette $\mathrm{N}$, et al. Ras in digestive oncology: from molecular biology to clinical implications. Curr Opin Oncol. 2014;26(4):45461.

27. Barbacid M. ras genes. Annu Rev Biochem. 1987;56:779-827.

28. Jancik $S$, et al. Clinical relevance of KRAS in human cancers. J Biomed Biotechnol. 2010;2010:150960.

29. Malumbres $\mathbf{M}$, et al. RAS oncogenes: the first 30 years. Nat Rev Cancer. 2003;3(6):459-65.

30. Malumbres $M$, et al. RAS pathways to cell cycle control and cell transformation. Front Biosci. 1998;3:d887-912.

31. Moodie SA, et al. Complexes of Ras.GTP with Raf-1 and mitogenactivated protein kinase kinase. Science. 1993;260(5114):1658-61.

32. Rodriguez-Viciana $P$, et al. Phosphatidylinositol-3-OH kinase as a direct target of Ras. Nature. 1994;370(6490):527-32.

33. Chetty R, et al. Gene of the month: KRAS. J Clin Pathol. 2013;66(7):548-50.

34. Prior IA, et al. A Comprehensive Survey of Ras Mutations in Cancer. Cancer Res. 2012;72(10):2457-67.

35. Serrano $M$, et al. Oncogenic ras provokes premature cell senescence associated with accumulation of p53 and p16INK4a. Cell. 1997;88(5):593-602.

36. Bos $J$, et al. A human gastric carcinoma contains a single mutated and an amplified normal allele of the Ki-ras oncogene. Nucleic Acids Res. 1986;14(3):1209-17.

37. Yoo J, et al. ras gene mutations and expression of ras signal transduction mediators in gastric adenocarcinomas. Arch Pathol Lab Med. 2002;126(9):1096-100.
38. van Grieken NC, et al. KRAS and BRAF mutations are rare and related to DNA mismatch repair deficiency in gastric cancer from the East and the West: results from a large international multicentre study. $\mathrm{Br}$ J Cancer. 2013;108(7):1495-501.

39. Gylling $A$, et al. Is gastric cancer part of the tumour spectrum of hereditary nonpolyposis colorectal cancer? A molecular genetic study. Gut. 2007;56(7):926-33.

40. Okines $A F$, et al. Biomarker analysis in oesophagogastric cancer: Results from the REAL3 and TransMAGIC trials. Eur J Cancer. 2013;49(9):2116-25.

41. Rohrberg KS, et al. Biomarkers in tissue from patients with upper gastrointestinal cancers treated with erlotinib and bevacizumab. Cancer Biol Ther. 2011;11(8):7329.

42. Moehler $M$, et al. An open-label, multicentre biomarker-oriented AIO phase ॥ trial of sunitinib for patients with chemorefractory advanced gastric cancer. Eur J Cancer. 2011;47(10):1511-20.

43. Pinto $C$, et al. Phase II study of cetuximab in combination with cisplatin and docetaxel in patients with untreated advanced gastric or gastro-oesophageal junction adenocarcinoma (DOCETUX study). Br J Cancer. 2009;101(8):1261-8.

44. Han SW, et al. Phase II study and biomarker analysis of cetuximab combined with modified FOLFOX6 in advanced gastric cancer. Br J Cancer. 2009;100(2):298-304.

45. Sakurai S, et al. Gastric adenoma-carcinoma sequence with special reference to p53 and Ki-ras gene alterations. Virchows Arch. 1995;427(2):119-24.

46. Kim TM, et al. The mutational burdens and evolutionary ages of early gastric cancers are comparable to those of advanced gastric cancers. J Pathol. 2014;234(3):365-74.

47. Hongyo $\mathrm{T}$, et al. Mutations of the K-ras and p53 genes in gastric adenocarcinomas from a high-incidence region around Flor- 
ence, Italy. Cancer Res. 1995;55(12):266572.

48. Ali SM, et al. Prospective comprehensive genomic profiling of advanced gastric carcinoma cases reveals frequent clinically relevant genomic alterations and new routes for targeted therapies. Oncologist. 2015;20(5):499-507.

49. Lordick F, et al. Cetuximab plus oxaliplatin/ leucovorin/5-fluorouracil in first-line metastatic gastric cancer: a phase II study of the Arbeitsgemeinschaft Internistische Onkologie (AIO). Br J Cancer. 2010;102(3):5005.

50. Lu W, et al. Identification of KRAS and PIK3CA but not BRAF mutations in patients with gastric cancer. Mol Med Rep. 2015;12(1):1219-24.

51. Arber N, et al. Activation of C-K-ras mutations in human gastrointestinal tumors. Gastroenterol. 2000;118(6):1045-50.

52. Sasao $S$, et al. Clinicopathologic and genetic characteristics of gastric cancer in young male and female patients. Oncol Rep. 2006;16(1):11-5.

53. Liu ZM, et al. Mutation detection of KRAS by high-resolution melting analysis in Chinese with gastric cancer. Oncol Rep. 2009;22(3):515-20.

54. Liu Z, et al. Epidermal growth factor receptor mutation in gastric cancer. Pathology. 2011;43(3):234-8.

55. Peng $\mathrm{N}$, et al. Comparison of mutations in lung, colorectal and gastric cancer. Oncol Lett. 2014;8(2):561-5.

56. Miki $\mathrm{H}$, et al. K-ras activation in gastric epithelial tumors in Japanese. Cancer Lett. 1991;58(1-2):107-13.

57. Nagata $Y$, et al. Glycine to aspartic acid mutations at codon 13 of the c-Ki-ras gene in human gastrointestinal cancers. Cancer Res. 1990;50(3):480-2.

58. Victor $T$, et al. No evidence for point mutations in codons 12, 13, and 61 of the ras gene in a high-incidence area for esophageal and gastric cancers. Cancer Res. 1990;50(16):4911-4.

59. Deng $\mathrm{N}$, et al. A comprehensive survey of genomic alterations in gastric cancer reveals systematic patterns of molecular exclusivity and co-occurrence among distinct therapeutic targets. Gut. 2012;61(5):67384.

60. Palacio-Rua KA, et al. Genetic analysis in APC, KRAS, and TP53 in patients with stomach and colon cancer. Rev Gastroenterol Mex. 2014;79(2):79-89.

61. Matsubara A, et al. Frequent GNAS and KRAS mutations in pyloric gland adenoma of the stomach and duodenum. J Pathol. 2013;229(4):579-87.

62. Takahashi $\mathrm{N}$, et al. Clinicopathological features and prognostic roles of KRAS, BRAF, PIK3CA and NRAS mutations in advanced gastric cancer. BMC Res Notes. 2014;7:271.

63. Betge J, et al. Gastric cancer and concomitant renal cancer: a systematic immunohistochemical and molecular analysis. Oncol Rep. 2011;26(3):567-75.

64. Tajima $Y$, et al. Differences in the histological findings, phenotypic marker expressions and genetic alterations between adenocarcinoma of the gastric cardia and distal stomach. $\mathrm{Br} J$ Cancer. 2007;96(4):631-8.

65. Tajima $Y$, et al. Gastric and intestinal phenotypic marker expression in early differentiated-type tumors of the stomach: clinicopathologic significance and genetic background. Clin Cancer Res. 2006;12(21):6469-79.

66. Park $S R$, et al. Predictive factors for the efficacy of cetuximab plus chemotherapy as salvage therapy in metastatic gastric cancer patients. Cancer Chemother Pharmacol. 2010;65(3):579-87.

67. Cristescu R, et al. Molecular analysis of gastric cancer identifies subtypes associated with distinct clinical outcomes. Nat Med. 2015;21(5):449-56. 
68. Warneke VS, et al. Prognostic and putative predictive biomarkers of gastric cancer for personalized medicine. Diagn Mol Pathol. 2013;22(3):127-37.

69. Kihana $\mathrm{T}$, et al. Point mutation of c-Ki-ras oncogene in gastric adenoma and adenocarcinoma with tubular differentiation. Jpn J Cancer Res. 1991;82(3):308-14.

70. Wu $M$, et al. BRAF/K-ras mutation, microsatellite instability, and promoter hypermethylation of hMLH1/MGMT in human gastric carcinomas. Gastric Cancer. 2004;7(4):246-53.

71. Russo A, et al. DNA aneuploidy and high proliferative activity but not K-ras-2 mutations as independent predictors of clinical outcome in operable gastric carcinoma. Cancer. 2001;92:294-302.

72. Hiyama T, et al. K-ras mutation in helicobacter pylori-associated chronic gastritis in patients with and without gastric cancer. Int J Cancer. 2002;97(5):562-6.

73. Koshiba $\mathrm{M}$, et al. Infrequent ras mutation in human stomach cancers. Jpn J Cancer Res. 1993;84(2):163-7.

74. Lee $\mathrm{JH}$, et al. Inverse relationship between APC gene mutation in gastric adenomas and development of adenocarcinoma. Am J Pathol. 2002;161(2):611-8.

75. Zhao $W$, et al. Mutations of BRAF and KRAS in gastric cancer and their association with microsatellite instability. Int J Cancer. 2004;108(1):167-9.

76. Lee $\mathrm{KH}$, et al. Clinicopathologic significance of the $\mathrm{K}$-ras gene codon 12 point mutation in stomach cancer. An analysis of 140 cases. Cancer. 1995;75(12):2794801.

77. Saxena A, et al. Analysis of p53, K-ras gene mutation \& Helicobacter pylori infection in patients with gastric cancer \& peptic ulcer disease at a tertiary care hospital in north India. Indian J Med Res. 2012;136(4):66470.

78. Kimura $K$, et al. No duplicate KRAS mutation is identified on the same allele in gastric or colorectal cancer cells with multiple KRAS mutations. J Int Med Res. 2007;35(4):450-7.

79. Qian Z, et al. Whole genome gene copy number profiling of gastric cancer identifies PAK1 and KRAS gene amplification as therapy targets. Genes, Chromosomes \& Cancer. 2014;53(11):883-94.

80. Mita $\mathrm{H}$, et al. A novel method, digital genome scanning detects KRAS gene amplification in gastric cancers: involvement of overexpressed wild-type KRAS in downstream signaling and cancer cell growth. BMC Cancer. 2009;9:198.

81. Kim S, et al. High-throughput sequencing and copy number variation detection using formalin fixed embedded tissue in metastatic gastric cancer. PLoS One. 2014;9(11):e111693.

82. Yashiro $\mathrm{M}$, et al. K-ras mutation influences macroscopic features of gastric carcinoma. J Surg Res. 2005;124(1):74-8.

83. Capella $G$, et al. Frequency and spectrum of mutations at codons 12 and 13 of the c-K-ras gene in human tumors. Environ Health Perspect. 1991;93:125-31.

84. Craanen ME, et al. Absence of ras gene mutations in early gastric carcinomas. Gut. 1995;37(6):758-62.

85. Oliveira $C$, et al. Concomitant RASSF1A hypermethylation and KRAS/BRAF mutations occur preferentially in MSI sporadic colorectal cancer. Oncogene. 2005;24(51):7630-4.

86. Hosoi H, et al. Using Biopsy Materials to Detect Mutations in Gastrointestinal Tumors. J Clin Gastroenterol. 1995;20(4):272-6.

87. Yoda $Y$, et al. Integrated analysis of cancerrelated pathways affected by genetic and epigenetic alterations in gastric cancer. Gastric Cancer. 2015;18(1):65-76.

88. Kim I-J, et al. Mutational analysis of BRAF and $\mathrm{K}$-ras in gastric cancers: absence of BRAF mutations in gastric cancers. Hum Genet. 2003;114(1):118-20. 
89. Ranzani GN, et al. Loss of heterozygosity and $\mathrm{K}$-ras gene mutations in gastric cancer. Hum Genet. 1993;92(3):244-9.

90. Richards $D$, et al. Results of docetaxel plus oxaliplatin (DOCOX) +/- cetuximab in patients with metastatic gastric and/ or gastroesophageal junction adenocarcinoma: results of a randomised Phase 2 study. Eur J Cancer. 2013;49(13):2823-31.

91. Brennetot $C$, et al. Frequent ki-ras mutations in gastric tumors of the MSI phenotype. Gastroenterol. 2003;125(4):1282-3.

92. Hao $Y$, et al. The role of ras gene mutation in gastric cancer and precancerous lesions. J Tongji Med Univ. 1998;18(3):141-4.

93. Lee $\mathrm{SH}$, et al. BRAF and KRAS mutations in stomach cancer. Oncogene. 2003;22(44):6942-5.

94. Woll $E$, et al. Oxaliplatin, irinotecan and cetuximab in advanced gastric cancer. A multicenter phase II trial (Gastric-2) of the Arbeitsgemeinschaft Medikamentose Tumortherapie (AGMT). Anticancer Res. 2011;31(12):4439-43.

95. Iwaya $T$, et al. Infrequent frameshift mutations of polynucleotide repeats in multiple primary cancers affecting the esophagus and other organs. Genes Chromosomes Cancer. 1998;23(4):317-22.

96. Kim JG, et al. Comprehensive DNA methylation and extensive mutation analyses reveal an association between the $\mathrm{CpG}$ island methylator phenotype and oncogenic mutations in gastric cancers. Cancer Lett. 2013;330(1):33-40.

97. Kusano $M$, et al. Genetic, epigenetic, and clinicopathologic features of gastric carcinomas with the CpG island methylator phenotype and an association with Epstein-Barr virus. Cancer. 2006;106(7):1467-79.

98. Corso $\mathrm{G}$, et al. Oncogenic mutations in gastric cancer with microsatellite instability. Eur J Cancer. 2011;47(3):443-51.

99. Chen $\mathrm{HC}$, et al. Genetic mutations of p53 and k-ras in gastric carcinoma pa- tients from Hunan, China. Tumour Biol. 2011;32(2):367-73.

100. Rahman MA, et al. B-Raf mutation: a key player in molecular biology of cancer. Exp Mol Pathol. 2013;95(3):336-42.

101. Roskoski R, Jr. RAF protein-serine/threonine kinases: structure and regulation. Biochem Biophys Res Commun. 2010;399(3):3137.

102. Dhomen $\mathrm{N}$, et al. New insight into BRAF mutations in cancer. Curr Opin Genet Dev. 2007;17(1):31-9.

103. Ikawa $\mathrm{S}$, et al. B-raf, a new member of the raf family, is activated by DNA rearrangement. Mol Cell Biol. 1988;8(6):2651-4.

104. Barnier JV, et al. The mouse B-raf gene encodes multiple protein isoforms with tissue-specific expression. J Biol Chem. 1995;270(40):23381-9.

105. Davies $\mathrm{H}$, et al. Mutations of the BRAF gene in human cancer. Nature. 2002;417(6892):949-54.

106. Rajagopalan $\mathrm{H}$, et al. Tumorigenesis: RAF/ RAS oncogenes and mismatch-repair status. Nature. 2002;418(6901):934.

107. Tsavachidou $D$, et al. SPRY2 is an inhibitor of the ras/extracellular signal-regulated kinase pathway in melanocytes and melanoma cells with wild-type BRAF but not with the V599E mutant. Cancer Res. 2004;64(16):5556-9.

108. Michaloglou $C$, et al. BRAF(E600) in benign and malignant human tumours. Oncogene. 2008;27(7):877-95.

109. Luber B, et al. Biomarker analysis of cetuximab plus oxaliplatin/leucovorin/5fluorouracil in first-line metastatic gastric and oesophago-gastric junction cancer: results from a phase II trial of the Arbeitsgemeinschaft Internistische Onkologie (AIO). BMC Cancer. 2011;11:509.

110. Oliveira $C$, et al. BRAF mutations characterize colon but not gastric cancer with mismatch repair deficiency. Oncogene. 2003:22(57):9192-6. 
111. Preusser $\mathrm{M}$, et al. No Evidence for BRAFV600E Mutations in Gastroeosophageal Tumors: Results From a High-throughput Analysis of 534 Cases Using a Mutationspecific Antibody. Appl Immunohistochem Molec Morphol. 2013;21(5):426-30.

112. Machnicki MM, et al. ARMS-PCR for detection of BRAF V600E hotspot mutation in comparison with Real-Time PCR-based techniques. Acta Biochim Pol. 2013;60(1):57-64.

113. Rivera F, et al. Cetuximab, its clinical use and future perspectives. Anticancer Drugs. 2008;19(2):99-113.

114. Ciardiello $F$, et al. EGFR antagonists in cancer treatment. N Engl J Med. 2008;358(11):1160-74.

115. Bickenbach $K$, et al. Comparisons of Gastric Cancer Treatments: East vs. West. J Gastric Cancer. 2012;12(2):55-62.

116. Richman SD, et al. Intra-tumoral heterogeneity of KRAS and BRAF mutation status in patients with advanced colorectal cancer $(\mathrm{aCRC})$ and cost-effectiveness of multiple sample testing. Anal Cell Pathol (Amst). 2011;34(1-2):61-6.

117. Anderson SM. Laboratory methods for KRAS mutation analysis. Expert Rev Mol Diagn. 2011;11(6):635-42.

118. Andreyev $\mathrm{HJ}$, et al. Kirsten ras mutations in patients with colorectal cancer: the multicenter "RASCAL" study. J Natl Cancer Inst. 1998;90(9):675-84.

119. Matsubara A, et al. Activating GNAS and KRAS mutations in gastric foveolar metaplasia, gastric heterotopia, and adenocarcinoma of the duodenum. $\mathrm{Br} J$ Cancer. 2015;112(8):1398-404.

120. Kumagai $R$, et al. Mucinous phenotype and CD10 expression of primary adenocarcinoma of the small intestine. World J Gastroenterol. 2015;21(9):2700-10.

121. Aparicio $\mathrm{T}$, et al. Small bowel adenocarcinoma phenotyping, a clinicobiological prognostic study. $\mathrm{Br} J$ Cancer. 2013;109(12):3057-66.
122. Hutchins $G$, et al. Value of mismatch repair, KRAS, and BRAF mutations in predicting recurrence and benefits from chemotherapy in colorectal cancer. J Clin Oncol. 2011;29(10):1261-70.

123. Calistri $D$, et al. KRAS, p53 and BRAF gene mutations and aneuploidy in sporadic colorectal cancer progression. Cell Oncol. 2006;28(4):161-6.

124. Samowitz WS, et al. Poor survival associated with the BRAF V600E mutation in microsatellite-stable colon cancers. Cancer Res. 2005;65(14):6063-9.

125. Wang $L$, et al. BRAF mutations in colon cancer are not likely attributable to defective DNA mismatch repair. Cancer Res. 2003;63(17):5209-12.

126. Kadowaki $S$, et al. Prognostic value of KRAS and BRAF mutations in curatively resected colorectal cancer. World I Gastroenterol. 2015;21(4):1275-83.

127. Chen D, et al. BRAFV600E mutation and its association with clinicopathological features of colorectal cancer: a systematic review and meta-analysis. PLoS One. 2014;9(3):e90607.

128. Cunningham D, et al. Colorectal cancer. Lancet. 2010;375(9719):1030-47.

129. Derakhshan $\mathbf{M H}$, et al. Oesophageal and gastric intestinal-type adenocarcinomas show the same male predominance due to a 17 year delayed development in females. Gut. 2009;58(1):16-23.

130. Tong $\mathrm{JH}$, et al. Characterization of rare transforming KRAS mutations in sporadic colorectal cancer. Cancer Biol Ther. 2014;15(6):768-76.

131. Andreyev $\mathrm{HJ}$, et al. Kirsten ras mutations in patients with colorectal cancer: the 'RASCAL II' study. Br J Cancer. 2001;85(5):6926.

132. Heinemann V, et al. Clinical relevance of EGFR- and KRAS-status in colorectal cancer patients treated with monoclonal antibodies directed against the EGFR. Cancer Treat Rev. 2009;35(3):262-71. 
133. Hotz B, et al. In vitro and in vivo antitumor activity of cetuximab in human gastric cancer cell lines in relation to epidermal growth factor receptor (EGFR) expression and mutational phenotype. Gastric Cancer. 2012;15(3):252-64.

134. Heindl $S$, et al. Relevance of MET activation and genetic alterations of KRAS and E-cadherin for cetuximab sensitivity of gastric cancer cell lines. J Cancer Res Clin Oncol. 2012;138(5):843-58.

135. Kneissl J, et al. Association of amphiregulin with the cetuximab sensitivity of gastric cancer cell lines. Int J Oncol. 2012;41(2):733-44

136. Shi $M$, et al. Cetuximab Inhibits Gastric Cancer Growth in vivo, Independent of KRAS Status. Curr Cancer Drug Targets. 2014;14(2):217-24.

137. Lordick F, et al. Capecitabine and cisplatin with or without cetuximab for patients with previously untreated advanced gastric cancer (EXPAND): a randomised, open-label phase 3 trial. Lancet Oncol. 2013;14(6):490-9.
138. Waddell T, et al. Epirubicin, oxaliplatin, and capecitabine with or without panitumumab for patients with previously untreated advanced oesophagogastric cancer (REAL3): a randomised, open-label phase 3 trial. Lancet Oncol. 2013;14(6):481-9.

139. Liu B, et al. Evaluation of driver mutations involving in RAS-RAF/PI3K-mToR pathway in gastric signet ring cell carcinoma. J Clin Oncol. 2015;33:suppl; abstr e15077.

140. Piessen $\mathrm{G}$, et al. Phase $\|/ /\|$ multicentre randomised controlled trial evaluating a strategy of primary surgery and adjuvant chemotherapy versus peri-operative chemotherapy for resectable gastric signet ring cell adenocarcinomas - PRODIGE 19 - FFCD1103 - ADCI002. BMC Cancer. 2013;13:281. 




\section{Chapter 3}

\section{$K R A S$ status is related to histological phenotype in gastric cancer - Results from a large multicentre study}

Lindsay C. Hewitt | Yuichi Saito |Tan Wang | Yoko Matsuda | Jan Oosting | Arnaldo N.S. Silva |Hayley L. Slaney | Veerle Melotte |Gordon Hutchins | Patrick Tan | Takaki Yoshikawa | Tomio Arai | Heike I. Grabsch 


\section{ABSTRACT}

Background | Gastric cancer (GC) is histologically a very heterogeneous disease, and the temporal development of different histological phenotypes remains unclear. Recent studies in lung and ovarian cancer suggest that KRAS activation (KRASact) can influence histological phenotype. KRASact likely results from KRAS mutation (KRASmut) or KRAS amplification (KRASamp). The aim of the study was to investigate whether KRASmut and/or KRASamp are related to the histological phenotype in GC.

Methods | Digitized Haematoxylin/Eosin stained slides from 1282 GC resection specimens were classified according to Japanese Gastric Cancer Association (JGCA) and the Lauren classification by at least two observers. The relationship between KRAS status, predominant histological phenotype and clinicopathological variables was assessed.

Results | KRASmut and KRASamp were found in 68 (5\%) and 47 (7\%) GCs, respectively. Within the KRASmut and KRASamp cases, the most frequent GC histological phenotype was moderately differentiated tubular 2 (tub2) type (KRASmut: $\mathrm{n}=27,40 \%$; KRASamp: $\mathrm{n}=21,46 \%$ ) or intestinal type (KRASmut: $\mathrm{n}=41,61 \% ;$ KRASamp: $\mathrm{n}=23,50 \%$ ). Comparing individual histological subtypes, mucinous carcinoma displayed the highest frequency of KRASmut (JGCA: $\mathrm{n}=6,12 \%, \mathrm{p}=0.012$; Lauren: $\mathrm{n}=6,12 \%, \mathrm{p}=0.013$ ), and KRASamp was more frequently found in poorly differentiated solid type $(n=12,10 \%, p=0.267)$ or indeterminate type ( $n=12,10 \%, p=0.480)$ GC. 724 GCs (57\%) had intratumour morphological heterogeneity.

Conclusions | This is the largest GC study investigating KRAS status and histological phenotype. We identified a relationship between KRASmut and mucinous phenotype. The high level of intratumour morphological heterogeneity could reflect KRASmut heterogeneity, which may explain the failure of anti-EGFR therapy in GC. 


\section{INTRODUCTION}

Gastric cancer (GC) is histologically a very a heterogeneous disease, and this is reflected in the numerous proposed histological classification schemes (1). The temporal development of different histological phenotypes in GC remains unclear. Recent studies suggest that Kirsten Rat Sarcoma Viral Oncogene Homolog (KRAS) activation and downstream signalling can impact on the properties and functions of the tumour microenvironment (2), and thus may influence histological phenotype. Likely mechanisms of KRAS activation include KRAS mutation (KRASmut) and KRAS amplification (KRASamp) (3).

Mutations in KRAS have been identified in many human cancers and result in the constitutive activation of KRAS and the receptor tyrosine kinase (RTK) pathway (4). The frequency of $K R A S m u t$ is variable across different cancer types, with the highest frequency in pancreatic cancer (90\%) followed by colon (34.6\%), lung (16.5\%) and ovarian (11\%) cancer and the lowest frequencies in cervical (6.6\%), prostate (5\%) and oesophageal cancer (2\%) (5). In a review of the literature we identified, on average, only $6.5 \%$ of GC have a KRASmut (6). In colorectal cancer, routine testing for KRASmut is now implemented as a predictor of response to anti-epidermal growth factor receptor (EGFR) therapy (7).

Several studies have demonstrated a relationship between KRASmut status and histological phenotype in lung and ovarian cancer. In the subgroup of invasive mucinous adenocarcinoma of the lung, KRAS is mutated in up to $86 \%$ of cases (8). In ovarian cancer, KRASmut has been identified in almost all cases with a mucinous histological phenotype (9). The relationship between KRASmut status and histological phenotype in GC remains to be clarified (6).

The reported frequency of KRASamp is $1-9 \%$ in GC (10-16). There are no reports of a relationship between KRAS DNA copy number and histological phenotype in other cancer types and in GC it has not been investigated in a large study. There is increasing recognition of the clinical importance of KRASamp in GC. KRASamp also associated with a worse survival $(3,10,12)$, whereas KRASmut do not appear to influence survival of GC patients (17).

Recently, image analysis on lung cancer HE stained sections using deep learning was predictive of mutation status (18), thus suggesting that morphological phenotype is reflective of molecular phenotype. Investigating the relationship between KRAS activation by KRASmut and/or KRASamp and histological phenotype may provide some insight into gastric adenomacarcinoma sequence progression and the origin of histological heterogeneity. Based on the studies in lung and ovarian cancer, we hypothesise that KRAS activation influences histological phenotype and is associated with a mucinous phenotype in GC. This would suggest that KRAS activation is an early event in GC, occurring before the phenotype is determined.

The aim of this multi-centre GC study was to investigate the relationship of KRAS activation status (KRASmut and/or KRASamp) with the histological phenotype in a large series of GCs from UK, Japan and The Cancer Genome Atlas (TCGA). In addition, the relationship between KRAS status, clinicopathological variables, survival and microsatellite instability status was assessed. 


\section{MATERIAL AND METHODS}

\section{Patients}

\section{Kanagawa Cancer Center Hospital (KCCH), Yokohama, Japan}

This cohort included 250 patients with TNM stage II/III GC who underwent potentially curative surgery at Kanagawa Cancer Center Hospital (Yokohama, Japan) between 2001 and 2010. One hundred and six (43\%) patients were treated with surgery alone, 108 (43\%), 22 (9\%), 14 (6\%) patients received S-1, Tegafur-uracil or S1 combined with other cytotoxic drug therapy, respectively. Demographical, clinical and pathological data were retrieved from hospital records. The study was approved by the Local Research Ethics Committee.

\section{Leeds Teaching Hospitals NHS Trust (LTHT), Leeds, UK}

This cohort included 277 patients with GC who underwent potentially curative surgery at the Department of Surgery, Leeds General Infirmary (Leeds, UK), between 1970 and 2004. Seven (3\%) patients were treated by chemotherapy followed by surgery and the remaining 270 $(98 \%)$ by surgery alone. Clinical and pathological data were retrieved from histopathology reports, electronic patient hospital records and the Northern and Yorkshire Cancer Registry. The study was approved by the Local Research Ethics Committee (LREC No. CA01/122).

\section{The Cancer Genome Atlas}

The TCGA stomach adenocarcinoma (STAD) clinicopathological and molecular dataset of 295 patients was obtained from the publically available TCGA database portal (19).

\section{Tokyo Metropolitan Geriatric Hospital and Institute of Gerontology (TMGH), Tokyo, Japan}

This cohort included 420 patients with 460 GC who were treated by surgery in the Tokyo Metropolitan Geriatric Hospital between 2000 and 2008. Three hundred and eighty patients had single carcinoma, and 36 had two or more carcinomas. Patients with Lynch syndrome were excluded from the current study. None of the patients underwent neoadjuvant chemotherapy. Histopathological examination and medical research were performed with informed written consent by the patients, and this work was approved by the ethics committee of the Tokyo Metropolitan Geriatric Hospital (\#230225, R16-23).

\section{Histopathological classification}

$\mathrm{pT}$ and $\mathrm{pN}$ stage were reported according to $7^{\text {th }}$ edition of the UICC TNM classification for GC (20).

In all cohorts, haematoxylin and eosin (H\&E) stained formalin fixed paraffin embedded (FFPE) tissue sections from the resection specimens were reviewed. In the KCCH and LTHT cohorts, H\&E stained slides were scanned at 40x magnification using an Aperio AT2 scanner 
for review. In the TCGA cohort, H\&E stained slides were viewed online using the cancer digital slide archive (http://cancer.digitalslidearchive.net/). In the TMGH cohort, classification was performed using the glass slide.

Histological classification according to JGCA scheme was performed (21). Mucinous carcinoma were defined by tumour cells in extra mucinous pools comprising an area greater than $50 \%$ of the total tumour. GC were classified as signet ring cell carcinoma when signet ring cells were present in more than $50 \%$ of the tumour volume. In cases where more than one histological phenotype was identified, the most predominant phenotype was recorded, and these GCs were categorised as heterogeneous. JGCA classification was converted to Lauren classification (22) according to table 1. As there is no Lauren classification for mucinous GC, we retained mucinous cancers as a separate category in order to distinguish them from other histological types.

Table 1 | Japanese Gastric Cancer Association histological classification of common types of gastric cancers in relation to Lauren classification.

\begin{tabular}{ll}
\hline Lauren & Histological classification \\
\hline Intestinal & Japanese Gastric Cancer Association (JGCA) \\
& Differentiated: \\
& Papillary adenocarcinoma (pap) \\
& Tubular adenocarcinoma (tub) \\
& Well-differentiated (tub1) \\
& Moderately differentiated (tub2) \\
\hline Diffuse & Undifferentiated: \\
& Poorly differentiated adenocarcinoma \\
& Non-solid type (por2) \\
& Signet-ring carcinoma (sig) \\
\hline Mucinous & Differentiated/undifferentiated: \\
& Mucinous adenocarcinoma (muc) \\
\hline Indeterminate & Undifferentiated: \\
& Poorly differentiated adenocarcinoma (por) \\
& Solid type (por1) \\
\hline
\end{tabular}

Table created after personal communication with H.Grabsch, March 12, 2019

\section{DNA extraction}

The area with the highest tumour cell density was identified on H\&E stained sections and the whole tumour area, irrespective of subregions with different histological phenotypes was microdissected after staining with Shandon instant haematoxylin (Thermo Scientific, Cheshire, UK) using a sterile surgical blade. Tumour DNA from FFPE material was extracted from KCCH and LTHT GCs using QIAmp DNA Micro Kit (Qiagen,

Hilden, Germany) as previously described (23). DNA concentration was measured by ND100 Spectrophotometer (Labtech International) and samples were diluted using Tris-EDTA buffer. In the TMGH cohort, DNA was extracted using a phenol-chloroform procedure as described previously (24). 


\section{KRAS gene copy number and data analyses}

KRAS copy number status was investigated in $\mathrm{KCCH}$, LTHT and TCGA cohorts. In the KCCH and LTHT cohort, KRAS gene copy number was determined by multiplex ligation-dependent probe amplification (MLPA) using the Salsa-FAM labelled MLPA reagent kit and probemix P458-A1 or the updated version -B1 (MRC Holland, Amsterdam, The Netherlands) as previously described (25). For further details on the KRAS probes included in this probemix see supplementary table 1. Fragment analysis of the MLPA reaction product was performed using capillary electrophoresis ABI-3130 XL (Applied Biosystems, California, USA) as previously described (25). Failed experiments were repeated at least twice before a case was finally excluded from the analyses.

KRAS DNA copy number data from $237 \mathrm{KCCH} \mathrm{GC}$ has been previously published (25), but was re-analysed using a different methodology in the current study. The output files (FSA files) from the sequencer were initially imported into Coffalyser.net for fragment analysis and results were exported as csv files. Subsequent analyses were performed using the MLPAInter method, as previously described (26), implemented in R. Samples were normalised per batch using reference samples processed in each batch. Quality control was performed to exclude samples with low overall intensity, with a large difference in intensity between short probes and long probes, with low intensity of denaturation controls, or high within gene variation, defined as the average of the standard deviation of log transformed values. Final values were calculated by averaging the peak height of each probe and then averaging the results of replicates. Copy number thresholds were set based on previously published studies (25, $27,28)$, with a DNA copy number $>1.31$ categorised as amplification. This analysis was performed separately for KCCH and LTHT cohorts.

In TCGA, KRASamp were determined by array-based somatic copy number analysis (29). Level 3 copy number segmentation data was downloaded from the TCGA data portal (19) and used to estimate copy number for KRAS. Based on previous studies, a LogRatio $>0.4$ was categorised as amplification (30).

\section{KRAS mutation status}

KRASmut data from a previous study were available for $230 \mathrm{KCCH}$ and $275 \mathrm{LTHT}$ GC patients (17). KRASmut testing was performed on an additional $12 \mathrm{KCCH} \mathrm{GCs} \mathrm{as} \mathrm{previously} \mathrm{described}$ (17). In TCGA, KRASmut status was determined by whole exome sequencing (29) and results were downloaded from the TCGA database portal (19) for 289 patients. In the TMGH cohort, KRAS (codon 12 and 13) was examined by polymerase chain reaction-restriction fragment length polymorphism (PCR-RFLP), using primers and methods previously described (31, 32).

\section{Microsatellite instability (MSI) status}

Immunohistochemistry of DNA mismatch repair proteins were used as a surrogate marker of MSI status. Results for MLH1, MSH2, MSH6 and PMS2 were available from 230 KCCH GCs, 
and MLH1 and MSH2 from 253 LTHT GCs from a previous study (17). MLH1, MSH2, MSH6 and PMS2 immunohistochemistry was performed on additional 13 GCs from the $\mathrm{KCCH}$ cohort for this study, as previously described (17).

In TCGA, MSI was determined by a DNA based MSI-Mono-Derived-Dinucleotide Assay using four mononucleotide repeat loci and three dinucleotide repeat loci using a multiplex fluorescent-labeled PCR and capillary electrophoresis (29). Results were obtained from the TCGA database portal (19) for 295 GC patients. MSI-low GCs were grouped with microsatellite stable (MSS) GCs for further analyses following current guidelines (33).

In the TMGH cohort, mononucleotide repeats BAT25 and BAT26 were investigated, as previously described (34-36) and GC were classified as MSS or MSI.

\section{Statistical analyses}

All statistical analyses were performed using SPSS software version 23 (SPSS Inc., Chicago, III). The relationship between KRASmut or KRASamp and clinicopathological variables (age, gender, depth of invasion (pT), lymph node status (pN), TNM stage, Lauren classification (22), JGCA classification (21), MSI status and morphological heterogeneity status) were assessed using chi-squared or Fisher's exact test. The relationship between KRASmut and survival in LTHT and KCCH cohorts has been published previously (17). Combining all cohorts, the relationship between KRASmut or KRASamp and 5 year overall survival was analysed using the Kaplan-Meier method and differences were assessed using the log rank test. A p-value of $<0.05$ was considered significant.

\section{RESULTS}

\section{Patient characteristics}

The median (range) age of GC patients was as follows; KCCH: 65 years ( $35-85$ years), LTHT: 72 years (14-96 years), TCGA: 68 years (35-90 years), TMGH: 78 (51-96). For a summary of other patient clinicopathological variables in each cohort see table 2 .

\section{Histological classification of gastric cancer}

Histological classification was available for 1271 GCs. Using the JGCA classification, the most predominant phenotype was tubular moderately differentiated [tub2] ( $n=408,32 \%)$, followed by poorly differentiated solid type [por1] ( $n=229,18 \%)$, poorly differentiated nonsolid type [por2] ( $n=227,18 \%)$, tubular well-differentiated [tub1] ( $n=219,17 \%)$, papillary [pap] ( $n=71,6 \%)$, signet-ring cell [sig] ( $n=66,5 \%)$ and mucinous [muc] ( $n=51,4 \%)$. According to Lauren classification, 293 (23\%) GCs were classified as diffuse type, 698 (55\%) as intestinal type, 51 (4\%) as mucinous and 229 (18\%) as indeterminate. Seven hundred and twenty-four GCs (57\%) had intratumour morphological heterogeneity (see table 2). 


\section{KRAS mutation status and relationship with clinicopathological variables}

KRASmut status was available from 1266 GCs (KCCH $n=242 ;$ LTHT $n=275 ;$ TCGA $n=289$, TMGH n=460). In total, 68 (5\%) GCs were KRAS mutant, with the highest frequency of KRASmut in the TCGA cohort (10\%) and lowest frequency in the TMGH cohort (3\%), see table 2. Within the KRASmut GC, the most frequent histological phenotype was intestinal type ( $n=41,61 \%$ ) or tub2 ( $n=27,40 \%$ ) by Lauren and JGCA classification, respectively (see figure 1a). Comparing individual histological subtypes, mucinous phenotype displayed the highest frequency of KRASmut by Lauren ( $p=0.013)$ and JGCA $(p=0.012)$ classification, respectively (see figure $1 \mathrm{~b})$. KRASmut was more frequent in MSI GC $(p<0.001)$. For the comparison of KRASmut status and other clinicopathological variables, see table 3 . The 5 year overall survival rate in patients with KRASmut or KRAS wildtype GC was $63.6 \%$ and $54.8 \%$, respectively, $p=0.541$, see figure $2 a$.
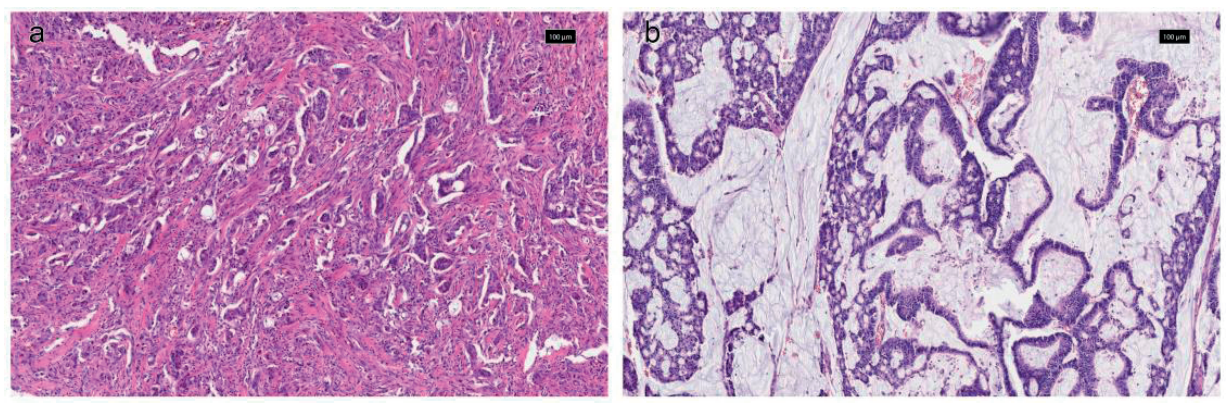

Figure 1 | Example of KRAS mutated GC with (A) moderately differentiated tubular (tub2) phenotype and (B) mucinous phenotype.
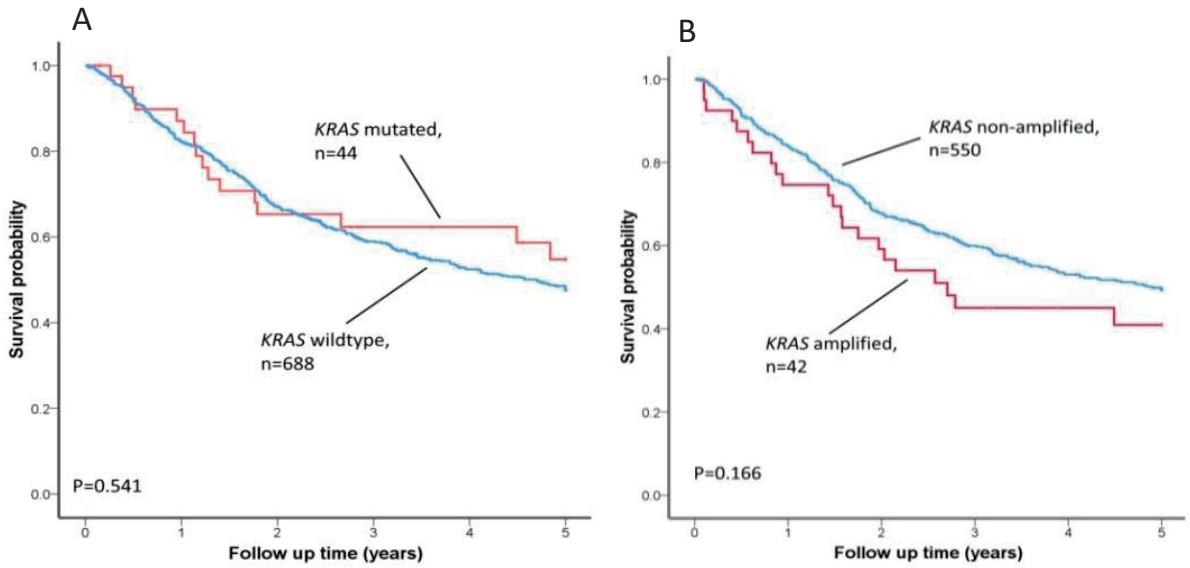

Figure 2 | Kaplan-Meier plots showing probability of overall survival in GC patients stratified by KRAS gene activation status. (A) Kaplan-Meier survival analysis showed no difference in survival when patients were stratified by KRAS mutation status. (B) Kaplan-Meier survival analysis showed no difference in survival when patients were stratified by KRAS amplification status. 
Table 2 | Comparison of clinicopathological variables in each gastric cancer cohort

\begin{tabular}{|c|c|c|c|c|c|c|c|c|c|c|c|}
\hline & & \multicolumn{2}{|c|}{ Total } & \multicolumn{2}{|c|}{$\mathrm{KCCH}$} & \multicolumn{2}{|c|}{ LTHT } & \multicolumn{2}{|c|}{ TCGA } & \multicolumn{2}{|c|}{ TMGH } \\
\hline & & $\mathrm{n}$ & $\%$ & $n$ & $\%$ & $n$ & $\%$ & $n$ & $\%$ & $n$ & $\%$ \\
\hline & & 1282 & & 250 & 20 & 277 & 22 & 295 & 23 & 460 & 36 \\
\hline \multirow[t]{2}{*}{ Age (years) } & $<65$ & 343 & 27 & 122 & 49 & 78 & 28 & 123 & 42 & 20 & 4 \\
\hline & $\geq 65$ & 936 & 73 & 128 & 51 & 199 & 72 & 169 & 58 & 440 & 96 \\
\hline \multirow[t]{2}{*}{ Gender } & Male & 769 & 60 & 175 & 70 & 164 & 59 & 182 & 62 & 248 & 54 \\
\hline & Female & 513 & 40 & 75 & 30 & 113 & 41 & 113 & 38 & 212 & 46 \\
\hline \multirow[t]{4}{*}{ T stage } & $\mathrm{pT} 1$ & 272 & 21 & 6 & 2 & 20 & 7 & 11 & 4 & 235 & 51 \\
\hline & pT2 & 138 & 11 & 43 & 17 & 24 & 9 & 44 & 15 & 27 & 6 \\
\hline & pT3 & 350 & 28 & 34 & 14 & 79 & 29 & 155 & 54 & 82 & 18 \\
\hline & pT4 & 512 & 40 & 167 & 67 & 154 & 56 & 75 & 26 & 116 & 25 \\
\hline \multirow[t]{4}{*}{ N stage } & pNO & 489 & 39 & 42 & 17 & 87 & 31 & 97 & 34 & 263 & 57 \\
\hline & pN1 & 247 & 19 & 58 & 23 & 52 & 19 & 64 & 23 & 73 & 16 \\
\hline & pN2 & 229 & 18 & 67 & 27 & 54 & 20 & 58 & 20 & 50 & 11 \\
\hline & pN3 & 306 & 24 & 83 & 33 & 84 & 30 & 65 & 23 & 74 & 16 \\
\hline \multirow[t]{4}{*}{ TNM stage } & I & 307 & 24 & 0 & & 34 & 12 & 32 & 12 & 241 & 53 \\
\hline & II & 384 & 30 & 97 & 39 & 81 & 29 & 116 & 42 & 90 & 20 \\
\hline & III & 507 & 40 & 153 & 61 & 151 & 55 & 111 & 40 & 92 & 20 \\
\hline & IV & 67 & 5 & 0 & & 11 & 4 & 20 & 7 & 36 & 8 \\
\hline \multirow{4}{*}{$\begin{array}{l}\text { Lauren } \\
\text { classification }\end{array}$} & Diffuse & 293 & 23 & 83 & 34 & 60 & 22 & 73 & 25 & 77 & 17 \\
\hline & Intestinal & 698 & 55 & 103 & 42 & 145 & 54 & 156 & 53 & 294 & 64 \\
\hline & Mucinous & 51 & 4 & 10 & 4 & 10 & 4 & 20 & 7 & 11 & 2 \\
\hline & Indeterminate & 229 & 18 & 51 & 21 & 56 & 21 & 44 & 15 & 78 & 17 \\
\hline \multirow{7}{*}{$\begin{array}{l}\text { JGCA } \\
\text { classification }\end{array}$} & Pap & 71 & 6 & 5 & 2 & 9 & 3 & 17 & 6 & 40 & 9 \\
\hline & Tub1 & 219 & 17 & 18 & 7 & 55 & 20 & 23 & 8 & 123 & 27 \\
\hline & Tub2 & 408 & 32 & 80 & 32 & 81 & 30 & 116 & 40 & 131 & 29 \\
\hline & Por1 & 229 & 18 & 51 & 21 & 56 & 21 & 44 & 15 & 78 & 17 \\
\hline & Por2 & 227 & 18 & 63 & 26 & 52 & 19 & 71 & 24 & 41 & 9 \\
\hline & Sig & 66 & 5 & 20 & 8 & 8 & 3 & 2 & 1 & 36 & 8 \\
\hline & Muc & 51 & 4 & 10 & 4 & 10 & 4 & 20 & 7 & 11 & 2 \\
\hline \multirow{2}{*}{$\begin{array}{l}\text { Morphological } \\
\text { heterogeneity }\end{array}$} & Homogenous & 542 & 43 & 102 & 42 & 82 & 30 & 185 & 63 & 173 & 38 \\
\hline & Heterogeneous & 724 & 57 & 140 & 58 & 189 & 70 & 108 & 37 & 287 & 62 \\
\hline \multirow{2}{*}{$\begin{array}{l}\text { KRAS mutation } \\
\text { status }\end{array}$} & Mutant & 68 & 5 & 10 & 4 & 16 & 6 & 28 & 10 & 14 & 3 \\
\hline & Wildtype & 1198 & 95 & 232 & 96 & 259 & 94 & 261 & 90 & 446 & 97 \\
\hline \multirow{2}{*}{$\begin{array}{l}\text { KRAS gene copy } \\
\text { number }\end{array}$} & Amplified & 47 & 7 & 12 & 6 & 17 & 8 & 18 & 8 & & \\
\hline & Other & 602 & 93 & 196 & 94 & 199 & 92 & 207 & 92 & & \\
\hline \multirow{2}{*}{$\begin{array}{l}\text { Microsatellite } \\
\text { instability status }\end{array}$} & MSI & 199 & 16 & 23 & 9 & 31 & 12 & 64 & 22 & 81 & 18 \\
\hline & MSS & 1057 & 84 & 223 & 91 & 224 & 88 & 231 & 78 & 379 & 82 \\
\hline
\end{tabular}

Note. Some variables do not add up to 1282 due to missing data.

Abbreviations: JGCA, Japanese Gastric Cancer Association; Pap, papillary adenocarcinoma; Tub1, well differentiated tubular adenocarcinoma; Tub2, moderately differentiated tubular adenocarcinoma; Por1, poorly differentiated adenocarcinoma solid type; Por2, poorly differentiated adenocarcinoma non-solid type; Sig, signet-ring cell carcinoma; Muc, mucinous adenocarcinoma; MSI, microsatellite instable; MSS, microsatellite stable; KCCH, Kanagawa Cancer Center Hospital; LTHT, Leeds Teaching Hospital Trust; TCGA, The Cancer Genome Atlas; TMGH, Tokyo Metropolitan Geriatric Hospital and Institute of Gerontology. 
Table 3 | Comparison of clinicopathological variables and KRAS mutation status in all gastric cancer cohorts combined

\begin{tabular}{|c|c|c|c|c|c|c|}
\hline & \multicolumn{6}{|c|}{ KRAS mutation status } \\
\hline & & $\begin{array}{l}M \\
n\end{array}$ & $\begin{array}{l}\mathbf{M} \\
\%\end{array}$ & $\begin{array}{l}\text { WT } \\
n\end{array}$ & $\begin{array}{l}\text { WT } \\
\%\end{array}$ & P-value \\
\hline \multirow[t]{2}{*}{ Age (years) } & $<65$ & 13 & 4 & 319 & 96 & \multirow{2}{*}{0.167} \\
\hline & $\geq 65$ & 55 & 6 & 876 & 94 & \\
\hline \multirow[t]{2}{*}{ Gender } & Male & 36 & 5 & 723 & 95 & \multirow{2}{*}{0.225} \\
\hline & Female & 32 & 6 & 475 & 94 & \\
\hline \multirow[t]{2}{*}{ T stage } & $\mathrm{pT} 1 / \mathrm{pT} 2$ & 20 & 5 & 388 & 95 & \multirow{2}{*}{0.639} \\
\hline & pT3/pT4 & 47 & 6 & 802 & 95 & \\
\hline \multirow[t]{2}{*}{ N stage } & pNO & 31 & 6 & 455 & 94 & \multirow{2}{*}{0.158} \\
\hline & pN1-pN3 & 35 & 5 & 734 & 95 & \\
\hline \multirow[t]{2}{*}{ TNM stage } & $|-| \mid$ & 35 & 5 & 651 & 95 & \multirow{2}{*}{0.756} \\
\hline & III-IV & 31 & 6 & 533 & 95 & \\
\hline \multirow[t]{4}{*}{ Lauren classification } & Diffuse & 7 & 2 & 283 & 98 & \multirow{4}{*}{0.013} \\
\hline & Intestinal & 41 & 6 & 652 & 94 & \\
\hline & Mucinous & 6 & 12 & 43 & 88 & \\
\hline & Indeterminate & 13 & 6 & 215 & 94 & \\
\hline \multirow[t]{7}{*}{ JGCA classification } & Pap & 7 & 10 & 64 & 90 & \multirow{7}{*}{0.012} \\
\hline & Tub1 & 7 & 3 & 212 & 97 & \\
\hline & Tub2 & 27 & 7 & 376 & 93 & \\
\hline & Por1 & 13 & 6 & 215 & 94 & \\
\hline & Por2 & 6 & 3 & 219 & 97 & \\
\hline & Sig & 1 & 2 & 64 & 99 & \\
\hline & Muc & 6 & 12 & 43 & 88 & \\
\hline \multirow[t]{2}{*}{ Morphological heterogeneity } & Homogeneous & 31 & 6 & 506 & 94 & \multirow{2}{*}{0.550} \\
\hline & Heterogeneous & 36 & 5 & 683 & 95 & \\
\hline \multirow[t]{2}{*}{ Microsatellite instability status } & MSI & 33 & 17 & 165 & 83 & \multirow{2}{*}{$<0.001$} \\
\hline & MSS & 32 & 3 & 1010 & 97 & \\
\hline
\end{tabular}

Note. Some variables do not add up to 1282 due to missing data.

Abbreviations: JGCA, Japanese Gastric Cancer Association; Pap, papillary adenocarcinoma; Tub1, well differentiated tubular adenocarcinoma; Tub2, moderately differentiated tubular adenocarcinoma; Por1, poorly differentiated adenocarcinoma solid type; Por2, poorly differentiated adenocarcinoma non-solid type; Sig, signetring cell carcinoma; Muc, mucinous adenocarcinoma; MSI, microsatellite instable; MSS, microsatellite stable.

\section{KRAS amplification and relationship with clinicopathological variables}

KRAS gene copy number status was available from 649 GCs (KCCH $n=208$, LTHT $n=216$, TCGA n=225). In total, 47 (7\%) GCs had a KRASamp (TCGA (8\%), LTHT (8\%) and KCCH $(6 \%))$, see table 2 . Within KRASamp GC, intestinal type $(n=23,(50 \%)$ or tub2 $(n=21,46 \%)$ was the most frequent histological phenotype by Lauren and JGCA classification, respectively (see figure 3a). Comparing individual histological subtypes, KRASamp was more frequently 
found in indeterminate type $(n=12,10 \%)$ or por1 $(n=12,10 \%)$ phenotype by Lauren and JGCA classification, respectively (see figure $3 \mathrm{~b}$ ). There was no relationship between KRASamp and histological phenotype or any other clinicopathological variables, see table 4 . The 5 year overall survival rate in GC patients with and without KRASamp was $47.6 \%$ versus $55.6 \%$, respectively, $p=0.166$, see figure $2 b$.

Only two GCs from the TCGA cohort had a concurrent KRASamp and KRASmut; one was a mucinous GC, the other was a por2 GC according to JGCA classification.
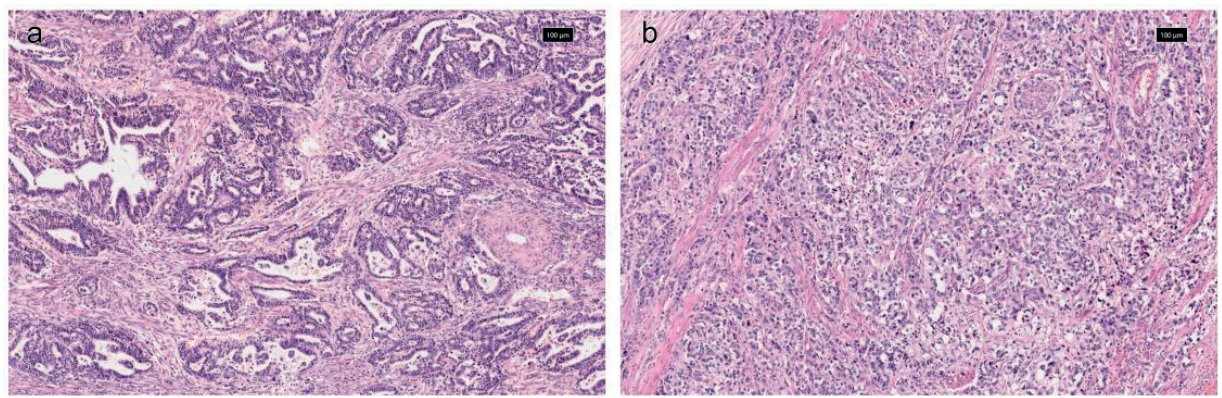

Figure 3 | Example of KRAS amplified GC with (A) moderately differentiated tubular (tub2) phenotype and (B) solid-type poorly differentiated adenocarcinoma (por1) phenotype.

Table 4 | Comparison of clinicopathological variables and KRAS copy number status in KCCH, LTHT and TCGA gastric cancer cohorts combined

\begin{tabular}{|c|c|c|c|c|c|c|}
\hline & & $\begin{array}{l}\text { KRAS } \\
\text { amplified } \\
\mathrm{n}\end{array}$ & $\begin{array}{l}\text { KRAS } \\
\text { amplified } \\
\%\end{array}$ & $\begin{array}{l}\text { KRAS } \\
\text { other } \\
\mathrm{n}\end{array}$ & $\begin{array}{l}\text { KRAS } \\
\text { other } \\
\%\end{array}$ & P-value \\
\hline \multirow[t]{2}{*}{ Age (years) } & $<65$ & 21 & 8 & 235 & 92 & \multirow{2}{*}{0.462} \\
\hline & $\geq 65$ & 26 & 7 & 364 & 93 & \\
\hline \multirow[t]{2}{*}{ Gender } & Male & 29 & 7 & 383 & 93 & \multirow{2}{*}{0.792} \\
\hline & Female & 18 & 8 & 219 & 92 & \\
\hline \multirow[t]{2}{*}{ T stage } & $\mathrm{pT} 1 / \mathrm{pT} 2$ & 8 & 7 & 109 & 93 & \multirow{2}{*}{0.867} \\
\hline & pT3/pT4 & 38 & 7 & 484 & 93 & \\
\hline \multirow[t]{2}{*}{ N stage } & $\mathrm{pNO}$ & 7 & 4 & 163 & 96 & \multirow{2}{*}{0.058} \\
\hline & pN1-pN3 & 40 & 9 & 428 & 92 & \\
\hline \multirow[t]{2}{*}{ TNM stage } & I-II & 14 & 5 & 262 & 95 & \multirow{2}{*}{0.061} \\
\hline & IIIIIV & 32 & 9 & 325 & 91 & \\
\hline \multirow{4}{*}{$\begin{array}{l}\text { Lauren } \\
\text { classification }\end{array}$} & Diffuse & 10 & 6 & 168 & 94 & \multirow{4}{*}{0.480} \\
\hline & Intestinal & 23 & 7 & 298 & 93 & \\
\hline & Mucinous & 1 & 3 & 29 & 97 & \\
\hline & Indeterminate & 12 & 10 & 107 & 90 & \\
\hline
\end{tabular}


Table 4 | Comparison of clinicopathological variables and KRAS copy number status in KCCH, LTHT and TCGA gastric cancer cohorts combined (continued)

\begin{tabular}{|c|c|c|c|c|c|c|}
\hline & & $\begin{array}{l}\text { KRAS } \\
\text { amplified } \\
\mathrm{n}\end{array}$ & $\begin{array}{l}\text { KRAS } \\
\text { amplified } \\
\%\end{array}$ & $\begin{array}{l}\text { KRAS } \\
\text { other } \\
\mathrm{n}\end{array}$ & $\begin{array}{l}\text { KRAS } \\
\text { other } \\
\%\end{array}$ & P-value \\
\hline \multirow[t]{7}{*}{ JGCA classification } & Pap & 0 & 0 & 24 & 100 & \multirow{7}{*}{0.267} \\
\hline & Tub1 & 2 & 3 & 70 & 97 & \\
\hline & Tub2 & 21 & 9 & 204 & 91 & \\
\hline & Por1 & 12 & 10 & 107 & 90 & \\
\hline & Por2 & 9 & 6 & 144 & 94 & \\
\hline & Sig & 1 & 4 & 24 & 96 & \\
\hline & Muc & 1 & 3 & 29 & 97 & \\
\hline \multirow{2}{*}{$\begin{array}{l}\text { Morphological } \\
\text { heterogeneity }\end{array}$} & Homogeneous & 19 & 6 & 282 & 94 & \multirow{2}{*}{0.437} \\
\hline & Heterogeneous & 27 & 8 & 315 & 92 & \\
\hline \multirow{2}{*}{$\begin{array}{l}\text { Microsatellite } \\
\text { instability status }\end{array}$} & MSI & 3 & 3 & 90 & 97 & \multirow{2}{*}{0.093} \\
\hline & MSS & 44 & 8 & 494 & 92 & \\
\hline
\end{tabular}

Note. Some variables do not add up to 822 due to missing data.

Abbreviations: JGCA, Japanese Gastric Cancer Association; Pap, papillary adenocarcinoma; Tub1, well differentiated tubular adenocarcinoma; Tub2, moderately differentiated tubular adenocarcinoma; Por1, poorly differentiated adenocarcinoma solid type; Por2, poorly differentiated adenocarcinoma non-solid type; Sig, signet-ring cell carcinoma; Muc, mucinous adenocarcinoma; MSI, microsatellite instable; MSS, microsatellite stable; KCCH, Kanagawa Cancer Center Hospital; LTHT, Leeds Teaching Hospital Trust; TCGA, The Cancer Genome Atlas.

\section{DISCUSSION}

This is the largest multicentre study to date to investigate the relationship between KRAS activation by mutation and/or amplification and histological phenotype in GC. The frequency of KRASamp (7\%) was slightly higher than that of KRASmut (5\%) which is consistent with other GC studies $(10,11,37)$. The higher frequency of KRASmut in the TCGA GC cohort compared to the other cohorts could be related to the methodology as TCGA used whole exome sequencing to test non-hotspot regions whereas other studies used less sensitive Sanger sequencing/PCR-RFLP. We found KRASamp and KRASmut were exclusive in $>99 \%$ of GC, which is consistent with previous reports $(11-13,38)$.

The relationship between KRASmut and histological phenotype had not been investigated in great detail and previous studies were limited by small sample sizes and hence lack of statistical power (6). In our study, we identified a relationship between KRASmut and mucinous histological phenotype, which is concordant with higher frequencies of KRASmut being reported in mucinous lung (8), ovarian (9) and colorectal cancer $(39,40)$. However, due to the relatively low frequency of GC with mucinous phenotype and KRASmut (12\%), it would not be feasible to use the presence of a mucinous phenotype as a predictor for the presence of a KRASmut in GC. The main components of mucinous GCs are extracellular mucins, which are high molecular weight glycoproteins regulated by expression of the MUC2, MUC5AC 
and MUC6 genes in humans (41). In mouse models with constitutively activated KRAS in the stomach, irregular MUC4+ cells were found with abnormal mucins confirmed by Alcianblue staining (42). Interestingly, our study suggests a relationship between KRASmut and mucinous phenotype, which is characterised by extracellular mucin, but is not related to signet-ring cell type GC, which is characterised by intracellular mucins. Our study confirmed the relationship between KRASmut and presence of $\mathrm{MSI}$, which our group and others have described previously in a smaller GC cohort $(43,44)$.

The prognostic significance of KRASmut in GC remains controversial (6). In our study, there was no association with presence of KRASmut and survival. Interestingly, in lung and colorectal cancer, $K R A S m u t$ are associated with a poor prognosis $(45,46)$, whereas in ovarian cancer, KRASmut are associated with an improved prognosis (47).

The relationship between KRASamp and clinicopathological variables, including histological phenotype in cancer is not well studied. In GC, we found no statistically significant relationship between KRASamp and histological phenotype, or any other clinicopathological variables. In contrast, others found that the presence of KRASamp is associated with a poor prognosis in $\mathrm{GC}(3,10,12)$. This difference might be due to case selection and methodology used.

In our study we used the JGCA scheme for the histological classification of GC and performed a conversion to the Lauren scheme, which is the most widely used histological classification system in Western countries (22). Previous studies investigating the relationship between KRASmut and histological phenotype performed classification according to the Lauren scheme (6), for which there is no separate category for mucinous $G C$. The relatively large number of GCs classified as indeterminate according to the Lauren scheme comes from conversion from the JGCA por1 histological phenotype. Direct classification according to the Lauren scheme, would likely result in a higher proportion of GCs classified as either intestinal or diffuse.

In colorectal cancer KRASmut is known to be an early event in the progression from normal colonic epithelial cell to adenoma, and finally to carcinoma (48). The evidence of sequential development by accumulation of genetic alterations, including KRASmut, is still controversial in GC (49-51). We were unable to make any comments regarding the role of KRASact in gastric carcinogenesis in our cohort as we did not investigate precancerous lesions in the current study. However, evidence from mouse models suggest that KRASmut is one of the key molecular alterations involved in the development of stomach dysplasia (52) and GC (53). Based on the evidence from other cancer types that KRASmut influence the progression of a mucinous histological phenotype, we therefore speculate based on our results that KRASmut in GC is an early event in GC development whereas KRASamp is likely to be a late event occurring after the histological phenotype has been established. This would correspond with experiments in mice expressing oncogenic KRAS in combination with $\mathrm{E}$-cadherin and p53 loss, which resulted in a rapid progression of GC compared to wildtype mice (53). 
Our study has some limitations. This is a retrospective study. Histological phenotyping was performed on a single slide. Given the high frequency of intra-tumoural morphological heterogeneity in this study and the previously reported intra-tumoural heterogeneity in KRASmut status in GC (54), the sensitivity of some of the techniques used in the current study may not be sufficient to detect KRAS activation in subclones of tumour cells. As we did not perform microdissection of tumour subregions, we cannot comment on KRAS status heterogeneity within the same tumour. Furthermore, we used different techniques for DNA extraction, KRASmut status analysis and MSI analysis in different cohorts included in the current study, each with differing sensitivities $(55,56)$.

In summary, we identified a relationship between KRASmut and mucinous histological phenotype in GC. The high level of intratumour morphological heterogeneity could reflect KRASmut heterogeneity, which may explain the failure of anti-EGFR therapy in GC. 


\section{REFERENCES}

1. Gullo I, et al. Heterogeneity in Gastric Cancer: From Pure Morphology to Molecular Classifications. Pathobiology. 2018;85(12):50-63.

2. Dias Carvalho $P$, et al. KRAS Oncogenic Signaling Extends beyond Cancer Cells to Orchestrate the Microenvironment. Cancer Res. 2018;78(1):7-14.

3. Wong GS, et al. Targeting wild-type KRAS-amplified gastroesophageal cancer through combined MEK and SHP2 inhibition. Nat Med. 2018;24(7):968-77.

4. Jancik $S$, et al. Clinical relevance of KRAS in human cancers. J Biomed Biotechnol. 2010;2010:150960.

5. Singh $\mathrm{H}$, et al. Improving Prospects for Targeting RAS. J Clin Oncol. 2015;33(31):3650-9.

6. Hewitt LC, et al. KRAS, BRAF and gastric cancer. Transl Gastroin Canc. 2015;4(6):429-47.

7. Er TK, et al. Current approaches for predicting a lack of response to anti-EGFR therapy in KRAS wild-type patients. Biomed Res Int. 2014;2014:591867.

8. Cha YJ, et al. Biology of invasive mucinous adenocarcinoma of the lung. Transl Lung Cancer Res. 2017;6(5):508-12.

9. Jayson $\mathrm{GC}$, et al. Ovarian cancer. Lancet. 2014;384(9951):1376-88.

10. Deng $\mathrm{N}$, et al. A comprehensive survey of genomic alterations in gastric cancer reveals systematic patterns of molecular exclusivity and co-occurrence among distinct therapeutic targets. Gut. 2012;61(5):67384.

11. Mita $H$, et al. A novel method, digital genome scanning detects KRAS gene amplification in gastric cancers: involvement of overexpressed wild-type KRAS in downstream signaling and cancer cell growth. BMC Cancer. 2009;9:198.

12. Qian $Z$, et al. Whole genome gene copy number profiling of gastric cancer identi- fies PAK1 and KRAS gene amplification as therapy targets. Genes, Chromosomes \& Cancer. 2014;53(11):883-94.

13. Ali SM, et al. Prospective comprehensive genomic profiling of advanced gastric carcinoma cases reveals frequent clinically relevant genomic alterations and new routes for targeted therapies. Oncologist. 2015;20(5):499-507.

14. Cristescu $R$, et al. Molecular analysis of gastric cancer identifies subtypes associated with distinct clinical outcomes. Nat Med. 2015;21(5):449-56.

15. Yoda $Y$, et al. Integrated analysis of cancerrelated pathways affected by genetic and epigenetic alterations in gastric cancer. Gastric Cancer. 2015;18(1):65-76.

16. Ooi $A$, et al. Gene amplification of CCNE1, CCND1, and CDK6 in gastric cancers detected by multiplex ligationdependent probe amplification and fluorescence in situ hybridization. Hum Pathol. 2017;61:58-67.

17. van Grieken NC, et al. KRAS and BRAF mutations are rare and related to DNA mismatch repair deficiency in gastric cancer from the East and the West: results from a large international multicentre study. $\mathrm{Br} J$ Cancer. 2013;108(7):1495-501.

18. Coudray $\mathrm{N}$, et al. Classification and mutation prediction from non-small cell lung cancer histopathology images using deep learning. Nat Med. 2018;24(10):1559-67.

19. The Cancer Genome Atlas. Comprehensive Molecular Characterization of Gastric Adenocarcinoma 2014 [Available from: https://tcga-data.nci.nih.gov/docs/publications/stad_2014].

20. Washington $K$. 7th edition of the AJCC cancer staging manual: stomach. Ann Surg Oncol. 2010;17(12):3077-9.

21. Japanese Gastric Cancer Association. Japanese classification of gastric carci- 
noma: 3rd English edition. Gastric Cancer. 2011;14(2):101-12.

22. Lauren P. The two histological main types of gastric carcinoma: diffuse and so called intestinal-type carcinoma. Acta Pathol Microbiol Scand. 1965;64:31-49.

23. Hutchins $G$, et al. Value of mismatch repair, KRAS, and BRAF mutations in predicting recurrence and benefits from chemotherapy in colorectal cancer. J Clin Oncol. 2011;29(10):1261-70.

24. Arai $\mathrm{T}$, et al. Solid-type poorly differentiated adenocarcinoma of the stomach: clinicopathological and molecular characteristics and histogenesis. Gastric Cancer. 2019;22(2):314-22.

25. Silva $\mathrm{AN}$, et al. Frequent Coamplification of Receptor Tyrosine Kinase and Downstream Signaling Genes in Japanese Primary Gastric Cancer and Conversion in Matched Lymph Node Metastasis. Ann Surg. 2016;267(1):114-21.

26. van Eijk $R$, et al. MLPAinter for MLPA interpretation: an integrated approach for the analysis, visualisation and data management of Multiplex Ligation-dependent Probe Amplification. BMC Bioinformatics. 2010;11:67.

27. Ooi A, et al. Gene amplification of ESR1 in breast cancers--fact or fiction? A fluorescence in situ hybridization and multiplex ligation-dependent probe amplification study. J Pathol. 2012;227(1):8-16.

28. Bunyan DJ, et al. Dosage analysis of cancer predisposition genes by multiplex ligation-dependent probe amplification. $\mathrm{Br}$ J Cancer. 2004;91(6):1155-9.

29. Cancer Genome Atlas Research Network. Comprehensive molecular characterization of gastric adenocarcinoma. Nature. 2014;513(7517):202-9.

30. Hanemaaijer NM, et al. Practical guidelines for interpreting copy number gains detected by high-resolution array in routine diagnostics. Eur J Hum Genet. 2012;20(2):161-5.
31. Ohshima $\mathrm{S}$, et al. Detection of c-Ki-ras gene mutation in paraffin sections of adenocarcinoma and atypical bronchioloalveolar cell hyperplasia of human lung. Virchows Arch. 1994;424(2):129-34.

32. Suzuki $Y$, et al. Detection of ras gene mutations in human lung cancers by single-strand conformation polymorphism analysis of polymerase chain reaction products. Oncogene. 1990;5(7):1037-43.

33. Umar A, et al. Revised Bethesda Guidelines for hereditary nonpolyposis colorectal cancer (Lynch syndrome) and microsatellite instability. J Natl Cancer Inst. 2004;96(4):261-8

34. Zhou XP, et al. Allelic profiles of mononucleotide repeat microsatellites in control individuals and in colorectal tumors with and without replication errors. Oncogene. 1997; 15(14):1713-8.

35. Cravo $M$, et al. BAT-26 identifies sporadic colorectal cancers with mutator phenotype: a correlative study with clinico-pathological features and mutations in mismatch repair genes. J Pathol. 1999;188(3):252-7.

36. Esemuede I, et al. Improved testing for microsatellite instability in colorectal cancer using a simplified 3-marker assay. Ann Surg Oncol. 2010;17(12):3370-8.

37. Warneke VS, et al. Prognostic and putative predictive biomarkers of gastric cancer for personalized medicine. Diagn Mol Pathol. 2013:22(3):127-37.

38. Valtorta $E$, et al. KRAS gene amplification in colorectal cancer and impact on response to EGFR-targeted therapy. Int J Cancer. 2013;133(5):1259-65.

39. Rosty C, et al. Colorectal carcinomas with KRAS mutation are associated with distinctive morphological and molecular features. Mod Pathol. 2013;26(6):825-34.

40. Khan $M$, et al. Prognostic Implications of Mucinous Differentiation in Metastatic Colorectal Carcinoma Can Be Explained by Distinct Molecular and Clinicopatho- 
logic Characteristics. Clin Colorectal Canc. 2018;17(4):E699-E709.

41. Boltin D, et al. Mucins in Gastric Cancer - An Update. J Gastrointest Dig Syst. 2013;3(123):15519.

42. Kinoshita $\mathrm{H}$, et al. Three types of metaplasia model through Kras activation, Pten deletion, or Cdh1 deletion in the gastric epithelium. J Pathol. 2019;247(1):35-47.

43. Polom K, et al. KRAS Mutation in Gastric Cancer and Prognostication Associated with Microsatellite Instability Status. Pathol Oncol Res. 2019;25(1):333-40.

44. Zhao W, et al. Mutations of BRAF and KRAS in gastric cancer and their association with microsatellite instability. Int J Cancer. 2004;108(1):167-9.

45. Andreyev $\mathrm{HJ}$, et al. Kirsten ras mutations in patients with colorectal cancer: the multicenter "RASCAL" study. J Natl Cancer Inst. 1998;90(9):675-84.

46. Zhang J, et al. Targeting KRAS-mutant non-small cell lung cancer: challenges and opportunities. Acta Biochim Biophys Sin (Shanghai). 2016;48(1):11-6.

47. Nodin B, et al. Clinicopathological correlates and prognostic significance of KRAS mutation status in a pooled prospective cohort of epithelial ovarian cancer. Diagn Pathol. 2013;8:106.

48. Arvelo F, et al. Biology of colorectal cancer. Ecancermedicalscience. 2015;9:520.

49. Maesawa $C$, et al. The sequential accumulation of genetic alterations characteristic of the colorectal adenoma-carcinoma sequence does not occur between gastric adenoma and adenocarcinoma. J Pathol. 1995;176(3):249-58.
50. Gong C, et al. KRAS mutations predict progression of preneoplastic gastric lesions. Cancer Epidemiol Biomarkers Prev. 1999;8(2):167-71.

51. Junttila $M R$, et al. Influence of tumour micro-environment heterogeneity on therapeutic response. Nature. 2013;501(7467):346-54.

52. Okumura T, et al. K-ras Mutation Targeted to Gastric Tissue Progenitor Cells Results in Chronic Inflammation, an Altered Microenvironment, and Progression to Intraepithelial Neoplasia. Cancer Res. 2010;70(21):8435-45.

53. Till JE, et al. Oncogenic KRAS and p53 Loss Drive Gastric Tumorigenesis in Mice That Can Be Attenuated by E-Cadherin Expression. Cancer Res. 2017;77(19):5349-59.

54. Queiros $P$, et al. KRAS mutations in microsatellite instable gastric tumours: impact of targeted treatment and intratumoural heterogeneity. Virchows Arch. 2015;467(4):383-92.

55. Matsunaga $\mathrm{M}$, et al. A comparison of four methods for detecting KRAS mutations in formalin-fixed specimens from metastatic colorectal cancer patients. Oncol Lett. 2016;12(1):150-6.

56. de la Chapelle A, et al. Clinical relevance of microsatellite instability in colorectal cancer. J Clin Oncol. 2010;28(20):3380-7. 
Chapter 3

Supplementary table 1: Information on KRAS probes incorporated into MRC-Holland gastric cancer probemix

\begin{tabular}{lrlllll}
\hline Probemix & $\begin{array}{r}\text { Length } \\
\text { (nucleotides) }\end{array}$ & $\begin{array}{l}\text { Chromosome } \\
\text { band }\end{array}$ & Exon & HG16 location & $\begin{array}{l}\text { HG18 } \\
\text { location }\end{array}$ \\
\hline P458-A1 & 180 & $17596-L 22078$ & $12 p 12.1$ & 2 & $12-025.289376$ & \\
P458-A1 & 392 & $09507-L 22081$ & $12 p 12.1$ & 3 & $12-025.271583$ & \\
P458-A1 & 382 & $17605-S P 0543-L 21602$ & $12 p 12.1$ & 4 & $12-025.269833$ & \\
P458-A1 & 202 & $17597-S P 0529-L 22061$ & $12 p 12.1$ & 6 & $12-025.252102$ & \\
P458-B1 & 124 & $20117-L 27312$ & $12 p 12.1$ & 6 & $12-025.252$ \\
P458-B1 & 197 & $20095-L 27280$ & $12 p 12.1$ & 4 & $12-025.270$ \\
P458-B1 & 399 & $19323-L 27531$ & $12 p 12.1$ & 3 & $12-025.272$ \\
\hline
\end{tabular}






\section{Chapter 4}

\section{Epstein-Barr Virus and Mismatch Repair Deficiency status differ between Oesophageal and Gastric Cancer: a large Multicentre Study}

Lindsay C. Hewitt | Imran Z. Inam | Yuichi Saito | Takaki Yoshikawa | Alexander Quaas | Arnulf Hoelscher | Elizabeth Bollschweiler | Gregorio E. Fazzi | Veerle Melotte | Ruth E. Langley | Matthew Nankivell | David Cunningham | William Allum | Gordon G. Hutchins | Heike I. Grabsch 


\section{ABSTRACT}

Background | Oesophageal $(\mathrm{OeC})$ and gastric $(\mathrm{GC})$ cancer patients are treated with similar multimodal therapy and have poor survival. There remains an urgent clinical need to identify biomarkers to individualise patient management and improve outcomes. Therapy with immune checkpoint inhibitors has shown promising results in other cancers. Proposed biomarkers to predict potential response to immune checkpoint inhibitors include DNA mismatch repair (MMR) and/or Epstein-Barr virus (EBV) status. The aim of this study was to establish and compare EBV status and MMR status in large multicentre series of $\mathrm{OeC}$ and GC.

Methods | EBV was assessed by EBV-encoded RNA (EBER) in situ hybridisation and MMR protein expression by immunohistochemistry (IHC) in 988 OeC and 1213 GC from multiple centres. In a subset of $\mathrm{OeC}$, microsatellite instability (MSI) was tested in parallel with MMR $\mathrm{IHC}$.

Results | Frequency of MMR deficiency (MMRdef) and MSI was low in OeC $(0.8 \%$ and $0.6 \%$, respectively) compared with GC (10.3\%). None of the OeCs were EBER positive in contrast to $4.8 \%$ EBER positive GC. EBV positive GC patients were younger $(p=0.01)$, more often male $(p=0.001)$ and had a better overall survival $(p=0.012)$. MMRdef GC patients were older $(p=0.001)$ and showed more often intestinal-type histology $(p=0.022)$.

Conclusions | This is the largest study to date indicating that EBV and MMRdef do not play a role in $\mathrm{OeC}$ carcinogenesis in contrast to GC. The potential clinical usefulness of determining MMRdef/EBV status to screen patients for eligibility for immune-targeting therapy differs between $\mathrm{OeC}$ and $\mathrm{GC}$ patients. 


\section{INTRODUCTION}

Oesophageal cancer ( $\mathrm{OeC}$ ) and gastric cancer (GC) are the eighth and fifth most common cancer worldwide, respectively, with an estimated total of 1,407,000 new cases and $1,123,000$ deaths in 2012 (1). The two main histological OeC subtypes are squamous cell carcinoma $(\mathrm{SqC})$ and adenocarcinoma $(\mathrm{AdC})$. The vast majority of $\mathrm{GC}$ are adenocarcinomas.

In Europe, the standard of care for $\mathrm{OeC}$ and GC patients with locally advanced resectable disease is chemotherapy or chemoradiotherapy, followed by surgery $(2,3)$. GC patients receive perioperative platinum/fluorouracil based chemotherapy. For $\mathrm{OeC}$, patients with $\mathrm{SqC}$ are treated with preoperative chemoradiotherapy with carboplatin/paclitaxel. Patients with $\mathrm{AdC}$ receive perioperative platinum/fluorouracil or preoperative chemoradiotherapy. Nevertheless, survival remains poor, with 5-year overall survival between $36-47 \%(4,5)$.

To date few targeted therapy options are available to OeC/GC patients with metastatic disease: trastuzumab for HER2 positive disease (6) and ramucirumab, a VEGFR-2 antagonist without biomarker based patient selection $(7,8)$. All other trials evaluating receptor tyrosine kinase or downstream signalling inhibitors in OeC/GC were unable to show a survival benefit (9). There remains an urgent clinical need to identify biomarkers to individualise and improve OeC/GC patient management.

DNA mismatch repair (MMR) has been used as a predictive biomarker for PD1 inhibitor therapy response in multiple different cancer types, including colorectal cancer (10). Evidence of Epstein-Barr virus (EBV) infection has been proposed as a potential marker for response to PD1/PDL1 inhibitors in GC (11). Pembrolizumab, an antibody against PD1, was approved by the FDA for the treatment of unresectable or metastatic solid tumours, including OeC and GC, with mismatch repair deficiency (MMRdef) or microsatellite instability (MSI)-High (12).

The potential of immunotherapy in $\mathrm{OeC}$ was shown recently in phase 2 trials in nonselected oesophageal SqC and GC patients treated with nivolumab, a monocolonal antibody inhibiting PD1, in second line treatment $(13,14)$ and in a phase 3 trial in heavily pretreated non-selected Asian GC patients (15). Furthermore, recent results from the phase $1 \mathrm{~b}$ trials in patients with PD-L1 expressing OeC (KEYNOTE-028) and GC (KEYNOTE-012), showed promising activity of pembrolizumab in the metastatic setting $(16,17)$. In metastatic colorectal cancer, a phase 2 study demonstrated the clinical benefit of pembrolizumab in patients with MMRdef (18).

In addition to the potential role of MMR proteins in selecting patients for immunotherapy, MMRdef has shown prognostic value (19) and seems to predict a poor response to fluorouracil based chemotherapy in colorectal cancer $(20,21)$. It has been shown recently in MAGIC trial patients, that gastro-oesophageal cancer patients with MMRdef/MSI tumours treated with surgery alone survived longer compared to those treated with perioperative cytotoxic chemotherapy (22). In OeC, MLH1 and MSH2 deficiency has been shown to be associated with poor prognosis in small series of SqC (23). 
To date, the frequency of MMRdef/MSI in OeC cancer remains unclear because of the small sample size of studies. The reported frequency of MSI-High (MSI-H) ranges from 0-27\% but a number of previous studies did not distinguish between MSI-H and MSI-Low (MSI-L) (for an overview of all published studies on MMR and MSI in OeC, see table 1). The recent study by The Cancer Genome Atlas (TCGA) did not find MSI in any of the $162 \mathrm{OeC}$ (24). With respect to the frequency of EBV infection in OeC, the majority of previous studies investigated SqC using different methodology, included relatively small number of patients and reported a frequency of EBV positivity from 0 to $36 \%$ (for an overview of all published studies on EBV

Table 1 | Summary of published literature relating to the frequency of mismatch repair deficiency and microsatellite instability in oesophageal cancer

\begin{tabular}{|c|c|c|c|c|c|c|}
\hline Authors & Year & $\begin{array}{l}\text { Oesophageal cancer } \\
\text { type }\end{array}$ & $\begin{array}{l}\text { Total } \\
\mathrm{n}\end{array}$ & $\begin{array}{l}\text { MMRdef } \\
\text { n (\%) }\end{array}$ & $\begin{array}{l}\text { MSI-High } \\
\mathrm{n}(\%)\end{array}$ & Method \\
\hline \multirow[t]{3}{*}{ TCGA (24) } & 2017 & $\mathrm{SqC}$ & 90 & $\mathrm{Nl}$ & 0 & PCR \\
\hline & & $\mathrm{AdC}$ & 70 & & 0 & \\
\hline & & undiff & 2 & & 0 & \\
\hline \multirow[t]{2}{*}{ Pandilla et al. (26) } & 2013 & $\mathrm{SqC}$ & 60 & $\mathrm{NI}$ & $6(10)$ & PCR \\
\hline & & $\mathrm{AdC}$ & 30 & & $2(7)$ & \\
\hline Farris et al. (27) & 2011 & $\mathrm{SqC}$ & 76 & $5(7)$ & $5(7)$ & $\mathrm{IHC}, \mathrm{PCR}$ \\
\hline \multirow[t]{2}{*}{ Vasavi et al. (28) } & 2010 & $\mathrm{SqC}$ & 45 & $\mathrm{NI}$ & $12(27)$ & PCR \\
\hline & & $\mathrm{AdC}$ & 5 & & $1(20)$ & \\
\hline Matsumoto et al. (29) & 2007 & $\mathrm{SqC}$ & 62 & $\mathrm{NI}$ & $5(8)$ & PCR \\
\hline Falkenback et al. (30) & 2005 & AdC & 59 & $2(3)$ & $2(3)$ & $\mathrm{IHC}, \mathrm{PCR}$ \\
\hline Naidoo et al. (31) & 2005 & $\mathrm{SqC}$ & 100 & $\mathrm{NI}$ & $5(5)^{*}$ & PCR \\
\hline Uehara et al. (23) & 2005 & $\mathrm{SqC}$ & 122 & $49(40)$ & $6(5)^{*}$ & $\mathrm{IHC}$ \\
\hline Evans et al. (32) & 2004 & $\mathrm{AdC}$ & 27 & $6(22)$ & 0 & $\mathrm{IHC}, \mathrm{PCR}$ \\
\hline Araki et al. (33) & 2004 & $\mathrm{SqC}$ & 100 & $\mathrm{NI}$ & 0 & PCR \\
\hline Hayashi et al. (34) & 2003 & $\mathrm{SqC}$ & 30 & $\mathrm{NI}$ & $1(3)$ & PCR \\
\hline Ikeguchi et al. (35) & 1999 & $\mathrm{SqC}$ & 20 & $\mathrm{NI}$ & $1(5)^{*}$ & PCR \\
\hline Wu et al. (36) & 1998 & $\mathrm{SqC}$ & 92 & $\mathrm{NI}$ & $5(5)^{*}$ & PCR \\
\hline \multirow[t]{2}{*}{ Muzeau et al. (37) } & 1997 & $\mathrm{SqC}$ & 20 & $\mathrm{NI}$ & 0 & PCR \\
\hline & & $\mathrm{AdC}$ & 26 & & 0 & \\
\hline Gleeson et al. (38) & 1996 & $\mathrm{AdC}$ & 17 & $\mathrm{NI}$ & $1(17)$ & $P C R$ \\
\hline Keller et al. (39) & 1995 & $\mathrm{AdC}$ & 15 & $\mathrm{NI}$ & $2(13)^{*}$ & PCR \\
\hline Ogasawara et al. (40) & 1995 & $\mathrm{SqC}$ & 35 & $\mathrm{NI}$ & $21(60)^{*}$ & PCR \\
\hline \multirow[t]{2}{*}{ Meltzer et al. (41) } & 1994 & $\mathrm{SqC}$ & 42 & $\mathrm{NI}$ & $1(2)^{*}$ & PCR \\
\hline & & $\mathrm{AdC}$ & 36 & & $2(6)^{*}$ & \\
\hline
\end{tabular}

Abbreviations: AdC, adenocarcinoma; SqC, squamous cell carcinoma; MMRdef, mismatch repair deficiency; MSI, microsatellite instability; PCR, polymerase chain reaction; IHC, immunohistochemistry; NI, not investigated; undiff, undifferentiated

* no distinction made between MSI-High and MSI-Low 
in OeC see table 2). Thus neither MSI/MMRdef nor EBV status has been investigated in large series of $\mathrm{OeC}$ using the same methodology and relating results to clinicopathological variables and patient survival.

The aim of this multi-centre study was to establish the EBV and MMR/MSI status in 988 OeC, including patients from the Medical Research Council (MRC) Oe02 trial (25), from Leeds (UK) and from Cologne (Germany), and relate the results to clinicopathological variables, survival and treatment interaction (preoperative chemo(radio)therapy). As patients with resectable $\mathrm{OeC}$ and $\mathrm{GC}$ are often treated using similar neoadjuvant therapy regimens and recruited into the same clinical trials across different countries or continents, we compared the frequency of EBV positivity and MMRdef in OeC with that of 1213 GC from Leeds (UK) and Yokohama (Japan).

Table $\mathbf{2}$ | Summary of published literature relating to the frequency of Epstein-Barr virus in oesophageal cancer

\begin{tabular}{|c|c|c|c|c|c|}
\hline Reference & Year & $\begin{array}{l}\text { Oesophageal } \\
\text { cancer type }\end{array}$ & Total n & $\begin{array}{l}\text { EBV positive } \\
\mathrm{n}(\%)\end{array}$ & Method \\
\hline \multirow[t]{3}{*}{ TCGA (24) } & \multirow[t]{3}{*}{2017} & $\mathrm{SqC}$ & 90 & 0 & \multirow{3}{*}{$\begin{array}{l}\text { Whole-exome } \\
\text { sequencing }\end{array}$} \\
\hline & & $\mathrm{AdC}$ & 70 & 0 & \\
\hline & & undiff & 2 & 0 & \\
\hline Genitsch et al. (42) & 2015 & $\mathrm{AdC}$ & 118 & 0 & EBER ISH \\
\hline Farris et al. (27) & 2011 & $\mathrm{AdC}$ & 76 & $1(1)$ & EBER ISH \\
\hline Sunpaweravong et al. (43) & 2005 & $\mathrm{SqC}$ & 104 & 0 & EBER ISH \\
\hline \multirow[t]{2}{*}{ Wu et al. (44) } & \multirow[t]{2}{*}{2005} & $\mathrm{SqC}$ & 151 & $6(4)$ & \multirow[t]{2}{*}{ EBER ISH } \\
\hline & & undiff & 13 & $4(31)$ & \\
\hline \multirow[t]{2}{*}{ Awerkiew et al. (45) } & \multirow[t]{2}{*}{2003} & $\mathrm{SqC}$ & 23 & $8(35)$ & \multirow[t]{2}{*}{ PCR } \\
\hline & & $\mathrm{AdC}$ & 14 & $5(36)$ & \\
\hline Yanai et al. (46) & 2003 & $\mathrm{SqC}$ & 34 & 0 & EBER ISH, PCR \\
\hline Mizobuchi et al. (47) & 1997 & $\mathrm{SqC}$ & 41 & 0 & PCR \\
\hline Wang et al. (48) & 1999 & $\mathrm{SqC}$ & 51 & 0 & EBER ISH, PCR \\
\hline Wang et al. (49) & 1999 & $\mathrm{SqC}$ & 31 & $11(36)$ & EBER ISH, PCR \\
\hline
\end{tabular}

Abbreviations: AdC, adenocarcinoma; SqC, squamous cell carcinoma; EBER ISH, EBV-encoded RNA in situ hybridisation; PCR, polymerase chain reaction; undiff, undifferentiated

\section{MATERIAL AND METHODS}

\section{Oesophageal and gastric cancer}

The definition whether a tumour is a gastric or oesophageal cancer is dependent on the macroscopic location of the bulk/epicentre of the tumour with respect to the gastro-oesophageal junction. Macroscopic images were not available to us for review as part of this study with the exception of the Japanese gastric cancer cases. In contrast to our Japanese colleagues who classify tumours as oesophageal, junctional or gastric, all other pathologists using the 
TNM classification categorise tumours as being either oesophageal or gastric. We therefore reviewed the macroscopic images from the Japanese junctional cancers to classify them as either oesophageal or gastric according to TNM rules. For all other cases we have used the classification of the originally reporting pathologist.

\section{Oesophageal cancer}

\section{Leeds Teaching Hospitals NHS Trust (LTHT), UK}

The LTHT cohort included $223 \mathrm{OeC}$ patients who underwent potentially curative surgery at the Department of Surgery, Leeds General Infirmary (Leeds, UK), between 1986 and 2006. 83 patients had preoperative chemotherapy. Clinical and pathological data were retrieved from pathology reports, electronic patient hospital records and the Northern and Yorkshire Cancer Registry. The study was approved by the Leeds Research Ethics Committee (LREC No. CA01/122).

\section{University Hospital Cologne (UHC), Germany}

The UHC cohort included $322 \mathrm{OeC}$ patients who underwent potentially curative surgery at the Department of Visceral Surgery, University of Cologne (Cologne, Germany), between 1999 and 2013. 197 patients had pre-operative chemotherapy. Clinical and pathological data were retrieved from pathology reports and electronic patient hospital records. The study was approved by the Ethics Committee at the University Hospital, Cologne (reference number: 09-232).

\section{Gastric cancer}

\section{Leeds Teaching Hospitals NHS Trust, UK}

The GC LTHT cohort included 799 patients who underwent potentially curative surgery at the Department of Surgery, Leeds General Infirmary (Leeds, UK) between 1970 and 2004. 11 patients had preoperative chemotherapy. Demographical, clinical and pathological data were retrieved from pathological reports, electronic patient hospital records and the Northern and Yorkshire Cancer Registry. The study was approved by the Leeds Research Ethics Committee (LREC No. CA01/122).

\section{Kanagawa Cancer Center Hospital (KCCH), Yokohama, Japan}

The KCCH cohort included 414 patients with stage II-IV GC who underwent potentially curative surgery at the Kanagawa Cancer Center Hospital (Yokohama, Japan) between 2001 and 2010. None of the patients had preoperative chemotherapy, 202 patients were treated with chemotherapy after surgery. Demographical, clinical and pathological data were retrieved from pathological reports and patient hospital records. The study was approved by the Local Research Ethics Committee. 


\section{Cancer Staging}

$\mathrm{pT}$ and $\mathrm{pN}$ stage was reported according to the Union for International Cancer control $6^{\text {th }}$ and $7^{\text {th }}$ edition of the TNM classification for $\mathrm{OeC}$ and GC, respectively.

The histological subtype of adenocarcinomas was established based on Lauren's classification (50). According to Lauren's classification signet-ring cell GCs were classified as diffusetype cancer. As there is no category for mucinous cancers in the Lauren classification, such cancers were classified together with the mixed-type cancers which we used as a category for truly mixed-type cancers and cancers with indeterminate phenotype like the mucinous cancers. The histology type of the case, as stated in the pathology report, was used for statistical analyses.

\section{Tissue microarray construction}

Slides from all resection specimens were reviewed and a block with the highest tumour cell density was selected for tissue microarray (TMA) construction and/or marked for microdissection for DNA extraction (see below). The areas selected were representative of the overall histology of the case. The LTHT, KCCH and OeO2 trial cases were reviewed by HG, LH and $\mathrm{GH}$, together with local pathologists. The UHC cases were reviewed by AQ. A total of 962 OeCs (417, 223 and 322 patients from the Oe02, LTHT, and UHC cohorts, respectively) and 1213 GCs (799 and 414 patients from LTHT and KCCH cohorts, respectively) were included in TMAs. TMA construction from the LTHT (OeC and GC) and Oe02 patient cohorts was performed using $0.6 \mathrm{~mm}$ tissue cores. $1.2 \mathrm{~mm}$ and $1 \mathrm{~mm}$ tissue cores were used for the UHC and $\mathrm{KCCH}$ cohorts, respectively.

\section{Immunohistochemistry for mismatch repair proteins}

MMR immunohistochemistry (IHC) data from previous studies were available for $230 \mathrm{KCCH}$ (51) and 175 LTHT (52) GCs. Additional 184 KCCH and 624 LTHT GCs were stained as part of the present study.

TMA sections from the Oe02 trial cohort were stained for MLH1, MSH2, MSH6, PMS2, from the UHC cohort for MLH1, MSH2 and MSH6 and from the KCCH and LTHT cohort (OeC and GC) for MLH1 and MSH2. For details on antigen retrieval, primary antibodies, detection system, staining protocols see table 1 in the supplementary material. For all cohorts, 3,3'-Diaminobenzidine (DAB) was used as a chromogen and haematoxylin as a counterstain.

A case was classified as MMR deficient (MMRdef) if tumour cell nuclei were negative for one or more MMR proteins in the presence of positively stained lymphocytes or fibroblasts as internal control. In the Oe02 trial cohort, 12 cases were negative for at least one MMR protein without positive internal controls on the TMA. For these cases IHC was repeated on full sections. A case was classified as MMR proficient (MMRprof) if tumour cell nuclei, irrespective of the number or intensity, were positive for all MMR proteins tested. 


\section{EBV RNA in situ hybridisation}

EBV data from a previous study were available for 437 LTHT and 216 KCCH GC (52). Additional 362 LTHT and 198 KCCH GCs were stained as part of the present study. EBV status was determined on TMAs in the LTHT (OeC and GC), OeO2 and KCCH cohorts by EBV-encoded RNA (EBER) in situ hybridisation as previously described (53). In the UHC cohort, a fluorescein-conjugated oligonucleotide probe in conjunction with a monoclonal anti-fluorescein antibody and DAB as chromogen (Leica Biosystems, Wetzlar, Germany) was used according to the instructions of the manufacturer. EBV positivity was defined as presence of staining in tumour cell nuclei, irrespective of the number of nuclei or intensity.

\section{DNA extraction}

DNA was extracted using a protocol based on the QIAmp DNA Micro Kit (Qiagen, Hilden, Germany) as previously described (54). DNA concentration was measured by ND-100 Spectrophotometer (Labtech International) and adjusted to a final concentration of $1 \mathrm{ng} / \mu \mathrm{l}$.

\section{Assessment of microsatellite instability}

The MSI Analysis System, version 1.2 (Promega, Southampton, UK), was used for the detection of MSI in 419 Oe02 patients. This kit allows the simultaneous evaluation of 5 fluorescently labelled MSI markers: BAT-25, BAT-26, NR-21, NR-24 and MONO-27. PCR products were analysed using a 3100-Avant genetic analyser (Applied Biosystems, California, USA) as previously described (51). Instability in two or more microsatellite loci was categorised as MSI-high (MSI-H) and in a single loci as MSI-low (MSI-L). Absence of MSI in all 5 markers and MSI-L were grouped as microsatellite stable (MSS) for further analyses following current guidelines (55).

\section{Statistical analyses}

All statistical analyses were performed using SPSS version 23 software (SPSS Inc., Chicago, III). The relationship between EBV or MMR status and clinicopathological variables (age, gender, depth of invasion (pT), lymph node status (pN), Lauren classification and neoadjuvant treatment) were assessed using chi-squared for categorical variables and Mann-Whitney $U$ for continuous variables. LTHT and KCCH GC data were combined for the analysis of the relationship between EBV or MMR status and overall 5-year survival and differences were assessed using the log rank test. $P$ values less than 0.05 were considered significant. 


\section{RESULTS}

\section{EBV status}

EBV data were available from 928 OeC patients (LTHT $n=223$; Oe02 $n=383$; UHC $n=322$ ) and $1178 \mathrm{GC}$ patients (LTHT $\mathrm{n}=768 ; \mathrm{KCCH} n=410)$. All OeC were EBV negative. A total of $56(4.8 \%)$ GC were EBV positive (LTHT: $n=30$ (3.9\%), KCCH: $n=26(6.3 \%))$. Supplementary figure 1 illustrates EBV staining in GC.

\section{Microsatellite status and mismatch repair protein expression}

MSI data were available from $362 \mathrm{OeC}$ from the Oe02 cohort. A total of 57 (13.6\%) cases had to be excluded due to repeated technical failures. A total of $356(98.3 \%)$ OeC patients were classified as MSS, 4 (1.1\%) OeC as MSI-L (3 AdC and $1 \mathrm{SqC}$ ) and 2 (0.6\%) OeC as MSI-H (both AdC). Supplementary figure 2 shows a typical capillary electrophoresis output for a MSI-H OeC and a MSS OeC. For 306 patients, MMR IHC (MLH1, MSH2, MSH6 and PMS2) data and MSI testing results were available and showed $99.0 \%$ concordant results. We therefore decided to only use IHC for the remaining cohorts.

MMR expression data were available from a total of 916 OeC (LTHT $n=220$; Oe02 n=374; UHC $n=322)$. A sum of $43(10.3 \%)$ and $3(1.3 \%)$ OeC from the Oe02 and LTHT cohorts, respectively, were excluded due to technical failures. Seven (0.8\%) OeC (5 AdC and $2 \mathrm{SqC}$ ) were classified as MMRdef (LTHT: 3 (1.4\%) MLH1 deficient, Oe02: 1 (0.3\%) MSH2 deficient, UHC: $3(0.9 \%)$ MLH1 deficient). Patient clinicopathological variables and MMR status for $\mathrm{OeC}$ are summarised in table 3. Owing to the very small number of MMRdef in OeC, it was not feasible to perform any statistical analysis with clinicopathological data or survival.

MMR protein expression data were available from 1098 GC (LTHT $n=702 ; \mathrm{KCCH} n=396)$. A total of $113(10.3 \%)$ cases were classified as MMRdef (LTHT: 70 (10.0\%), KCCH: 43 (10.9\%)). Supplementary figure 3 illustrates MMR protein expression in a MMRdef GC.

For 1063 GCs, both EBV and MMR data were available. A single GC from the LTHT cohort was MMRdef and EBV positive. This patient was male, 67 years old at the time of diagnosis, and survived 17 years despite having an advanced intestinal-type GC (pT4, pN3) in the resected specimen.

\section{Relationship of EBV status and MMR status with clinicopathological variables in patients with gastric cancer}

Patients with EBV positive GC were younger (median (range) age EBV positive GC: 63 years (32-89 years) versus 68 years (14-96 years) in EBV negative $G C, p=0.01$ ). A total of 48 (85.7\%) patients with EBV positive GC were male compared with $8(14.3 \%)$ of female patients $(p=0.001)$. EBV positive GC patients had a better overall 5 -year survival compared with EBV negative GC patients (60.7\% versus $41.7 \%$; hazard ratio 1.72 , 95\% confidence interval 1.12-2.63 $[p=0.012])$. 
Table 3 | Mismatch repair status and clinicopathological variables in patients with oesophageal cancer

\begin{tabular}{|c|c|c|c|c|c|c|c|c|c|c|c|c|c|}
\hline \multicolumn{2}{|c|}{ Clinicopathological variables } & \multicolumn{6}{|c|}{ Mismatch repair proficient } & \multicolumn{6}{|c|}{$\begin{array}{l}\text { Mismatch repair } \\
\text { deficient }\end{array}$} \\
\hline & & \multicolumn{2}{|c|}{ LTHT } & \multicolumn{2}{|c|}{ Oe02 } & \multicolumn{2}{|c|}{ UHC } & \multicolumn{2}{|c|}{ LTHT } & \multicolumn{2}{|c|}{ Oe02 } & \multicolumn{2}{|c|}{ UHC } \\
\hline & & $n$ & $\%$ & $n$ & $\%$ & $n$ & $\%$ & $n$ & $\%$ & $n$ & $\%$ & $n$ & $\%$ \\
\hline \multirow{2}{*}{ Sex } & Male & 137 & 63.1 & 294 & 78.8 & 287 & 89.9 & 2 & 66.7 & & & 3 & 100 \\
\hline & Female & 80 & 36.9 & 79 & 21.2 & 32 & 10.1 & 1 & 33.3 & 1 & 100 & & \\
\hline \multirow{5}{*}{ (y)pт(6) } & TO & 2 & 0.9 & & & 3 & 0.9 & & & & & & \\
\hline & $\mathrm{T} 1$ & 32 & 14.7 & 27 & 7.2 & 63 & 19.7 & & & & & 1 & 33.3 \\
\hline & $\mathrm{T} 2$ & 38 & 17.5 & 36 & 9.7 & 63 & 19.7 & 1 & 33.3 & & & & \\
\hline & T3 & 136 & 62.7 & 301 & 80.7 & 185 & 58 & 2 & 66.7 & 1 & 100 & 2 & 66.7 \\
\hline & $\mathrm{T} 4$ & 9 & 4.1 & 9 & 2.4 & 5 & 1.6 & & & & & & \\
\hline \multirow{3}{*}{ (y)pN(6) } & NO & 83 & 38.2 & 123 & 33 & 122 & 38.2 & & & 1 & 100 & 3 & 100 \\
\hline & N1 & 133 & 61.3 & 250 & 67 & 197 & 61.8 & 3 & 100 & & & & \\
\hline & unknown & 1 & 0.5 & & & & & & & & & & \\
\hline \multirow{3}{*}{$\begin{array}{l}\text { Histological } \\
\text { type }\end{array}$} & Adenocarcinoma & 165 & 76 & 275 & 73.7 & 319 & 100 & 2 & 66.7 & & & 3 & 100 \\
\hline & Squamous cell carcinoma & 49 & 22.6 & 87 & 23.3 & & & 1 & 33.3 & 1 & 100 & & \\
\hline & Other & 3 & 1.4 & 11 & 2.9 & & & & & & & & \\
\hline \multirow{3}{*}{$\begin{array}{l}\text { Neoadjuvant } \\
\text { treatment }\end{array}$} & Yes & 80 & 36.9 & 177 & 47.5 & 194 & 60.8 & 2 & 66.7 & 1 & 100 & 2 & 66.7 \\
\hline & No & 133 & 61.3 & 196 & 52.5 & 125 & 39.2 & 1 & 33.3 & & & 1 & 33.3 \\
\hline & unknown & 4 & 1.8 & & & & & & & & & & \\
\hline
\end{tabular}

Abbreviations: LTHT, Leeds Teaching Hospital Trust; Oe02, oesophageal cancer trial 02 (25); UHC, University Hospital Cologne

Patients with MMRdef GC were older (median [range] age MMRdef GC: 71 years [51-90 years] versus 68 years [24-96 years] in MMRprof $G C, p=0.001)$. A total of 77 (69.4\%) MMRdef GC had intestinal-type histology compared with 20 (18.0\%) with diffuse-type histology $(p=0.022)$. There was no difference in overall survival between MMRdef and MMRprof GCs $(p=0.383)$. There was no relationship with any other clinicopathological variables (table 4).

A summary of the EBV, MMR and MSI status in each cohort is provided in table 5.

\section{DISCUSSION}

This is the largest gastro-oesophageal cancer study to date investigating MMR and EBV status in $988 \mathrm{OeC}$ and $1213 \mathrm{GC}$. The extremely low frequency of MMR/MSI and lack of EBV infection in OeC relative to GC in our study confirms the recent TCGA results which investigated MSI and EBV in smaller series of $164 \mathrm{OeC}$ (24) and 295 GC (11) using different methodologies. 
All OeC were EBV negative which is consistent with the majority of previously published studies $(42,43,46-48,56)$. Therefore, we can conclude now that EBV does not play a role in $\mathrm{OeC}$ carcinogenesis neither in $\mathrm{SqC}$ nor in $\mathrm{AdC}$. A small number of previous studies reported an EBV positivity rate between $1-36 \%$ in $\operatorname{OeC}(27,44,45,49)$. This discrepancy is most likely related to different potentially less reliable methodology, such as PCR, which would also detect EBV in tumour-infiltrating lymphocytes (46) leading to false positive results. The present study used the generally accepted 'gold standard' EBER methodology. In our study EBV positive GC patients had a significantly better overall survival compared to EBV negative patients which is consistent with results from other studies (57).

In the Oe02 cohort, we detected a very low frequency of MSI-H (0.6\%) using the Bethesda microsatellite panel (55). This result is consistent with the recent smaller TCGA study which found no MSI-H cases in 72 oesophageal AdC (24). However, our result is in contrast to the literature reporting a frequency of $\mathrm{MSI}-\mathrm{H}$ in OeC between $0-27 \%$ in $\mathrm{SqC}(28,33,35$, $37)$ and $0-20 \%$ in $\operatorname{AdC}(22,27,28,30,32,37)$. Discrepancies in the frequency of MSI-H amongst studies could be related to different definitions of MSI-H (32), as well as differences in location (28) and number of microsatellite loci tested (35). Recent studies in GC suggest that a mononucleotide and dinucleotide markers different to those included in the so-called Bethesda panel might improve accuracy and sensitivity of MSI testing in GC $(58,59)$.

There are few small studies reporting a MMRdef frequency of 3-40\% in OeC mostly based on $\mathrm{IHC}$ of MLH1 and MSH2 $(23,27,30,32)$. Some of the previous studies scores were based on staining intensity and cell proportions and classifying cases with weak staining and/or low percentages of positively stained tumour cells as MMRdef. Thus, when using our MMR scoring system where a case was classified as MMRprof, irrespective of the number of positive nuclei or staining intensity, the frequency of MMRdef in our study is comparable to previously published studies. Another potential reason for discrepant results in the literature could be the misclassification of $\mathrm{AdC}$ with a tumour bulk located in the stomach which extends into the GOJ as OeC. In contrast to the results from the MAGIC trial patients (22), there was no overall survival difference between MMRdef GC and MMRprof GC in our study. This is likely due to differences in disease stage, histological subtypes and age of GC patients in our study.

The frequency of MMRdef and EBV positivity in our GC cohort is consistent with the current literature (60-62). As the same methodology was used to stain GC and OeC, our GC results also indirectly support the reliability of the low frequency of MMRdef and EBV in $\mathrm{OeC}$ in the present study. Furthermore, our results are comparable with results from a smaller study in the MAGIC trial patients comparing the frequency of MSI and MMRdef in GC and OeC (22).

Our study has some limitations. First, this is a retrospective study. Secondly, due to limited tissue availability, we were unable to perform IHC for all four MMR proteins in all cases and we did not test all cases for MSI. However, evidence in the literature from GC found MMRdef was due to loss of MLH1 in 95.8\% of cases, and deficiency in MSH6 and PMS2 was rare (60). 
Table 4 | Comparison of mismatch repair and EBV status with clinicopathological variables in patients with gastric cancer

\begin{tabular}{|c|c|c|c|c|c|c|c|}
\hline \multicolumn{2}{|c|}{ Clinicopathological variables } & \multicolumn{6}{|c|}{ Mismatch repair proficient } \\
\hline & & \multicolumn{2}{|c|}{ LTHT } & \multicolumn{2}{|c|}{$\mathrm{KCCH}$} & \multicolumn{2}{|l|}{ Total } \\
\hline & & $\mathrm{n}$ & $\%$ & $n$ & $\%$ & $\mathrm{n}$ & $\%$ \\
\hline \multirow[t]{3}{*}{ Gender } & Male & 415 & 59 & 250 & 63 & 665 & 61 \\
\hline & Female & 214 & 30 & 102 & 26 & 316 & 29 \\
\hline & Unknown & 3 & 0 & 1 & 0 & 4 & 0 \\
\hline \multirow[t]{5}{*}{ (y)pT(7) } & T1 & 83 & 12 & 34 & 9 & 117 & 11 \\
\hline & $\mathrm{T} 2$ & 69 & 10 & 52 & 13 & 121 & 11 \\
\hline & T3 & 179 & 25 & 52 & 13 & 231 & 21 \\
\hline & $\mathrm{T} 4$ & 301 & 43 & 214 & 54 & 515 & 47 \\
\hline & Unknown & & & 1 & 0 & 1 & 0 \\
\hline \multirow[t]{5}{*}{ (y)pN(7) } & No & 206 & 29 & 70 & 18 & 276 & 25 \\
\hline & N1 & 123 & 18 & 80 & 20 & 203 & 18 \\
\hline & N2 & 146 & 21 & 91 & 23 & 237 & 22 \\
\hline & N3 & 156 & 22 & 111 & 28 & 267 & 24 \\
\hline & Unknown & 1 & 0 & 1 & 0 & 2 & 0 \\
\hline \multirow[t]{4}{*}{ Lauren classification } & Intestinal & 403 & 57 & 181 & 46 & 584 & 53 \\
\hline & Diffuse & 145 & 21 & 154 & 39 & 299 & 27 \\
\hline & Mucinous/ mixed & 82 & 12 & 15 & 4 & 97 & 9 \\
\hline & Unknown & 2 & 0 & 3 & 1 & 5 & 0 \\
\hline \multirow[t]{3}{*}{ Neoadjuvant treatment } & Yes & 8 & 1 & 177 & 45 & 185 & 17 \\
\hline & No & 624 & 89 & 164 & 41 & 788 & 72 \\
\hline & Unknown & & & 12 & 3 & 12 & 1 \\
\hline
\end{tabular}

Abbreviations: KCCH, Kanagawa Cancer Center Hospital; LTHT, Leeds Teaching Hospital Trust

Similarly, a colorectal cancer study reported a positive predictive value and specificity of IHC for MMR proteins of $99.1 \%$ and $99.6 \%$, respectively, compared with MSI (63). Our own study showed that MSI status is in $99.0 \%$ of cases concordant with the MMR IHC status. Another potential limitation is our inability to determine the proportion of junctional (GOJ) AdC versus true oesophageal or true gastric $\mathrm{AdC}$ which might potentially be clinically relevant. This is related to the fact that detailed pre-chemotherapy endoscopic information regarding the location was not available for most cases. There are very few studies investigating EBV and MMRdef in GOJ cancer with inconsistent results most likely related to low sample sizes $(22,42,64)$ or differences in defining the GOJ $(65)$.

Our OeC findings suggest that $\mathrm{OeC}$ carcinogenesis is not associated with EBV infection and MMRdef/MSI does not appear to be an important underlying mechanism in OeC, neither $\mathrm{SqC}$ nor AdC. The use of EBV and/or MMR/MSI status to determine OeC patient eligibility for immunotherapy or adjuvant cytotoxic therapy cannot be recommended and there remains the need to find alternative biomarkers for such therapy approaches in this patient population. 


\begin{tabular}{|c|c|c|c|c|c|c|c|c|c|c|c|c|c|c|c|c|c|c|c|}
\hline \multicolumn{7}{|c|}{ Mismatch repair deficient } & \multicolumn{6}{|c|}{ EBV negative } & \multicolumn{7}{|c|}{ EBV positive } \\
\hline \multicolumn{2}{|c|}{ LTHT } & \multicolumn{2}{|c|}{$\mathrm{KCCH}$} & \multicolumn{3}{|c|}{ Total } & \multicolumn{2}{|c|}{ LTHT } & \multicolumn{2}{|c|}{$\mathrm{KCCH}$} & \multicolumn{2}{|c|}{ Total } & \multicolumn{2}{|c|}{ LTHT } & \multicolumn{2}{|c|}{$\mathrm{KCCH}$} & \multicolumn{2}{|c|}{ Total } & \multirow[b]{2}{*}{$\mathrm{p}$ value } \\
\hline $\mathrm{n}$ & $\%$ & $\mathrm{n}$ & $\%$ & $\mathrm{n}$ & $\%$ & $p$ value & $\mathrm{n}$ & $\%$ & $\mathrm{n}$ & $\%$ & $n$ & $\%$ & $\mathrm{n}$ & $\%$ & $\mathrm{n}$ & $\%$ & $n$ & $\%$ & \\
\hline 42 & 6 & 33 & 8 & 75 & 7 & 0.761 & 456 & 59 & 273 & 67 & 729 & 62 & 26 & 3 & 22 & 5 & 48 & 4 & 0.001 \\
\hline \multirow[t]{2}{*}{28} & 4 & 10 & 3 & 38 & 3 & & 281 & 37 & 110 & 27 & 391 & 33 & 4 & 1 & 4 & 1 & 8 & 1 & \\
\hline & & & & & & & 1 & 0 & 1 & 0 & 2 & 0 & & & & & & & \\
\hline 5 & 1 & 3 & 1 & 8 & 1 & 0.074 & 105 & 14 & 37 & 9 & 142 & 12 & 4 & 1 & 2 & 0 & 6 & 1 & 0.794 \\
\hline 2 & 0 & 5 & 1 & 7 & 1 & & 75 & 10 & 58 & 14 & 133 & 11 & 5 & 1 & 4 & 1 & 9 & 1 & \\
\hline 26 & 4 & 3 & 1 & 29 & 3 & & 210 & 27 & 52 & 13 & 262 & 22 & 9 & 1 & 3 & 1 & 12 & 1 & \\
\hline \multirow[t]{2}{*}{37} & 5 & 32 & 8 & 69 & 6 & & 348 & 45 & 236 & 58 & 584 & 50 & 12 & 2 & 17 & 4 & 29 & 2 & \\
\hline & & & & & & & & & 1 & 0 & 1 & 0 & & & & & & & \\
\hline 22 & 3 & 13 & 3 & 35 & 3 & 0.722 & 242 & 32 & 82 & 20 & 324 & 28 & 13 & 2 & 4 & 1 & 17 & 1 & 0.931 \\
\hline 19 & 3 & 6 & 2 & 25 & 2 & & 155 & 20 & 83 & 20 & 238 & 20 & 6 & 1 & 5 & 1 & 11 & 1 & \\
\hline 14 & 2 & 8 & 2 & 22 & 2 & & 152 & 20 & 96 & 23 & 248 & 21 & 7 & 1 & 7 & 2 & 14 & 1 & \\
\hline \multirow[t]{2}{*}{15} & 2 & 16 & 4 & 31 & 3 & & 189 & 25 & 122 & 30 & 311 & 26 & 4 & 1 & 10 & 2 & 14 & 1 & \\
\hline & & & & & & & & & 1 & 0 & 1 & 0 & & & & & & & \\
\hline 49 & 7 & 28 & 7 & 77 & 7 & 0.022 & 461 & 60 & 204 & 50 & 665 & 56 & 20 & 3 & 15 & 4 & 35 & 3 & 0.919 \\
\hline 10 & 1 & 10 & 3 & 20 & 2 & & 185 & 24 & 156 & 38 & 341 & 29 & 6 & 1 & 10 & 2 & 16 & 1 & \\
\hline \multirow[t]{2}{*}{11} & 2 & 3 & 1 & 14 & 1 & & 90 & 12 & 17 & 4 & 107 & 9 & 4 & 1 & 1 & 0 & 5 & 0 & \\
\hline & & 2 & 1 & & & & 2 & 0 & 7 & 2 & 9 & 1 & & & & & & & \\
\hline 1 & 0 & 16 & 4 & 17 & 2 & 0.305 & 11 & 1 & 185 & 45 & 196 & 17 & & & 13 & 3 & 13 & 1 & 0.293 \\
\hline \multirow[t]{2}{*}{69} & 10 & 27 & 7 & 96 & 9 & & 727 & 95 & 185 & 45 & 912 & 77 & 30 & 4 & 13 & 3 & 43 & 4 & \\
\hline & & & & & & & & & 14 & 3 & 14 & 1 & & & & & & & \\
\hline
\end{tabular}

Table $\mathbf{5}$ | Summary of EBV, mismatch repair and microsatellite instability status in oesophageal and gastric cancer

\begin{tabular}{|c|c|c|c|c|c|c|c|c|c|c|c|}
\hline & & \multicolumn{6}{|l|}{$\mathrm{OeC}$} & \multicolumn{4}{|l|}{ GC } \\
\hline & & \multicolumn{2}{|l|}{ Oe02 } & \multicolumn{2}{|l|}{ LTHT } & \multicolumn{2}{|l|}{ UHC } & \multicolumn{2}{|l|}{ LTHT } & \multicolumn{2}{|l|}{$\mathrm{KCCH}$} \\
\hline & & $n=443$ & $\%$ & $n=223$ & $\%$ & $n=322$ & $\%$ & $n=768$ & $\%$ & $n=410$ & $\%$ \\
\hline \multirow[t]{2}{*}{ EBV } & Negative & 383 & 100 & 223 & 100 & 322 & 100 & 738 & 96 & 384 & 94 \\
\hline & Positive & 0 & 0 & 0 & 0 & 0 & 0 & 30 & 4 & 26 & 6 \\
\hline \multirow[t]{2}{*}{ MMR } & Proficient & 373 & 100 & 217 & 99 & 319 & 99 & 632 & 90 & 353 & 89 \\
\hline & Deficient & 1 & 0 & 3 & 1 & 3 & 1 & 70 & 10 & 43 & 11 \\
\hline \multirow[t]{3}{*}{ Microsatellite } & Stable & 356 & 98 & $\mathrm{NI}$ & & $\mathrm{NI}$ & & $\mathrm{NI}$ & & $\mathrm{NI}$ & \\
\hline & Instable-Low & 4 & 1 & $\mathrm{NI}$ & & $\mathrm{NI}$ & & $\mathrm{NI}$ & & $\mathrm{NI}$ & \\
\hline & Instable-High & 2 & 1 & $\mathrm{NI}$ & & $\mathrm{NI}$ & & $\mathrm{NI}$ & & $\mathrm{NI}$ & \\
\hline
\end{tabular}

Abbreviations: EBV, Epstein-Barr Virus; GC, gastric cancer; KCCH, Kanagawa Cancer Center Hospital; LTHT, Leeds Teaching Hospitals NHS Trust; MMR, mismatch repair; MSI, microsatellite instability; MSS, microsatellite stable; OeC, oesophageal cancer; UHC, University Hospital Cologne; NI, not investigated 
The difference in the frequency of MMRdef and EBV infection between OeC and GC indicate not only pathophysiological differences in oesophageal and gastric carcinomas but might also have important implications for patient selection for future treatment and study planning. In contrast to the current practice of recruiting patients with GC or OeC into the same trials, trials involving immunotherapy require most likely disease specific different designs and selection criteria for patients with $\mathrm{OeC}$. 


\section{REFERENCES}

1. Ferlay J, et al. Cancer incidence and mortality worldwide: sources, methods and major patterns in GLOBOCAN 2012. Int J Cancer. 2015;136(5):E359-86.

2. Smyth EC, et al. Gastric cancer: ESMO Clinical Practice Guidelines for diagnosis, treatment and follow-up. Ann Oncol. 2016;27(suppl 5):v38-v49.

3. Lordick F, et al. Oesophageal cancer: ESMO Clinical Practice Guidelines for diagnosis, treatment and follow-up. Ann Oncol. 2016;27(suppl 5):v50-v7.

4. Alderson D, et al. Neoadjuvant cisplatin and fluorouracil versus epirubicin, cisplatin, and capecitabine followed by resection in patients with oesophageal adenocarcinoma (UK MRC OE05): an open-label, randomised phase 3 trial. Lancet Oncol. 2017;18(9):1249-60.

5. Shapiro J, et al. Neoadjuvant chemoradiotherapy plus surgery versus surgery alone for oesophageal or junctional cancer (CROSS): long-term results of a randomised controlled trial. Lancet Oncol. 2015;16(9):1090-8.

6. Bang YJ, et al. Trastuzumab in combination with chemotherapy versus chemotherapy alone for treatment of HER2-positive advanced gastric or gastro-oesophageal junction cancer (ToGA): a phase 3, openlabel, randomised controlled trial. Lancet. 2010;376(9742):687-97.

7. Fuchs CS, et al. Ramucirumab monotherapy for previously treated advanced gastric or gastro-oesophageal junction adenocarcinoma (REGARD): an international, randomised, multicentre, placebo-controlled, phase 3 trial. Lancet. 2014;383(9911):31-9.

8. Wilke $\mathrm{H}$, et al. Ramucirumab plus paclitaxel versus placebo plus paclitaxel in patients with previously treated advanced gastric or gastro-oesophageal junction adenocarcinoma (RAINBOW): a double-blind, randomised phase 3 trial. Lancet Oncol. 2014;15(11):1224-35.

9. Smyth EC, et al. Oesophageal cancer. Nat Rev Dis Primers. 2017;3:17048.

10. Le DT, et al. Mismatch-repair deficiency predicts response of solid tumors to PD-1 blockade. Science. 2017;357(6349):40913.

11. Cancer Genome Atlas Research Network. Comprehensive molecular characterization of gastric adenocarcinoma. Nature. 2014;513(7517):202-9.

12. Food and Drug Administration. FDA approves first cancer treatment for any solid tumor with a specific genetic feature 2017 [Available from: https://www.fda.gov/ NewsEvents/Newsroom/PressAnnouncements/ucm560167.htm.].

13. Kudo $T$, et al. Nivolumab treatment for oesophageal squamous-cell carcinoma: an open-label, multicentre, phase 2 trial. Lancet Oncol. 2017;18(5):631-9.

14. Janjigian $Y Y$, et al. CheckMate-032: Phase I/II open-label study of safety and activity of nivolumab (nivo) alone or with ipilimumab (ipi) in advanced and metastatic (A/M) gastric cancer (GC). J Clin Oncol. 2016;34(15S):abst 4010.

15. Kang YK, et al. Nivolumab in patients with advanced gastric or gastro-oesophageal junction cancer refractory to, or intolerant of, at least two previous chemotherapy regimens (ONO-4538-12, ATTRACTION-2): a randomised, double-blind, placebo-controlled, phase 3 trial. Lancet. 2017;390(10111):2461-71.

16. Muro K, et al. Pembrolizumab for patients with PD-L1-positive advanced gastric cancer (KEYNOTE-012): a multicentre, open-label, phase $1 \mathrm{~b}$ trial. Lancet Oncol. 2016;17(6):717-26.

17. Doi $T$, et al. Updated results for the advanced esophageal carcinoma cohort of the phase $1 \mathrm{~b}$ KEYNOTE-028 
study of pembrolizumab. J Clin Oncol. 2016;34(15S):abst 4046.

18. Le DT, et al. PD-1 Blockade in Tumors with Mismatch-Repair Deficiency. N Engl J Med. 2015;372(26):2509-20.

19. Hutchins $G$, et al. Value of mismatch repair, KRAS, and BRAF mutations in predicting recurrence and benefits from chemotherapy in colorectal cancer. J Clin Oncol. 2011;29(10):1261-70.

20. Ribic CM, et al. Tumor microsatelliteinstability status as a predictor of benefit from fluorouracil-based adjuvant chemotherapy for colon cancer. N Engl J Med. 2003;349(3):247-57.

21. Sargent DJ, et al. Defective mismatch repair as a predictive marker for lack of efficacy of fluorouracil-based adjuvant therapy in colon cancer. J Clin Oncol. 2010;28(20):3219-26.

22. Smyth EC, et al. Mismatch Repair Deficiency, Microsatellite Instability, and Survival : An Exploratory Analysis of the Medical Research Council Adjuvant Gastric Infusional Chemotherapy (MAGIC) Trial. JAMA Oncol. 2017;3(9):1197-203.

23. Uehara $\mathrm{H}$, et al. Deficiency of hMLH1 and hMSH2 expression is a poor prognostic factor in esophageal squamous cell carcinoma. J Surg Oncol. 2005;92(2):109-15.

24. Cancer Genome Atlas Research Network. Integrated genomic characterization of oesophageal carcinoma. Nature. 2017;541(7636):169-75.

25. Allum $W H$, et al. Long-Term Results of a Randomized Trial of Surgery With or Without Preoperative Chemotherapy in Esophageal Cancer. J Clin Oncol. 2009;27(30):5062-7.

26. Pandilla $R$, et al. Distinct genetic aberrations in oesophageal adeno and squamous carcinoma. Eur I Clin Invest. 2013;43(12):1233-9.

27. Farris $A B, 3 r d$, et al. Clinicopathologic and molecular profiles of microsatellite unstable Barrett Esophagus-associated adenocarcinoma. Am J Surg Pathol. 2011;35(5):647-55.

28. Vasavi $M$, et al. Microsatellite instability analysis and its correlation with hMLH1 repair gene hypermethylation status in esophageal pathologies including cancers. Cancer Biomark. 2010;7(1):1-10.

29. Matsumoto $Y$, et al. Microsatellite instability and clinicopathological features in esophageal squamous cell cancer. Oncol Rep. 2007;18(5):1123-7.

30. Falkenback $D$, et al. Defective mismatchrepair as a minor tumorigenic pathway in Barrett esophagus-associated adenocarcinoma. Cancer Genet Cytogenet. 2005;157(1):82-6.

31. Naidoo $R$, et al. Aberrations in the mismatch repair genes and the clinical impact on oesophageal squamous carcinomas from a high incidence area in South Africa. J Clin Pathol. 2005;58(3):281-4.

32. Evans SC, et al. Microsatellite instability in esophageal adenocarcinoma. Cancer Lett. 2004;212(2):241-51.

33. Araki $\mathrm{K}$, et al. Frequent loss of heterozygosity but rare microsatellite instability in oesophageal cancer in Japanese and Chinese patients. Oncology. 2004;67(2):1518.

34. Hayashi M, et al. Microsatellite instability in esophageal squamous cell carcinoma is not associated with hMLH1 promoter hypermethylation. Pathol Int. 2003;53(5):270-6.

35. Ikeguchi $M$, et al. Detection of loss of heterozygosity at microsatellite loci in esophageal squamous-cell carcinoma. Oncology. 1999;56(2):164-8.

36. Wu TT, et al. Genetic alterations in Barrett esophagus and adenocarcinomas of the esophagus and esophagogastric junction region. Am J Pathol. 1998;153(1):287-94.

37. Muzeau $F$, et al. Infrequent microsatellite instability in oesophageal cancers. $\mathrm{Br} \mathrm{J}$ Cancer. 1997;75(9):1336-9.

38. Gleeson $\mathrm{CM}$, et al. Ubiquitous somatic alterations at microsatellite alleles oc- 
cur infrequently in Barrett's-associated esophageal adenocarcinoma. Cancer Res. 1996;56(2):259-63.

39. Keller $\mathrm{G}$, et al. Microsatellite instability in adenocarcinomas of the upper gastrointestinal tract. Relation to clinicopathological data and family history. Am J Pathol. 1995;147(3):593-600.

40. Ogasawara $\mathrm{S}$, et al. Frequent microsatellite alterations on chromosome $3 p$ in esophageal squamous cell carcinoma. Cancer Res. 1995;55(4):891-4.

41. Meltzer SJ, et al. Microsatellite instability occurs frequently and in both diploid and aneuploid cell populations of Barrett'sassociated esophageal adenocarcinomas. Cancer Res. 1994;54(13):3379-82.

42. Genitsch $V$, et al. Epstein-barr virus in gastro-esophageal adenocarcinomas single center experiences in the context of current literature. Front Oncol. 2015;5:73.

43. Sunpaweravong $S$, et al. Absence of Epstein-Barr virus in esophageal squamous cell carcinoma. Dis Esophag. 2005;18(6):398-9.

44. Wu MY, et al. Detection of HSV and EBV in esophageal carcinomas from a highincidence area in Shantou China. Dis Esophag. 2005;18(1):46-50.

45. Awerkiew $\mathrm{S}$, et al. Esophageal cancer in Germany is associated with Epstein-Barr-virus but not with papillomaviruses. Med Microbiol Immunol (Berl). 2003;192(3):137-40.

46. Yanai $H$, et al. Epstein-Barr virus association is rare in esophageal squamous cell carcinoma. Int J Gastrointest Cancer. 2003;33(2-3):165-70.

47. Mizobuchi $S$, et al. Absence of human papillomavirus-16 and -18 DNA and Epstein-Barr virus DNA in esophageal squamous cell carcinoma. Jpn J Clin Oncol. 1997;27(1):1-5.

48. Wang J, et al. Esophageal squamous cell carcinomas arising in patients from a highrisk area of North China lack an association with Epstein-Barr virus. Cancer Epidemiol Biomarkers Prev. 1999;8(12):1111-4.

49. Wang LS, et al. Detection of EpsteinBarr virus in esophageal squamous cell carcinoma in Taiwan. Am J Gastroenterol. 1999;94(10):2834-9.

50. Lauren P. The two histological main types of gastric carcinoma: diffuse and so called intestinal-type carcinoma. Acta Pathol Microbiol Scand. 1965;64:31-49.

51. van Grieken NC, et al. KRAS and BRAF mutations are rare and related to DNA mismatch repair deficiency in gastric cancer from the East and the West: results from a large international multicentre study. $\mathrm{Br} J$ Cancer. 2013;108(7):1495-501.

52. Lin SJ, et al. Signatures of tumour immunity distinguish Asian and nonAsian gastric adenocarcinomas. Gut. 2015;64(11):1721-31.

53. Zur Hausen $A$, et al. Epstein-Barr virus in gastric carcinomas and gastric stump carcinomas: a late event in gastric carcinogenesis. J Clin Pathol. 2004;57(5):487-91.

54. Weiss MM, et al. Comparative genomic hybridisation. Mol Pathol. 1999;52(5):24351.

55. Umar A, et al. Revised Bethesda Guidelines for hereditary nonpolyposis colorectal cancer (Lynch syndrome) and microsatellite instability. J Natl Cancer Inst. 2004;96(4):261-8.

56. Awerkiew S, et al. Presence of Epstein-Barr virus in esophageal cancer is restricted to tumor infiltrating lymphocytes. Med Microbiol Immunol (Berl). 2005;194(4):18791.

57. Camargo MC, et al. Improved survival of gastric cancer with tumour Epstein-Barr virus positivity: an international pooled analysis. Gut. 2014;63(2):236-43.

58. Kim JG, et al. Comparison between mononucleotide and dinucleotide marker panels in gastric cancer with loss of hMLH1 or hMSH2 expression. Int J Biol Markers. 2017;32(3):e352-e6. 
59. Park J, et al. Evaluation of the Three Customized MSI Panels to Improve the Detection of Microsatellite Instability in Gastric Cancer. Clin Lab. 2017;63(4):705-16.

60. Setia $N$, et al. A protein and mRNA expression-based classification of gastric cancer. Mod Pathol. 2016;29(7):772-84.

61. Kim HS, et al. Comprehensive expression profiles of gastric cancer molecular subtypes by immunohistochemistry: implications for individualized therapy. Oncotarget. 2016;7(28):44608-20.

62. Gonzalez RS, et al. Immunohistochemistry as a surrogate for molecular subtyping of gastric adenocarcinoma. Hum Pathol. 2016;56:16-21.
63. Engel $C$, et al. Novel strategy for optimal sequential application of clinical criteria, immunohistochemistry and microsatellite analysis in the diagnosis of hereditary nonpolyposis colorectal cancer. Int J Cancer. 2006;118(1):115-22.

64. Chong IY, et al. The genomic landscape of oesophagogastric junctional adenocarcinoma. J Pathol. 2013;231(3):301-10.

65. Hamilton $\mathrm{S}$, et al. World Health Organization Classification of Tumours. Pathology and Genetics of Tumours of the Digestive System. Hamilton S, Aaltonen LE, editors. Lyon: IARC Press; 2000. 


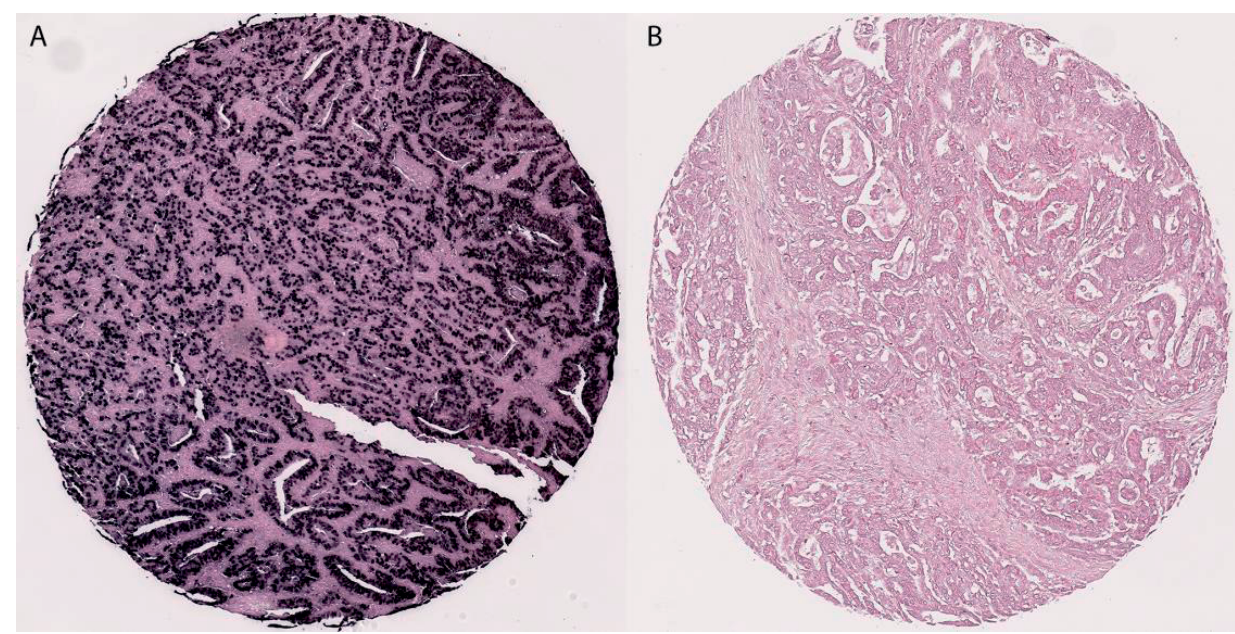

Supplementary figure 1 | Epstein Barr Virus-encoded RNA in situ hybridization staining. A: EBV positive gastric cancer (black = 5-bromo-4-chloro-3-indolylphosphate and nitroblue tetrazolium, red = counterstain with nuclear fast red). B: EBV negative gastric cancer. 

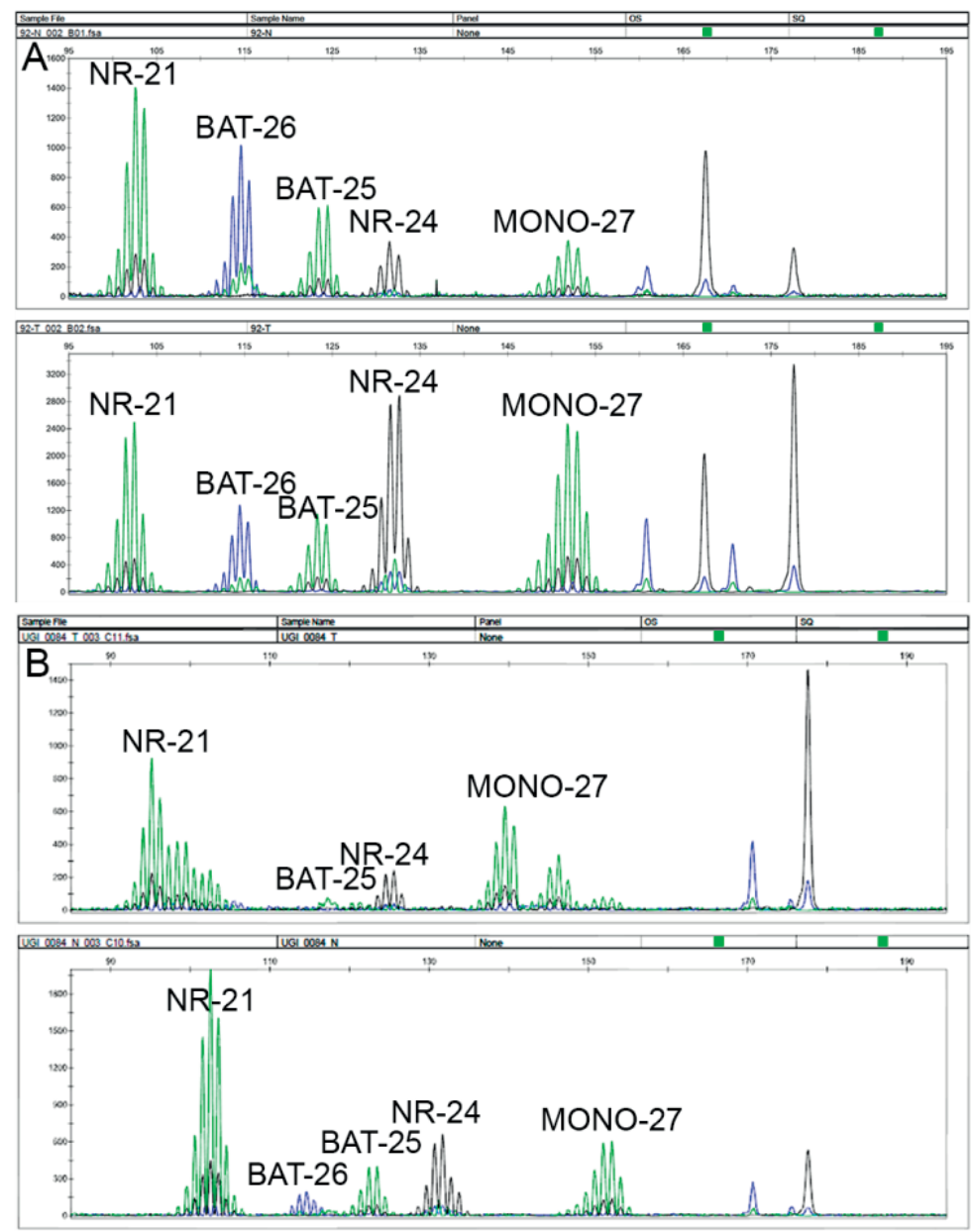

Supplementary figure 2 | MSI analysis output. A: Microsatellite stable oesophageal cancer (upper panel) and matched normal sample (lower panel). B: Microsatellite allele length changes in a microsatellite instable-high oesophageal cancer (upper panel) compared to the matched normal sample (lower panel). 


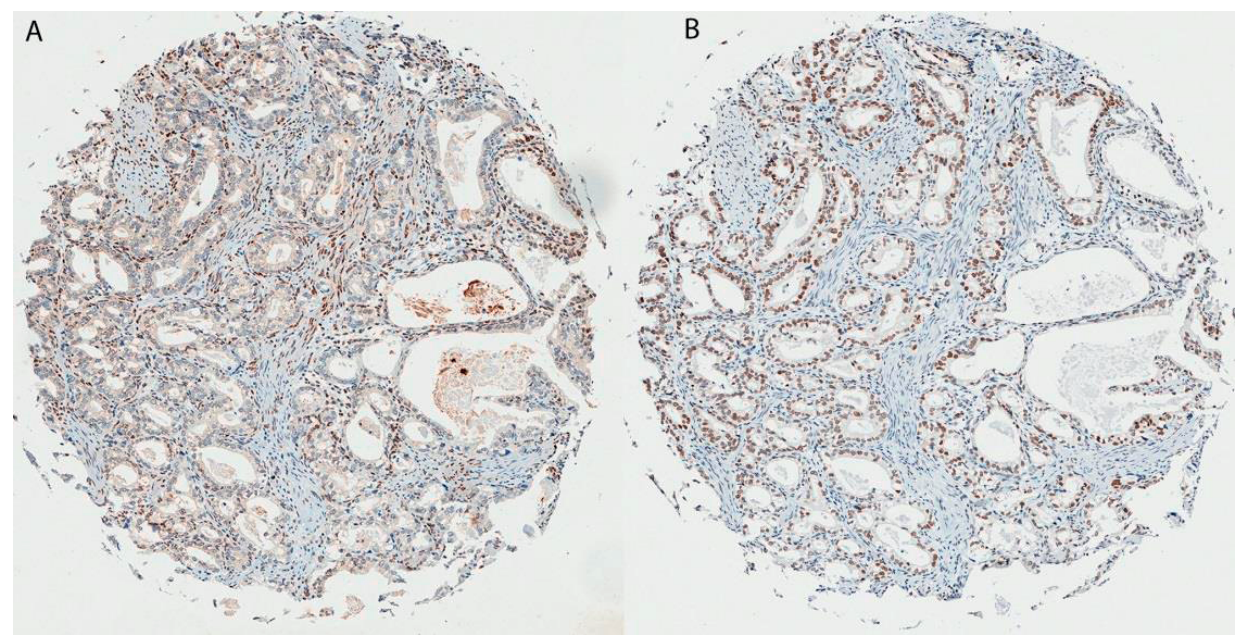

Supplementary figure 3 | Expression of mismatch repair proteins by immunohistochemistry in a mismatch repair deficient gastric cancer. A: Tumour cell nuclei are negative for MLH1, adjacent lymphocytes are positive (brown $=\mathrm{DAB}$, blue $=$ haematoxylin counterstain). B: Tumour cell nuclei are positive staining for MSH2 (brown $=\mathrm{DAB}$, blue $=$ haematoxylin counterstain). 



\section{Embargo as requested}

\section{Chapter 5}

Intratumour heterogeneity of the tumour content in the diagnostic biopsy predicts survival benefit from neoadjuvant chemotherapy in patients with oesophageal cancer - results from the OEO2 trial

Naser Davarzani* | Lindsay C. Hewitt* | Matthew D. Hale | Veerle Melotte | Matthew Nankivell | Gordon G. A. Hutchins | David Cunningham | William H. Allum | Ruth E. Langley | Shahab Jolani\# | Heike I. Grabsch"

* joint first authors

\# joint last authors

Submitted 


\section{Chapter 6}

Density of tumour infiltrating lymphocytes predicts survival benefit from adjuvant chemotherapy in patients with stage II/III gastric cancer - results from the CLASSIC trial

Lindsay C Hewitt* | Vincent Vromen* | Yannick Janssen* | Naser Davarzani | Derek Magee | Gregorio E Fazzi | Shahab Jolani | Veerle Melotte | Young-Woo Kim | Myeong-Cherl Kook | Jae-Ho Cheong | Heike I Grabsch

* Authors contributed equally

In preparation 


\section{Embargo as requested \\ Chapter 7 \\ General discussion \\ Emerging technologies partly adapted from: Hypothesis-free deep survival learning applied to the tumor microenvironment in gastric cancer}

Armin Meier | Katharina Nekolla | Lindsay C Hewitt | Sophie Earle | Takaki Yoshikawa | Takashi Oshima | Yohei Miyagi | Günter Schmidt | Heike I. Grabsch 

Globally, oesophagogastric cancer (OGCa) remains a major health problem with an estimated $1,407,000$ new cases and 1,123,000 deaths each year. Patients with early stage OGCa are often asymptomatic. Due to the absence of an OGCa screening programme, patients in Western countries most commonly present with locally advanced disease at the time of diagnosis. Currently patient prognosis and treatment decisions in OGCa are based on TNM stage, patient's performance status and patient's preferences. However, OGCa patients with the same TNM stage can have very different outcomes. OGCa patients have a poor prognosis with a 5 -year survival in Europe of $45-47 \%$ when diagnosed at a disease stage where the tumour is resectable and is treated with neoadjuvant/peri-operative chemo(radio)therapy and surgery. The survival benefit from neoadjuvant/peri-operative chemotherapy is modest at 6-14\% improved 5-year survival compared to treatment by surgery alone, suggesting that only a subset of patients benefits from chemotherapy. Thus, there remains an urgent clinical need to identify biomarkers to individualise and improve OGCa patient management.

The aim of this thesis was to investigate prognostic and predictive biomarkers in locally advanced resectable OGCa. We first focussed on the molecular characterisation of the tumour cells and thereafter on the characterisation of the tumour microenvironment.

As KRAS and BRAF mutations in colorectal cancer are known predictors of poor response to EGFR targeting agents, in chapter 2 we performed a literature review to analyze and summarize the current literature on KRAS and BRAF mutations, including KRAS amplifications in gastric cancer (GC). We included a total of 69 studies and found the current knowledge on KRAS and BRAF in GC to be limited due to small sample size of investigated tumours and the use of a variety of different methodologies, making any comparisons between studies difficult. The frequency of KRAS mutation and KRAS amplification is low (<10\%) in GC. In particular, the frequency of KRAS mutations in GC is much lower than that in colorectal cancer. KRAS mutations and KRAS amplifications seem to be mutually exclusive, suggesting the potential need to screen GC patients for both genetic aberrations when searching for KRAS activation. BRAF V600E mutations are extremely rare in GC. So far, all clinical studies in unselected patients with metastatic GC have failed to show a significant benefit for EGFR targeting therapy. Post hoc analysis of the REAL3 trial showed no relationship between KRAS mutation status and EGFR treatment effect.

Studies in lung and ovarian cancer suggest a relationship between KRAS activation and histological phenotype. Therefore, we investigated whether KRAS mutation and/or KRAS amplification (collectively called KRAS activation) are also related to the histological phenotype in GC which could then potentially indicate whether KRAS activation is an early or late event in gastric cancer carcinogenesis (chapter 3). Digitized Haematoxylin/Eosin stained slides from 1282 GC resection specimens were classified according to Japanese Gastric Cancer Association (JGCA) and the Lauren classification by at least two observers. KRAS mutation and KRAS amplification were found in 68 (5\%) and 47 (7\%) GCs, respectively. We confirmed a relationship between presence of KRAS mutation and mucinous phenotype in 
GC as described in ovarian cancer and lung cancer. Interestingly, 724 GCs (57\%) showed more than one histological phenotype. This relatively high level of intratumour morphological heterogeneity could reflect KRAS mutation heterogeneity, which may explain the failure of anti-EGFR therapy in GC.

Immune checkpoint targeting therapy has recently shown promise in several cancer types. Proposed biomarkers to predict potential response to immune checkpoint inhibitors include DNA mismatch repair (MMR) and/or Epstein-Barr virus (EBV) status. Therefore, in chapter 4, we determined the frequency of EBV and MMR in a large multicentre series of 988 oesophageal cancer (OeC) and 1213 GC using EBV-encoded RNA in situ hybridisation and MMR protein expression by immunohistochemistry (IHC), respectively. In a large subset of $\mathrm{OeC}$, we tested microsatellite instability (MSI) in parallel with MMR IHC. The frequency of MMR deficiency and MSI was very low in OeC (0.8\% and $0.6 \%$, respectively) and much lower than in GC (10.3\%). None of the OeCs were EBER positive in contrast to $4.8 \%$ EBER positive GC. This is the largest study to date demonstrating that in contrast to GC, EBV and MMR deficiency do not play a role in OeC carcinogenesis. Thus, the potential clinical usefulness of determining MMR deficiency/EBV status to screen patients for eligibility for immune checkpoint targeting therapy differs between OeC and GC patients.

Whilst many OGCa studies have focused on the characterisation of tumour epithelial cells, there is a growing interest in the role of the tumour microenvironment in cancer development and progression. Therefore, in chapter 5, we investigated whether the intratumour heterogeneity of the tumour/stroma content in the diagnostic biopsy of OeC patients is related to survival after neoadjuvant chemotherapy. Firstly, we established a new method using a statistical mixed effect model (MEM) to measure intratumour heterogeneity of the proportion of tumour (IHPOT). We used the newly developed method to estimate IHPOT (variation of the proportion of tumour in haematoxylin/eosin stained pre-treatment biopsy pieces from the same patient) in the pre-treatment biopsies from $218 \mathrm{OeC}$ OE02 trial patients. We found that patients with a low IHPOT index (biopsies from the same tumour have a similar proportion of tumour) had a survival benefit from cytotoxic chemotherapy. This is the first study suggesting that IHPOT measured in the pre-treatment biopsy can predict chemotherapy survival benefit in OeC patients. IHPOT may represent a clinically useful biomarker for patient treatment stratification.

Based on these biopsy findings we were interested to know which components of the stroma (including fibroblasts, extracellular matrix, vessels and immune cells) are contributing to its relationship with chemotherapy response. Studies in GC suggested a clinical value of tumour infiltrating lymphocytes (TILs) with respect to patient prognosis $(52,53)$, thus we selected TILs as our initial focus of investigation of the stroma components (chapter 6). We analysed the number of lymphocytes per area (so called TIL density) in patients with resectable, stage II-III GC from the Korean phase III CLASSIC trial. We used image analysis software (MIM from HeteroGenius, UK) to build a colour model for the identification of 
lymphocytes. We calculated the TIL density using digital haematoxylin and eosin (HE) stained tissue microarrays constructed from GC resection specimens from 629 CLASSIC trial patients. TIL density proved to be an independent prognostic and predictive biomarker for survival benefit from adjuvant chemotherapy. Patients with high TIL density GC had a significantly improved survival and derived little or no benefit from adjuvant chemotherapy (Xelox) compared with patients with low TIL density GC. Patients with low TIL had a significant benefit from adjuvant chemotherapy. We concluded that TIL density measured on routine HE stained tissue sections may represent a new clinically useful biomarker identifying GC patients who may not require adjuvant chemotherapy and for whom treatment could be de-escalated. Validation of these results following the biomarker roadmap principle is ongoing.

In Chapter 7, we discuss the implications of our research in the context of the current literature. We also critically discuss the problems and shortcomings of current OGCa prognostic and predictive biomarker studies. To address one aspect of this, we outline plans for validation studies in the near future to fully assess the prognostic and predictive value of TILS. We also discuss the potential role of emerging technologies in the clinical management of OGCa patients in the future. 

Valorisation 

Oesophagogastric cancer (OGCa) remains a major public health issue with an estimated $1,407,000$ new cases and 1,123,000 deaths worldwide in 2012 (1). This is despite the decline in newly diagnosed gastric cancer (GC) cases in recent years (1). OGCa is often asymptomatic and patients usually present with advanced stage disease. The standard of care treatment for locally advanced resectable disease is neoadjuvant/peri-operative chemo(radio)therapy and surgery. Survival remains poor, with 5-year overall survival up to $47 \%$ (2). Patients presenting with metastatic disease have a median life expectancy of less than 12 months if treated with cytotoxic chemotherapy (3). Thus, OGCa represents a substantial burden to patients in terms of morbidity and mortality.

Cancer-related health care costs have increased over the past decades (4), with OGCa having one of the largest expenditures in cancer care during the first 12 months after initial diagnosis (5). The estimated national cost of OGCa healthcare in the US was 3.15 billion USD in 2010 (5). In the Netherlands, €121 million was spent on OGCa patient health care in 2011 (6). With the use of emerging technologies such as advanced endoscopic imaging and deep-sequencing based technologies, and the high costs of new targeted therapies, including immune checkpoint targeting therapy, the already considerable economic burden related to OGCa is predicted to rise.

The prognosis prediction and treatment decisions for OGCa patients are currently based on TNM staging (7). As the cost of OGCa patient care increases with disease stage $(8,9)$, early detection is an important factor in reducing the economic burden. However, population screening by endoscopy is only cost effective in areas with high incidence $(10,11)$. New, potentially cheaper methods of screening, such as the cytosponge are currently under investigation (12). Furthermore, there are currently no biomarkers implemented in the clinic that could be measured in the blood, urine or tissue with sufficient sensitivity and specificity for early detection of OGCa (13). As patients with the same stage of disease can have very different outcomes, there remains a need to individualise and improve OGCa patient management to benefit the patient and improve efficiency in healthcare expenditure.

There are currently no prognostic or predictive biomarkers used in clinical practice for the management of OGCa patients. A prognostic biomarker provides information on clinical outcome. A predictive biomarker indicates the likely benefit of a treatment. Both likely prognosis and likely benefit from a particular treatment, together with patient's wishes, are used to guide patient management decisions (14). In this thesis, we investigated prognostic and predictive biomarkers in the epithelial tumour cells (chapter 2, 3 and 4) and tumour microenvironment (chapter $\mathbf{5}$ and $\mathbf{6}$ ) of patients with locally advanced resectable OGCa.

In chapter 4, we investigated the frequency of Epstein-Barr virus (EBV) and mismatch repair (MMR) deficiency in OGCa as they have been suggested as potential biomarkers for patient selection for immunotherapy or adjuvant cytotoxic therapy. We found the frequency of EBV and MMR is extremely low in OGCa, thus a large number of patients would need to be screened to identify the few patients with 'positive' tumours. Hence, we concluded that it 
may not be economically feasible to screen patients for these tumour based molecular markers. We have recently used deep learning to predict MSI status (a surrogate marker for MMR deficiency) based on HE stained images (not part of this thesis) (15). Whilst this may offer a cost effective solution, the results from this study require validation in independent datasets which are ongoing. However, the challenge remains, that EBV and MSI/MMR deficiency status would only be able to influence the management in a minority of OGCa patients.

Similarly, the frequency of KRAS mutation (chapter 2) and KRAS amplification (chapter 3) is low in GC. Aside from the low frequency and economic feasibility of KRAS testing in OGCa, anti-epidermal growth factor receptor (EGFR) therapy in KRAS mutant OGCa does not appear to be effective (3). This is in contrast to colorectal cancer, where routine testing for KRAS mutation is implemented as a predictor of response to EGFR therapy (16). Thus, there is a clinical need to understand the biological differences in response to EGFR therapy between colorectal cancer and GC.

In subsequent chapters we expanded our work to the tumour microenvironment. In chapter $\mathbf{5}$ we stratified oesophageal cancer $(\mathrm{OeC})$ patients according to survival benefit from neoadjuvant chemotherapy based on the proportion of tumour/stroma heterogeneity between $\mathrm{OeC}$ biopsy pieces from the same patient. Patients with a low level of morphological heterogeneity had a survival benefit from cytotoxic chemotherapy. This was an exploratory, hypothesis generating image analysis based study which requires validation. If validated, future studies need to assess whether proportion of tumour/stroma heterogeneity can be assessed by a pathologist on routine haematoxylin and eosin (HE) stained slides.

In a separate study using tissue from 629 patients recruited into the Korean CLASSIC trial, we showed for the first time that tumour infiltrating lymphocyte (TIL) density measured on haematoxylin and eosin (HE) stained resection specimens may be used as a biomarker to predict survival benefit from adjuvant chemotherapy in GC patients (chapter 6). Patients with high TIL density had little or no survival benefit from adjuvant cytotoxic chemotherapy and may therefore be potential candidates for treatment de-escalation. The results of this study also require validation but may have the potential to reduce patient morbidity due to (unnecessary) chemotherapy as well as reducing the healthcare costs normally related to the treatment of OGCa patients with adjuvant chemotherapy. From the patient perspective, the use of HE based TIL density as a predictive biomarker may offer more certainty about the potential success of chemotherapy. This may help to reduce the impact of unnecessary physical and psychological side effects of chemotherapy (either temporary or permanent), enabling patients to return to work earlier, thus reducing the financial impact of their illness on themselves and their families. Ultimately, predictive biomarkers may be able to improve outcomes and quality of life for OGCa patients. From the economic perspective, predictive biomarkers in OGCa to stratify patients for treatment with cytotoxic chemotherapy has the potential to improve the efficiency of the treatment and make it more cost-effective as only those patients who benefit and require chemotherapy would be treated. Importantly, for 
prognostic and predictive biomarkers to reduce healthcare costs, the investment in technology should not offset the savings. As we performed TIL density using routine diagnostic HE stained slides produced at the time of pathological evaluation of the resection specimen and image analysis software, the costs are minimal and this test could be introduced relatively quickly into the routine setting, after appropriate validation. Studies in breast cancer have shown that TIL density on the HE can be assessed manually, thus reducing the cost even further. The results of this pilot work in the CLASSIC trial patients allowed us to obtain a Cancer Research UK project grant for validation and assessment of introduction of HE based TIL density into the routine clinic.

In conclusion, the knowledge generated in this thesis is not only of scientific importance, but will likely have societal and economic impact in the future. If validated, as described in the future perspectives (chapter 7), HE based TIL density has the potential to improve the clinical management of GC patients while reducing expenditure on expensive chemotherapeutic drugs by ensuring only those patients benefiting from the drugs will be treated. 


\section{REFERENCES}

1. Ferlay J, et al. Cancer incidence and mortality worldwide: sources, methods and major patterns in GLOBOCAN 2012. Int J Cancer. 2015;136(5):E359-86.

2. Shapiro J, et al. Neoadjuvant chemoradiotherapy plus surgery versus surgery alone for oesophageal or junctional cancer (CROSS): long-term results of a randomised controlled trial. Lancet Oncol. 2015;16(9):1090-8.

3. Waddell T, et al. Epirubicin, oxaliplatin, and capecitabine with or without panitumumab for patients with previously untreated advanced oesophagogastric cancer (REAL3): a randomised, open-label phase 3 trial. Lancet Oncol. 2013;14(6):481-9.

4. Elkin EB, et al. Cancer's next frontier: addressing high and increasing costs. JAMA. 2010;303(11):1086-7.

5. Mariotto $A B$, et al. Projections of the Cost of Cancer Care in the United States: 20102020. J Natl Cancer Inst. 2011;103(2):11728.

6. Rijksinstituut voor Volksgezondheid en Milieu (RIVM). Cost of illness (2011) [cited 20192 July]. Available from: https://costofillnesstool.volksgezondheidenzorg.info].

7. Brierley JD, et al. Union for International Cancer Control. TNM Classification of Malignant Tumours. 8th ed: Wiley-Blackwell; 2016. 272 p.

8. Kim JH, et al. Early Detection is Important to Reduce the Economic Burden of Gastric Cancer. J Gastric Cancer. 2018;18(1):82-9.

9. Thein $\mathrm{HH}$, et al. Estimates and predictors of health care costs of esophageal adenocarcinoma: a population-based cohort study. BMC Cancer. 2018;18(1):694.
10. Lee KS, et al. Gastric cancer screening in Korea: report on the national cancer screening program in 2008. Cancer Res Treat. 2011;43(2):83-8.

11. Hamashima $C$, et al. Update version of the Japanese Guidelines for Gastric Cancer Screening. Jpn J Clin Oncol. 2018;48(7):673-83.

12. Offman J, et al. Barrett's oESophagus trial 3 (BEST3): study protocol for a randomised controlled trial comparing the CytospongeTFF3 test with usual care to facilitate the diagnosis of oesophageal pre-cancer in primary care patients with chronic acid reflux. BMC Cancer. 2018;18(1):784.

13. Shen $M$, et al. Five common tumor biomarkers and CEA for diagnosing early gastric cancer: A protocol for a network meta-analysis of diagnostic test accuracy. Medicine (Baltimore). 2018;97(19):e0577.

14. Sechidis K, et al. Distinguishing prognostic and predictive biomarkers: an information theoretic approach. Bioinformatics. 2018;34(19):3365-76

15. Kather JN, et al. Deep learning can predict microsatellite instability directly from histology in gastrointestinal cancer. Nat Med. 2019;25:1054-56

16. ErTK, et al. Current approaches for predicting a lack of response to anti-EGFR therapy in KRAS wild-type patients. Biomed Res Int. 2014;2014:591867. 




\section{Acknowledgements}



My time as a PhD student seems to have gone so quickly and yet there were days when I thought I would never make it to the end. But the fact I am writing this means I did it (hooray!), and I would like to give a MASSIVE thank you to everyone who made it possible.

First and foremost, thank you to my promotion team:

Prof. dr. H. I. Grabsch. Heike, we've worked together for over 10 years now and I have so much to thank you for. Thanks for giving me the opportunity to do a PhD, and to live and work in another country. I never thought I would do any of these things in my lifetime. Thank you for challenging me when I needed challenging, and supporting me when I needed supporting. Your commitment to your work, and enthusiasm and passion for pathology and upper GI research is inspirational. I feel privileged to have been able to work with the samples that you have spent years collecting after working so hard to establish collaborations throughout the world and secure grant funding.

Dr. V. Melotte. Veerle, I know that you sometimes felt like you wanted and needed to do more as a supervisor but I can truly say that I would not have made it to the end without you. Your support, encouragement and honesty in the final year were invaluable. You helped me develop from a technician to an independent-minded scientist. I hope you learned lots about oesophagogastric cancer along the way!

Dear members of the assessment committee, Prof. dr. Ad Masclee, Prof. dr. Nicole Bouvy, Prof. dr. Thorsten Cramer, Prof. dr. M. van Engeland and Dr. Jan Stoot, thank you for taking the time to read and critically evaluate my thesis, especially during the summer holidays! Thank you to Dr. T. Porta Siegel for accepting the invitation to join my defence committee.

I would like to say thank you to all my collaborators and co-authors. This thesis would not have been possible without you. In particular, I would like to thank Dr. Jan Oosting for your expertise in MLPA data analysis. Also our Korean collaborators (Prof. Jae-Ho Cheong, Dr. Young-Woo Kim and Dr. Myeong-Cherl kook) and Japanese collaborators (Prof. dr. Takaki Yoshikawa and Prof. dr. Tomio Arai) for sharing your samples, and for your scientific input and nice discussions. Thank you also to Dr. Katharina Nekolla, Dr. Gunther, Dr. Armin Meier, Dr. Ralf Huss at Definiens for a fruitful collaboration. It was nice to visit you in Munich and I very much enjoyed our interesting meetings.

I would sincerely like to thank all patients who have contributed material to studies included in this thesis and to Cancer Research UK for funding for the Oe02 sample collection.

Thank you to Gregorio, who aside from all the technical support in the lab, was my first point of contact with ICT issues; my own personal ICT helpdesk! Thank you also for your invaluable Photoshop skills, helping to design and produce the beautiful front cover of my thesis, and for being my paranymph. It has been a pleasure working with you.

I would also like to thank Naser and Shahab for your statistical support, interesting discussions and endless patience for those not statistically minded! Thank you to Yuichi for teaching me to classify gastric cancer based on the Japanese histological scheme. We had 
a very pleasant year working together and I learnt a lot about Japanese culture during this time. I hope I can visit Japan one day.

To the UGI team back in Leeds, thank you Hayley for all your hard work with the MLPA experiments and data analysis, to Pip for all the re-staining and re-coverslipping, and to Gordon for the tumour classifications. Thanks to Mike Hale for scanning our many hundreds of slides.

Thank you to all my colleagues, past and present, from the cancer pathology research group (Glenn, Zheng, Maartje, Laura, Kim L, Kim S, Manon, Simone, Selena, Kelly, Josien, Jaleesa, Nikkie, Kathleen, Peter, Edith, Faisel, Imke, Emil, Musa, Frans and Karin) for the interest in my research and shared interest in eating cake, vlaai and ice cream! With special thanks to Tim and Sophie, my UNS40 roomies, who helped me find my feet when I first moved to The Netherlands. To Alexander for sharing the joys and (occasional) frustrations of parenting. To Nathalie for helping to keep me sane in the final year, with the help of many Frangipanes and chocolate, and for being my paranymph! To Muriel for our nice chats over coffee, and to Kim W for keeping me supplied with essential English products :)

Audrey and Tonneke, thank you for all your secretarial support. Without your help I would have had no idea where to begin with all the paperwork for my PhD submission.

Thank you to Christina, Laura and Sarah for your great friendship over the years, for coming to visit me for a fantastic girlie weekend, and for all your words of support and encouragement along the way. Also. I also want to express my thanks to Sally. As someone who has gone through the PhD journey, I could share my PhD highs and lows, successes and frustrations with you. Funny to think we both made it this far after the lab practical during our Bachelor studies at the University of York where we accidently threw away our extracted DNA!

Thank you to my parents, for your love and support and without whom I would never have enjoyed so many opportunities.

And most of all thank you to my husband, best friend, proof reader, chef and artist - Thank you Michael for moving to a new country to allow me to pursue my career. I'm so glad we decided to give it a go! I wouldn't have done it without you by my side. Thank you to my son, Freddie, for teaching me that doing a PhD is hard but being a parent is harder. After a long hard day in the lab or office, I always looked forward to coming home to you both (and Charlie $\boldsymbol{c o s}^{0}$. 


About the author 

Lindsay Charlotte Hewitt (née Ward) was born on 10 $0^{\text {th }}$ August 1983 in Bradford, UK. Her interest in science began at school and she studied for her Bachelor degree in Molecular Cell Biology at the University of York, UK. After graduating in 2004, Lindsay worked in the histology and cytology department at IDEXX, an animal diagnostic laboratory. In 2006, whilst continuing to work, she began studying part-time for her Master's degree in Pathological Sciences at Sheffield Hallam University, UK. After graduating in 2008, Lindsay wanted to pursue a career in cancer research and began working as a research technician at the Faculty of Medicine and Health, Section of Pathology and Tumour Biology, University of Leeds, based at St James's University Hospital, UK. Lindsay provided pathological and molecular laboratory support, and was involved in the retrospective collection of tissue samples in the multicentre randomised controlled clinical trial of pre-operative chemotherapy in resectable oesophageal cancer (Oe02) and biological sample collection (blood and tissue) from patients entering the multicentre randomised controlled OE05 and ST03 clinical trials. In 2011, she was promoted to senior research technician. In March 2015, Lindsay moved to The Netherlands to start work as a PhD student in the Pathology Department, Maastricht University Medical Center+, under the supervision Prof. dr Grabsch and Dr Melotte, investigating prognostic and predictive biomarkers in oesophagogastric cancer.

In October 2019 Lindsay started working as Clinical Safety Specialist at Medtronic Bakken Research Center in Maastricht. 


Hewitt LC, Saito Y, Wang T, Matsuda Y, Oosting J, Silva ANS, Slaney HL, Melotte V, Hutchins G, Tan P, Yoshikawa T, Arai T, Grabsch HI. KRAS status is related to histological phenotype in gastric cancer: results from a large multicentre study. Gastric Cancer. 2019 May 20. doi: 10.1007/s10120-019-00972-6.

Hewitt LC, Inam IZ, Saito Y, Yoshikawa T, Quaas A, Hoelscher A, Bollschweiler E, Fazzi GE, Melotte V, Langley RE, Nankivell M, Cunningham D, Allum W, Hutchins GG, Grabsch HI. Epstein-Barr virus and mismatch repair deficiency status differ between oesophageal and gastric cancer: A large multi-centre study. Eur J Cancer. 2018 May; 94:104-114.

Davarzani N, Hutchins GGA, West NP, Hewitt LC, Nankivell M, Cunningham D, Allum WH, Smyth E, Valeri N, Langley RE, Grabsch HI. Prognostic value of pathological lymph node status and primary tumour regression grading following neoadjuvant chemotherapy - results from the MRC OE02 oesophageal cancer trial. Histopathology. 2018 Feb 21. doi: 10.1111/ his. 13491.

Silva ANS, Coffa J, Menon V, Hewitt LC, Das K, Miyagi Y, Bottomley D, Slaney H, Aoyama T, Mueller W, Arai T, Tan IB, Deng N, Chan XB, Tan P, Tsuburaya A, Sakamaki K, Hayden JD, Yoshikawa T, Zondervan I, Savola S, Grabsch HI. Frequent Coamplification of Receptor Tyrosine Kinase and Downstream Signaling Genes in Japanese Primary Gastric Cancer and Conversion in Matched Lymph Node Metastasis. Ann Surg. 2018; 267(1):114-121

Hale MD, Nankivell M, Hutchins GG, Stenning SP, Langley RE, Mueller W, West NP, Wright Al, Treanor D, Hewitt LC, Allum WH, Cunningham D, Hayden JD, Grabsch HI. Biopsy proportion of tumour predicts pathological tumour response and benefit from chemotherapy in resectable oesophageal carcinoma: results from the UK MRC OE02 trial_Oncotarget. 2016; 7(47):77565-77575

Obulkasim A, Ylstra B, van Essen HF, Benner C, Stenning S, Langley R, Allum W, Cunningham D, Inam I, Hewitt LC, West NP, Meijer GA, van de Wiel MA, Grabsch HI. Reduced genomic tumor heterogeneity after neoadjuvant chemotherapy is related to favorable outcome in patients with esophageal adenocarcinoma. Oncotarget. 2016; 7(28):44084-44095

Hewitt LC, Hutchins GG, Melotte V, Saito Y, Grabsch HI. KRAS, BRAF and gastric cancer. Trans/ Gastrointest Cancer 2015; 4(6):429-447

Zhang S, Tan IB, Sapari NS, Grabsch HI, Okines A, Smyth EC, Aoyama T, Hewitt LC, Inam I, Bottomley D, Nankivell M, Stenning SP, Cunningham D, Wotherspoon A, Tsuburaya A, Yoshikawa T, Soong R, Tan P. Technical reproducibility of single-nucleotide and size-based DNA 
biomarker assessment using DNA extracted from formalin-fixed, paraffin-embedded tissues. J Mol Diagn. 2015; 17(3):242-50

van Grieken NC, Aoyama T, Chambers PA, Bottomley D, Ward LC*, Inam I, Buffart TE, Das K, Lim T, Pang B, Zhang SL, Tan IB, Carvalho B, Heideman DA, Miyagi Y, Kameda Y, Arai T, Meijer GA, Tsuburaya A, Tan P, Yoshikawa T, Grabsch HI. KRAS and BRAF mutations are rare and related to DNA mismatch repair deficiency in gastric cancer from the East and the West - Results from a large international multicentre study. Br J Cancer. 2013;108(7); 1495-501

Ooi CH, Ivanova T, Wu J, Lee M, Tan IB, Tao J, Ward L*, Koo JH, Gopalakrishnan V, Zhu Y, Cheng LL, Lee J, Rha SY, Chung HC, Ganesan K, So J, Soo KC, Lim D, Chan WH, Wong WK, Bowtell D, Yeoh KG, Grabsch H, Boussioutas A, Tan P. Oncogenic Pathway Combinations Predict Clinical Prognosis in Gastric Cancer. PLoS Genet. 2009; 5(10): e1000676

Sundar R, Ng A, Zouridis H, Padmanabhan N, Sheng T, Zhang S, Lee MH, Ooi WF, Qamra A, Inam I, Hewitt LC, So JB, Koh V, Nankivell M, Langley R, Allum W, Cunningham D, Rozen S, Yong WP, Grabsch HI, Tan P. DNA epigenetic signature predictive of benefit from neoadjuvant chemotherapy in esophageal adenocarcinoma: results from the MRC OE02 trial.

Accepted in European Journal of Cancer

Davarzani N, Hewitt LC, Hale MD, Melotte V, Nankivell M, Hutchins GGA, Cunningham D, Allum WH, Langley RE, Jolani $\mathrm{S}^{\#}$, Grabsch $\mathrm{HI}^{\#}$. Intratumour heterogeneity of the tumour content in the diagnostic biopsy predicts survival benefit from neoadjuvant chemotherapy in patients with oesophageal cancer - results from the OE02 trial

Submitted

Meier A, Nekolla K, Hewitt LC, Earle S, Yoshikawa T, Oshima T, Miyagi Y, Schmidt G, Grabsch $\mathrm{HI}$. Hypothesis-free deep survival learning applied to the tumor microenvironment in gastric cancer

Submitted

Hewitt LC, Vromen V, Janssen Y, Davarzani N, Magee D, Fazzi GE, Shahab J, Melotte V, Kim YW, Kook MC, Cheong JH, Grabsch HI. Density of tumour infiltrating lymphocytes predicts survival benefit from adjuvant chemotherapy in patients with stage I/III gastric cancer - results from the CLASSIC trial

In preparation

*Maiden name

Page | 186 